



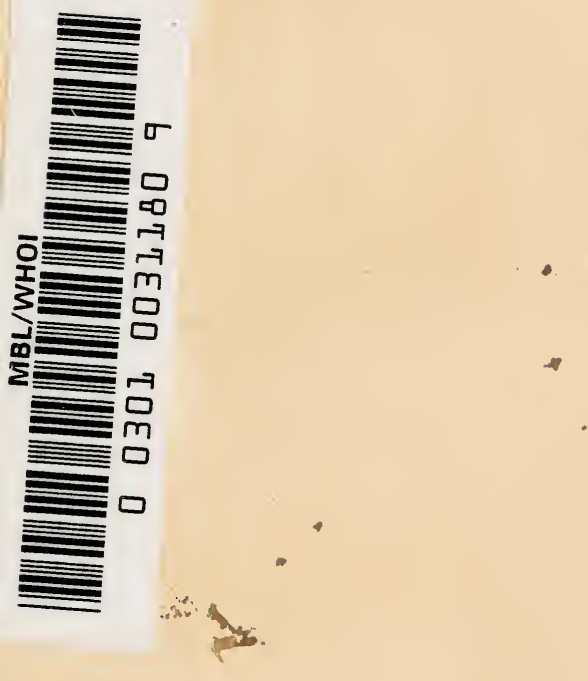





LECTURES ON SEX AND HEREDITY 


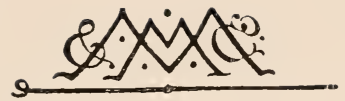

M.ACMILLAN AND CO., Limited

LONDON - BOMBAY - CALCUTTA - MADRAS MELBOURNE

THE MACMILLAN COMPANY

NEW YORK - BOSTON - CHICAGO

DALLAS - SAN FRANCISCO

THE MACMILLAN CO. OF CANADA, LTD. TORONTO 


\title{
LECTURES ON
}

\section{SEX AND HEREDITY}

DELIVERED IN GLASGOW, 1917-18

\author{
$\mathrm{BI}$ \\ F. O. BOWER \\ J. GRAHAM KERR \\ ANI) \\ IV. E. AGAR
}

MACMILLAN AND CO., LIMITED ST. MARTIN'S STREET, LONDON 


\section{CONTENTS}

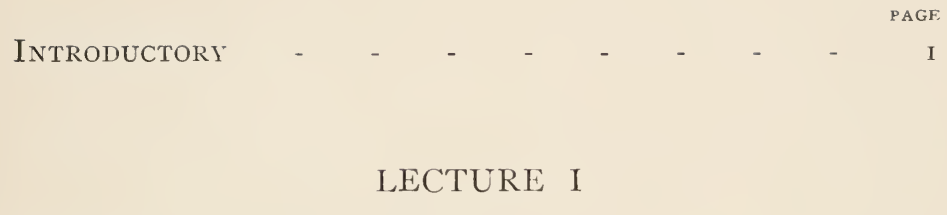

The Origin of Sex in Plants - $\quad$ - $\quad$ - $\quad$ - 8

\section{LECTURE II}

The Effect of a Fixed Position on the Sexuality of Plants

\section{LECTURE III}

The Reproductive Process in Animals: Solie of the

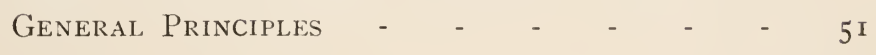

\section{LECTURE IV}

Some of the Modifications of the Reproductive Process as Adaptations to Life upon Land - 


\section{LECTURE V}

Heredity - $\quad-\quad \cdots$

Heredity in MaN

Glossary and INDEX - $\quad-\quad+\quad-\quad$ - $\quad$ II 


\section{INTRODUCTORY}

THE object with which these Lectures were given was to convey in as simple terms as possible the leading facts relating to Sex in Animals and Plants, together with suggestions bearing on the use and effect of sexual propagation. Sex is a very wide-spread fact among living things. Its manifestations are most obvious in the Higher Animals and in the Higher Plants. But sex is not general for all living organisms. Some very simple and, as we believe, primitive beings are sexless, while others show rudimentary sexual characters, others again more advanced conditions. It is possible to arrange such examples in order, so as to show how the sexual mode of propagation may have come into existence, and how in the rising scale of Animals and Plants the difference of the sexes became gradually more marked. This is the evolutionary aspect of the theme, and it will be taken up in the two first Lectures as it is seen in Plants. The third and fourth Lectures will deal with the same question in Animals. A discussion follows in the fifth and sixth Lectures on Heredity.

The whole body of any one of the higher Animals or Plants is made up of various tissues, differing in texture and in function. In the Animal body everyone recognizes skin, muscle, bone, and nerve. In the Plant body there is also an external skin; tissues that are soft and sappy when young lie within it, together with firmer 
strands that mature into wood and bast in older trunks. Such tissue-masses are familiar to everyone. Their microscopic study shows that, whether in Animals or Plants, these tissues are all made up of certain structural units. called cells. Each cell is so minute that as a rule it cannot be seen with the naked eye. It consists essentially of a viscous body of protoplasm, a substance of the nature of white-of-egg, in which all the activities of Life are carried out. Within it lies a definite body of roundish or oval form, the mucleus, which is itself part of the Protoplasm. It appears to dominate the cell, and serves as the centre of its vitality. Very simple and minute organisms may consist of only one cell each. These are called unicellular organisms, and they lie at the base of the series either of Animals or Plants. But those Animals or Plants which are ordinarily known as such by the general public are multicellular. They are composed of very many, even of millions of these structural units, or cells, which live together a common life, and compose what is known as an individual, such as a horse or a tree. We may go further and say that the whole of each Animal or Plant is composed of such cells, or their derivatives. This has been called the cell-theory. But it is now so fully proved in detail that it may be stated not as a theory but as a fact of observation (Fig. I).

There is reason to believe that Animals and Plants have advanced independently in the origin of Sex. But notwithstanding this, one of the most striking features in the whole story is that the leading facts of scxuality in Plants and Animals are very much alike. Their similarity is indeed so great that the same terms may be used in describing both. The essential feature of Sexuality whether in Animals or Plants, consists in the fusion of two 
cells, derived from more or less distinct sources, to form one new cell. The parental cells which thus fuse are called sexual cells, or gametes, which are detached from the parental body. The result of their fusion is called a
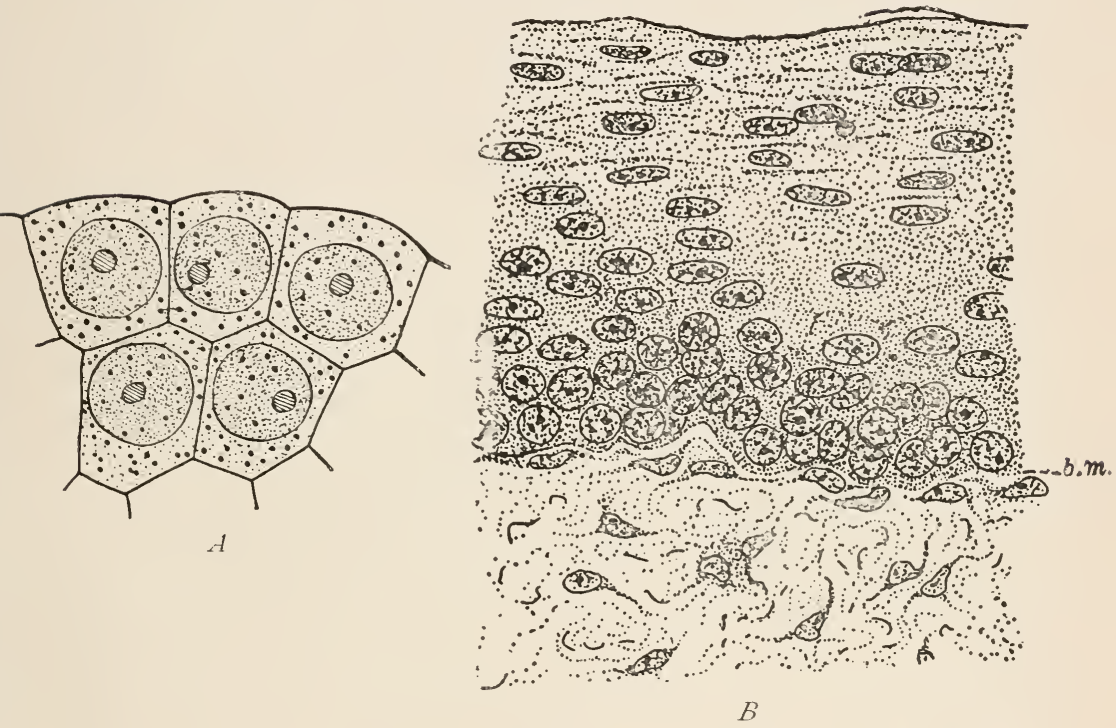

FIG. I.

$A$, Five young vegetable cells, each with its granular protoplasm surrounding a large spherical nucleus. Each cell is delimited by a cell-wall which is thin while young, but may become much thickened as the cell becomes mature. ( $\times 800$.)

$B$, Part of a transverse section of the stratified, epithelial lining of a cat's œsophagus. b.m., basement membrane. Here each cell is not delimited by a cellwall, as is the case in plant-tissues. ( $\times$ 7oo. From Dahlgren and Kepner.)

zygote, and it forms the starting point for the development of a new individual. This individual may remain unicellular, as in the case of the simplest living things. Or, as in higher organisms, it may undergo cell-division; and this if continued may give rise to a large and complex individual, such as a horse or a tree. But whatever the size or form of the sexually-produced offspring may be, the genesis of it is essentially the same, by fusion of two 
sexual cells, which are developed for the purpose. This fusion is called "Syngamy."

In very simple sexually produced organisms, whether Animals or Plants, these parental cells are both alike. They are then called Isogametes, and in most primitive organisms they are motile through water. Such gametes are believed to represent a rudimentary and primitive state. A more advanced type is that where the two are unlike. The difference is first seen in size, and this is usually followed also by difference in motility. The smaller is as a rule more actively motile, and it is called the MALE GAMETE, or micro-gamete, or spermatozoon, or spermatozoid. The larger is as a rule non-motile, and is called the FEMALE GAMETE, or macro-gamete, or ovum, that is the egg. All these terms are equally applicable to the phenomena shown in Animals and in Plants, and they will be used in the descriptions which follow (Fig. 2).

The most obvious result of sex, as seen in the higher Animals and in many of the higher Plants, appears to be an increase in the number of individuals. In horses, in cattle, and in Man this is the only method of propagation. The same is the case with some Plants, such as the Pines and Firs, and certain large brown Seaweeds. But while this is true for the most advanced Animals, and for some highly organised Plants, it does not apply for organisms lower in the scale. In these, whether Animals or Plants, there are other methods of increase in numbers, for instance by various types of budding. Such budding is very common indeed among the Highest Plants. It would then be a mistake to think that for living things generally multiplication is only by a sexual process, or that multiplication and sexuality are necessarily connected. A study of the lower organisms shows clearly 


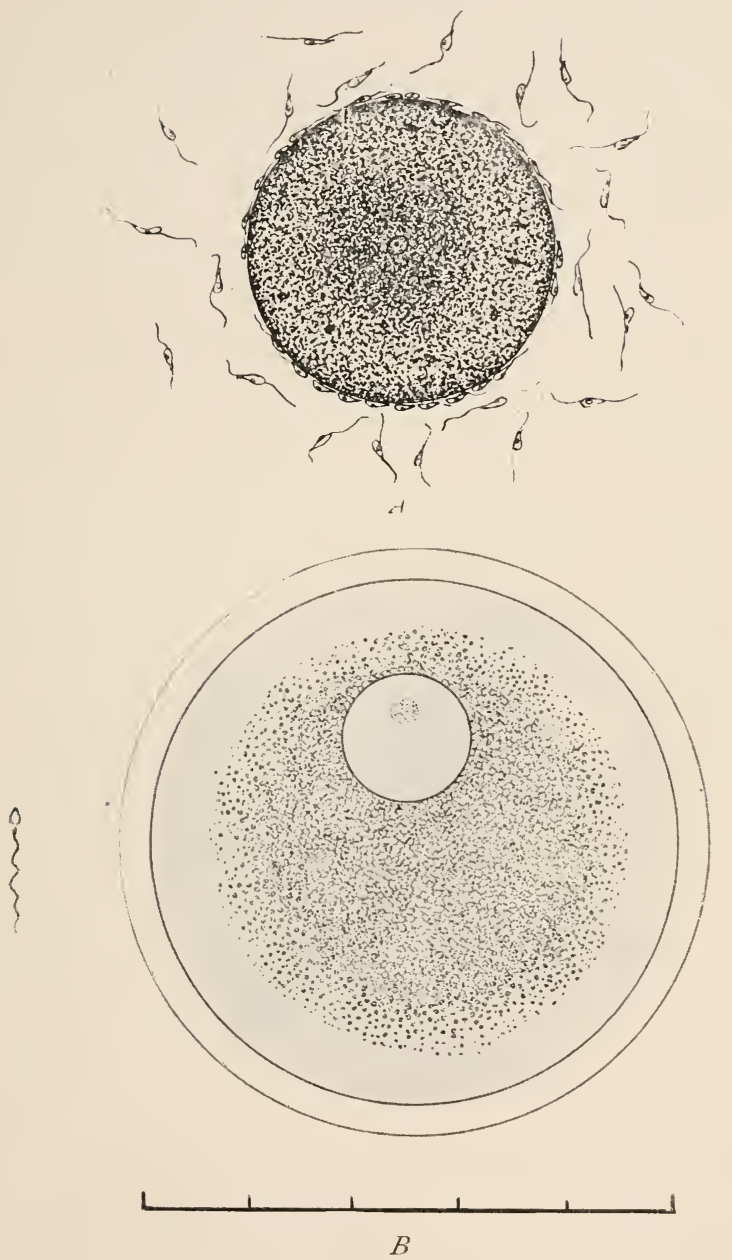

FIG. 2 .

$A$, Large spherical egg (female gamete) of Bladder Wrack (Fucus), surrounded by many small motile spermatozoids (male gametes). (After Thuret. $\times 330$.)

$B$, Human gametes highly magnified : egg to the right, spermatozoon to the left. The egg is enclosed in a transparent envelope which disappears during development. Each division of the scale represents $.05 \mathrm{~mm}$., or about in inch. 
that increase in numbers was not in the first instance an essential consequence of sex. In the very simplest Animals and Plants sex involves an actual decrease in number. Where the whole organism consists of only a single cell, and two such individuals fuse sexually to form one zygote, obviously the immediate result is a fall in number to one half. So we must seek some other initial reason for sex than increase in number. Many believe that in the first instance the advantage following from sexual fusion lay in nutrition. The two gametes fused together form a stronger cell than either of them was alone. It seems natural then to conclude that in unicellular organisms sexuality may have originated in the nutritional advantage that followed on their fusion.

But with this fusion there follows as a consequence the pooling of such qualities as the fusing cells themselves possess. So far as these qualities can be transmitted to the offspring, the mechanism of fusion offers the opportunity for their transmission. And we do positively know that the general characteristics of the parents, and even many quite trivial peculiarities, are liable to be transmitted to the offspring. Any human family gives evidence of this. What is seen in Man appears also in Animals and Plants, as every breeder of prize stock and every horticulturalist knows. There is no doubt whatever that Heredity is a fact. But the chances that the sexually produced offspring will exactly' repeat all the characters of either parent are extremely remote. It shares the characters of both parents, but practically in all cases it differ's in some degree from each of them.

Whether produced, as in very simple creatures, by direct fission, or as in more advanced organisms by budding, or through sexual fusion, the progeny is always 
derived from a living source. There is no such thing as spontaneous generation known to scientific men. Life under present conditions is always derived from life. The processes of fission or of budding suggest merely the increase in number of living things without any change in quality; and in practice the offspring of budding is found to repeat, as a rule, very exactly, the characters of the original organism from which the bud sprang. In Plants this fact is made use of by horticulturalists. Roses are propagated by "budding"; strawberries by " runners " ; apples, pears and plums by " grafts," which are each of them parts of an original plant removed and encouraged to grow on as new individuals. These retain the exact qualities of colour, scent, and flavour of the original stock, though not necessarily the size, or season of maturity. But it is different with the offspring produced by the sexual method. The fact that it is a blend of two parental characters at once distinguishes it from the result of mere fission or budding. The sexually produced offspring is not a mere repetition of either parent. In the fusion of gametes there is a mechanism which provides for a summation of parental characters from both parents. But it is a matter of common observation that the sexually produced offspring does not repeat all the characters of both parents. The later Lectures of the series will take up the question how the characters that are inherited are distributed in the sexually produced offspring. And as many of the Higher Plants and all of the Higher Animals, including Man himself, are sexually produced, it will be at once seen how large a question is here involved. For sexual propagation is not a mere matter of increase in number, but one which touches the very springs of Evolution and of Progress in Living Beings. 


\section{LECTURE I}

\section{THE ORIGIN OF SEN IN PLANTS}

Differences of Sex, and the fact that the sexes mate and breed, are obvious for the Higher Animals, and for Man himself. Hence the fact of Sex in Animals was recognised from the earliest times. This is shown by the Mosaic Cosmogeny, which reflects the knowledge of still earlier periods. There is, however, no such early reference to Sex in Plants. It is true Aristotle and Theophrastus explained certain facts relating to the Fig and the Date on a theory of Sex, based on an assumed analogy with what was then known of the Higher Animals. But this was no more than vague surmise. Real knowledge of the facts of Sex in Plants was still wanting, however clearly it might be realised that propagation was effected by means of the Flower, and the Seeds produced from it in the Higher Plants.

Neither in Animals nor in Plants could any detailed knowledge of Sex be expected till after the invention of the compound microscope, for the sexual cells themselves are minute. The compound microscope came into use at the end of the serenteenth century. But it was long after that before the details of sexual propagation in Plants were actually observed. The story has been 


\section{THE ORIGIN OF SEX IN PLANTS}

rapidly advanced in the last decades. Many Botanists still living have witnessed the gradual steps of observation. These were first made among the simpler, or lower organisms. Observations have since been extended, till

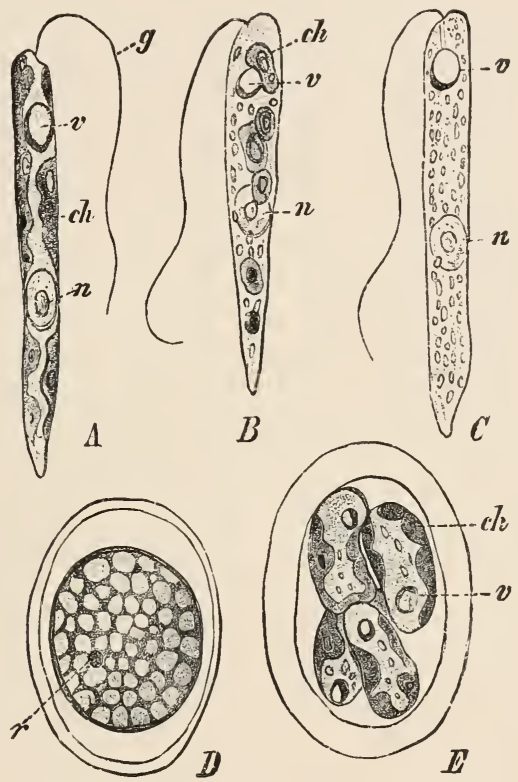

FIG. 3.

Euglena gracilis. $A$, form with green colouring bodies (ch.); $n=$ nucleus ; $v=$ vacuole and red eye-spot; $g=$ flagellum ; $B=$ form with small green colouring bodies; $C=$ colourless saprophytic form, occurring in nutrient solutions in absence of light ; $D=$ resting cyst ; $r=$ red eye-spot ; $E=$ germination of resting cyst by division into four daughter cells, which later escape. (After Zumstein. $A, C \times 630 ; B \times 650 ; D, E \times$ 1000. From Strasburger.)

now a continuous record can be given even of the complicated sexual production of new germs in the Higher Plants. Moreover, by comparison of lower and simpler forms of Plant-Life it is possible now to obtain some idea of the origin and nature of Sex in Plants. A 
few examples will be described illustrating the probable course of its Evolution.

The first example is one of those lowly organisms which it is difficult to rank definitely either as an Animal or as a Plant; for it shares the qualities of both. It is Euglena, one of the Flagellates, which in summer is commonly found colouring the foul water draining from manure heaps a vivid green. If a drop of this water be examined under the microscope, many free-swimming, pear-shaped bodies will be seen, propelled each by a

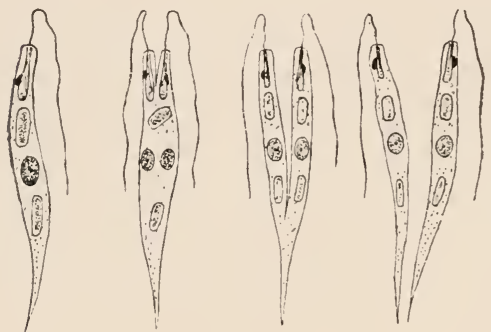

Fig. 4 .

Successive stages of fission in Euglena : semidiagrammatic. single lashing flagellum (Fig. 3). Each one is a separate individual, and contains within its little naked mass of protoplasm a nucleus, and several green bodies to which its colour is due. There is also a bright red eye-spot close to the base of the flagellum or cilium. These individuals multiply by fission or cleavage of the motile cell to form two equal parts, each of which is a new individual (Fig. 4). Here then is an increase in number without any sexual process. The organism is motile in water, a characteristic shared by many very simple Animals. There is, however, a second phase of its life which it enters when the circumstances are unfavourable. The creature ceases to move, and surrounds itself with a cell-wall. It becomes encysted (Fig. 3, D). But later, when the conditions are favourable, it reverts to the motile state, its protoplasm dividing, and escaping from the ruptured cyst. In its encysted state Euglena 
structurally resembles many simple Plants. Whether in the motile or the encysted phase it shows its primitive character by being unicellular, and by the absence of any sexual mode of increase.

Another simple example is seen in Protococcus viridis, which is commonly found growing as a fine green powder on the windward side of tree-trunks in damp climates. The single cell is stationary, spherical, and bounded in a cell-wall (Fig. 5). In these respects it resembles the encysted Euglena. Each cell may divide, and the divisions may be repeated, so that a group of cells is formed. But sooner or later they round off and separate, each being in fact an independent individual. Here again no sexual process is known. In being non-motile, encysted, and containing green chloro-

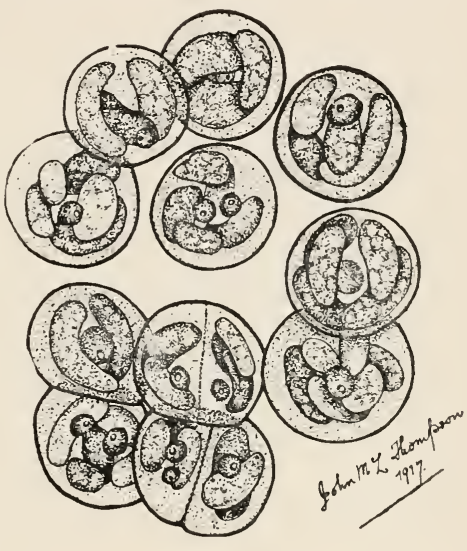

FIG. 5 .

Protococcus viridis, a unicellular plant, existing singly, or in groups. $(\times 730$. phyll, Protococcus shows features that are usual in Plants. It is accordingly referred to the Plant-Kingdom. These two examples will serve to suggest that very minute and simple creatures exist, some of which are difficult to refer to the one Kingdom or to the other; and that they show no sexual process whatever. They are probably very primitive living beings, such as in Evolution preceded the introduction of Sex.

The next example is Ulothrix, a small green Alga found very commonly attached to stones in fresh-water streams. 
It is not quite so simple in structure as those before described, for it consists of a number of encysted cells

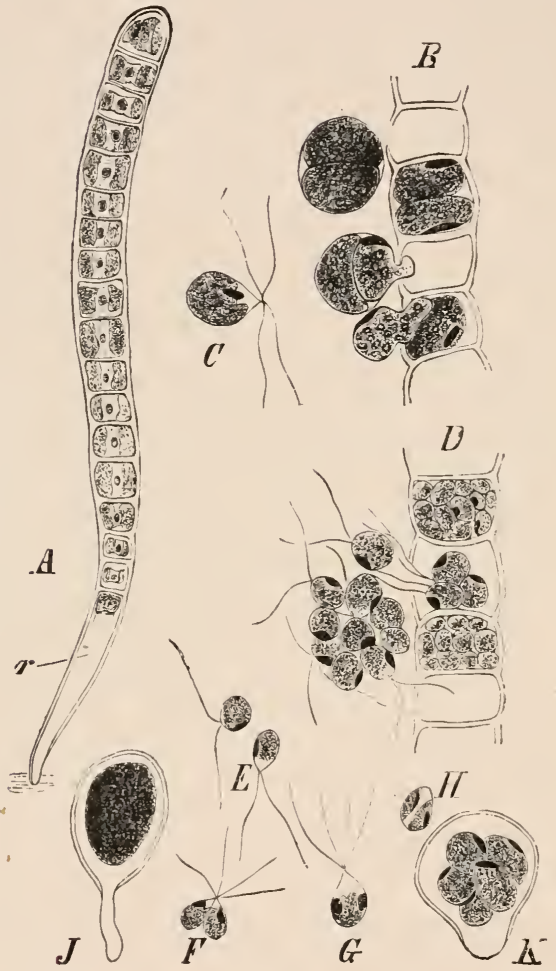

Fig. 6.

Ulothrix zonata. $A$, young filament attached by rhizoid, $r(\times 300)$; $B$, portion of filament with escaping swarm-spores; $C=$ single swarm-spore; $D=$ formation and escape of gametes ; $E=$ gametes ; $F, G=$ conjugation of gametes ; $H=$ zygote ; $J=$ zygote after period of rest; $K=$ zygote after division into swarm-spores. (After Dodel-Port. From Strasburger. $B-K \times 482$.)

attached end to end, and sharing a common life. It is thus a Plant with a multicellular body, which is fixed at its base to the substratum (Fig. 6). In this state the plant leads a vegetative existence, its cells nourishing 
themselves, growing and dividing. But sooner or later the protoplasmic contents of some of its cells, usually after division into two or more parts, may escape through a hole in the cell-wall, as motile naked bodies, into the water in which the plant lives. In fact they pass from the stationary encysted state, where each formed part of the fixed plantbody, to that corresponding to the motile Euglena. Sometimes the whole protoplasm of a cell escapes without division, but more commonly it divides into two or more parts. According to the number of divisions, the motile bodies differ in their size. If the protoplasm is undivided, or has divided into a small number of parts such as two or four, these escape into the water through an opening in the wall, as relatively large, pear-shaped zoospores; this name is given to them because they show active movements, due to the lashing of four delicate cilia attached to the transparent pointed end (Fig. 6, C). Each zoo-spore consists of a small mass of living protoplasm, with a nucleus, a green chlorophyll-body, and a red eye-spot; features which it shares with Euglena, though differing in the number of the cilia. After a period of movement in water it settles, draws in its cilia, and forms a cell-wall. This encysted cell may then germinate, and divide to form a new multicellular filament like the parent. This is a vegetative or non-sexual mode of increase, which merely secures multiplication, together with dispersal of the new plants by the movement of the zoo-spores.

But in other cases the division of the protoplasm of the cells of the Ulothrix-filament may be carried further; consequently the parts will themselves be smaller, though more numerous; and when these escape as before, they appear similar in form to the zoo-spores, but only with 
two cilia (Fig. 6, D). They are gametes, or sexual cells. It has been observed that if gametes escaping from different filaments meet, they coalesce in pairs (Fig. 6, $E, F, G$ ). They show that type of syngamy called conjugation, in which the two sexual cells are alike in form and structure, though of distinct origin. There is here no differentiation of sex. It is impossible to distinguish one as male and the other as female. The result of the fusion is called the zygote. It soon retracts its cilia, settles and grows, and after a period of rest germinates, driding its contents, which then escape as zoo-spores.

Ulothrix is an interesting instance of rudimentary sexuality. It shows syngamy; but the gametes are isogametes. In form they are like the zoo-spores, except in the number of the cilia. But after fusion the zygote has like them four cilia. There are differences in size and behaviour of the zoo-spores, some resulting from repeated divisions of the parent cell, being smaller than the type, though still having four cilia ; and they germinate like them. Further, it has been seen that sometimes the gametes themselres may germinate without fusing. These facts have an important bearing on the theory of origin of the gametes in so simple a plant. They suggest that the gamete is really a zoo-spore reduced in size and quality as a consequence of repeated divisions of the parent cell. And that fusion, or syngamy, between such gametes of a distinct source gives an impetus to new development in these weakened cells. When we further reflect that the motile is probably the primitive state of these cells, and compare them with such an organism as Euglena, it seems probable that sex may have arisen as an offset against a weakening of the cells by divisions repeated more rapidly than thei substance is increased by growth. 
The immediate effect of such simple syngamy as this is a reduction in number of cells from two to one. A consequence of it is an opportunity for the pooling of the heritable qualities of two cells, which have been of slightly different origin. These are the fundamental lessons taught by Ulothrix, a plant in which the sexes are not distinguishable from one another.

Whether in Animals or Plants, it is only in the simplest cases that the distinction between the two sexes is absent. There is evidence from both sources that a difference between the sexes has been acquired by gradual steps. In no group of Plants is this more clearly shown than in the Brown Seaweeds, the best known of which is the Common Bladder Wrack (Fucus vesiculosus), present on all shores. This plant, however, with its broad leathery fronds, is itself an advanced type of its class. Some of the Brown Seaweeds are simple and filamentous; and it is among these that the most primitive conditions of sex are found. In fact, complexity of structure and elaboration of sex run parallel in them. For instance, in Ectocarpus siliculosus, which consists of delicate filaments, partitioned sporangia are found at the ends of the branches, which open when ripe, and allow their contents to escape into the sea-water as motile gametes (Fig. 7). In form and size these are all alike, being pear-shaped, with two cilia attached laterally; while within the protoplasm is a nucleus, and a red eye-spot. But though the sexual cells are thus isogametes as regards form, those from distinct sporangia differ in their behaviour, so that they may be ranked functionally either as male or female. For it is found that the gametes from certain sporangia are at first motile, but soon lose their motility, and attach themselves to some solid substratum. These 
may be regarded as functionally female, and they act as centres of attraction to gametes from other sporangia, which gather round them in crowds, coming into contact with them by their advanced cilia (Fig. 7 (I)). These gametes which retain their motility may be held to be

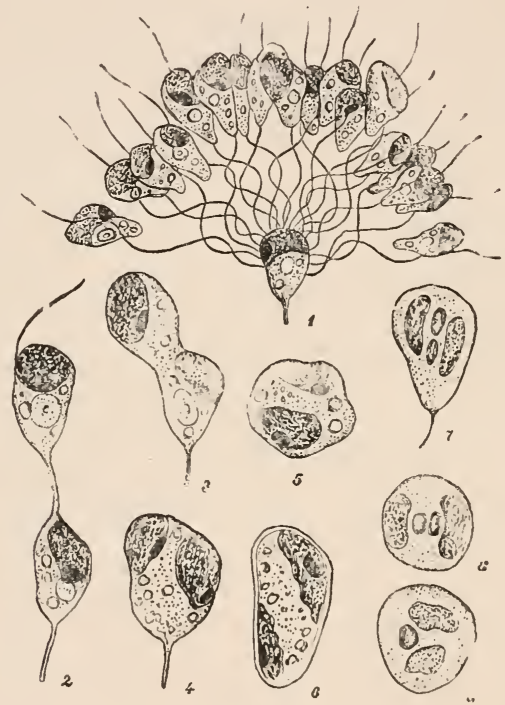

FIG. 7 .

Ectocarpus siliculosus. I, female gamete surrounded by a number of male gametes, seen from the side; $2-5$, stages in the fusion of gametes; 6 , zygote after 24 hours ; 7-9, fusion of the nuclei in conjugation, as seen after fixing and staining. ( $\mathrm{I}-5$ after Berthold ; 6-9 after Oltmanns. From Strasburger.)

male. Finally, the cilium of one of them gradually shortens and grows thicker, the male gamete approaching the female till fusion of the two is fully carried out (Fig. $7(2,3,4,5))$. The nuclei, which at first remained separate (Iiig. $7(7,8)$ ), also fuse together (9), and the zygote is then uni-nucleate. After the fusion begins all the other gametes move away, the attraction having ceased. The 
zygote then rounds off, forms a cell-wall, and presently may germinate into a new plant. Here then is a primitive distinction of sex, which is, however, only functional. Structurally the sexual cells are isogametes ; but functionally the female may be recognised by its early loss of motility, and by the attraction which it exercises over the motile males.
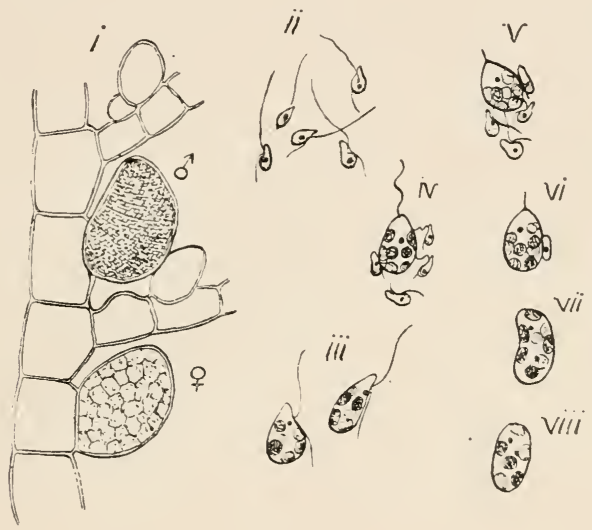

Fig. 8 .

Ectocarpus secundus. $i=$ filament bearing male ( $\hat{\delta})$, and female ( $q$ ) gametangia ; $\mathrm{ii}=$ male gametes $; \mathrm{iii}=$ female gametes $; \mathrm{iv}$-vi=stages of fertilization; vii-vii $=$ zygotes. (After Sanvageau.)

The next step is a distinction in size between the two types of gamete, and it is seen in another species of the genus Ectocarpus, viz. E. secundus. In this plant the partitioned sporangia are of two different kinds, which are borne on the same individual. One is small-celled, and gives rise to small male gametes (Fig. 8, i, of, ii); the other is larger-celled, and gives rise to larger female gametes (Fig. 8, i, + \&, iii). Both kinds of gametes are, however, motile, and have the form usual in the Brown 
Seaweeds: being pear-shaped, with two cilia attached laterally. The female gamete acts attractively upon the smaller actively motile males, which collect round it (Fig. \&, iv, v). Finally one fuses with it ; it then retracts its cilia, settles, and germinates. Here then is a step in advance of $E$. siliculosus. The sexual distinction is not merely functional, but is marked by difference of size, and that difference can already be seen in the sporangia that give rise to the gametes (gametangia).

A further step in the distinction of sex appears in Cutleria, an Alga with a narrow thong-like frond, which bears gametangia of two distinct sorts. The one kind is small-celled, and produces a small male gamete from each cell. The other is larger-celled, and produces large female gametes. Both, though differing greatly in size, have the characteristic pear-like form with two cilia attached laterally; and at first both are motile. But soon the larger female gametes retract their cilia, and lose their motility, and round off to a sphere, with a clear receptive spot. The male gamete which retains its motility is attracted to it, and fuses with it as before (Fig. 9). The points of advance here are the greater difference in size of the gametes, and the loss of the motility and rounding off of the female before fertilization. We may now distinguish the smaller male gamete as a spermatozoid, and the larger female gamete as an ovum, or egg.

The next step is illustrated in Fucus, in the fact that the large spherical female gamete, or egg, is never motile at all, while the small spermatozoid retains its motility. The large leathery frond of the Common Wrack is fertile at the ends of some of its branches. Flask-shaped cavities are there borne (conceptacles), and they contain the sexual organs. In some species they are both borne 


\section{THE ORIGIN OF SEX IN PLANTS}

together on the same plant ( $F$. vesiculosus), in others the male may be borne on one individual plant and the female organs on another (Fucus serratus). Thus there may be in Fucus not only a distinction of sexual cells but also a sex-difference in the plants that bear them.

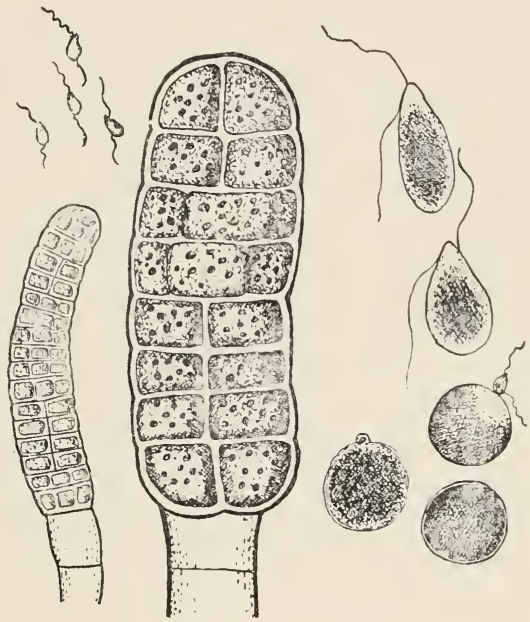

FIG. 9.

cutleria, showing the smaller male, and larger female gametangia. Top-left are small male gametes; top-right are large female gametes. Below are three stages of fertilization. (After Reinke.)

The sexual cells of Fucus differ greatly in size. The eggs are produced by division of the protoplasm of a single large cell into eight parts. When ripe these are set free into the sea-water as dense, non-motile spheres, large enough to be seen with the naked eve (Fig. Io (5i)). Each is a naked mass of granular protoplasm, with a single nucleus at the centre. The antheridial cells are smaller; and each produces, by clearage of its protoplasm, sixtyfour minute spermatozoids (Fig. Io $(\mathrm{I}-\mathrm{f})$ ). But notwith- 
standing the difference of size and cleavage, the antheridium and the oogonium have features in common, which point to their having originated in Descent from a common

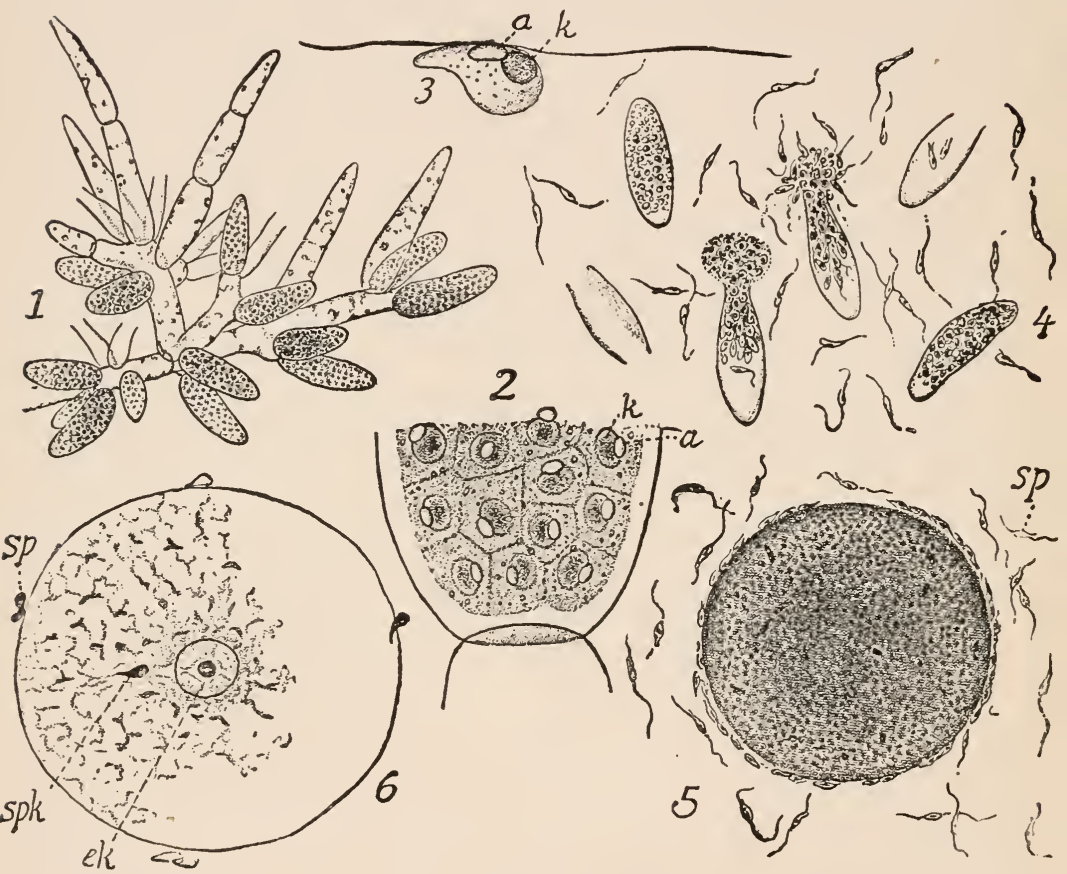

FIG. Ic.

Gametes and fertilization in Fucus. I, group of antheridia, borne on a branched hair; 2, part of an antheridium showing development of spermatozoids; 3 , spermatozoid : $a=$ eye-spot, $k=$ nucleus ; 4 , isolated antheridia liberating the spermatozoids; 5 , egg surrounded by spermatozoids; 6 , section through a fertilized egg; $s k=$ nucleus of egg, $s p k=$ sperm-nucleus, $s p=$ spermatozoids. ( $1,4,5$, after Thuret ; 2, 3, after Guignard ; 6, after Farmer. From Strasburger's Textbook.)

source. The spermatozoids are of the form usual for the gametes of the Brown Seaweeds (Fig. Io (3)). If seawater containing active spermatozoids be added to water containing living ova, the latter attract the former, which, 
being motile, collect around them in large numbers, coming into close contact with their surface (Fig. Io (5)). One of them penetrates into the egg, and its nucleus has been followed in its course inwards to the central nucleus of the egg (Fig. Io (6) ). Finally the two nuclei fuse together. These details have been successfully observed by Professor Farmer, who notes how immediately after the entrance of the fertilizing spermatozoid into the ovum all the rest leave it, as though repelled by some common impulse. The fertilized egg, or zygote, may then grow directly into a new Fucus plant.

This series of Brown Seaweeds probably indicates the general course which the differentiation of sex has taken in primitive Plants. The strength of the argument that it does so lies not only in the gradual steps which they show, but also in the fact that these observations do not stand alone. Other large groups illustrate the same thing. For instance, those closely related Green Algae which are called the Siphonales and Siphonocladiales, afford a series of steps which are quite comparable with those seen in the Brown Seaweeds. Starting with the conjugation of equal gametes, as it is seen in Acetabularia (Fig. II, i), we arrive by steps of increasing inequality in size and behaviour at the complete distinction of sex seen in Vaucheria (Fig. II, v). Here, as in Fucus, there is a very large immobile egg, which is fertilized by a very small motile spermatozoid. Other groups show also a like progression from isogametes to spermatozoid and ovum, distinguished by size and behaviour. Such progressions may be matched in Animals as well.

The question naturally arises why such progressions should appear in several distinct evolutionary lines. That the differentiation of $\operatorname{sex}$ has occurred more than once 
makes it seem probable that some real advantage has prompted it. The advantage appears to lie in the fact that the larger the amount of food that is contained in the egg the better nourished the offspring will be at its first stages, and the better accordingly will be the chance of its passing successfully through the dangerous

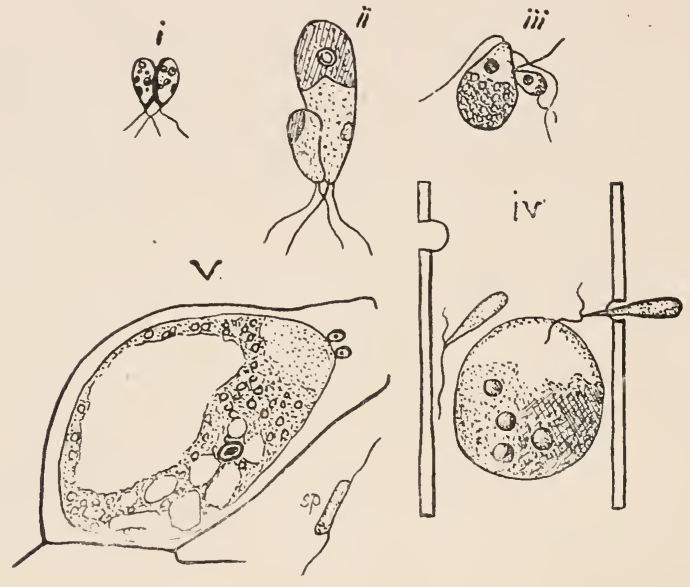

lig. Ir.

Examples showing increasing difference in proportion of the pairing gametes in the green Siphonocladiales, and Siphonales. (After Oltmanns.) i, isogametes of Acetabularia; ii, unequal gametes of Bryopsis; iii, unequal gametes of Codium; iv, motile spermatozoids and non-motile egg of Sphaeroplea; v, large non-motile egg, and minute spermatozoids of Vaucheria.

risks of youth. But the larger the egg the less mobile it will be. Even in a fluid medium a large body is less easily moved than a small one. We naturally associate this with the fact that the larger eggs have lost their motility. Motility of the egg is, however, immaterial so long as the spermatozoids remain small and actively motile, provided the egg can influence their movements so that it shall act as a centre of attraction; and this we have seen 


\section{THE ORIGIN OF SEX IN PLANTS}

to be the case. Such advantages as follow from the pooling of the hereditary factors of the two sexual cells can still be secured by such means, notwithstanding the loss of motility of the enlarged female gamete. Thus the nett advantage lies with the plant: for without sacrificing the benefits that follow from syngamy it can still secure for its offspring the probability of successful germination. Conjugating organisms, with their equivalent gametes which are usually small, may be regarded as a plant-proletariat that produces numerous offspring with little physiological capital; so that each individual when produced must depend chiefly on its own efforts. The organism which shows differentiation of its gametes, with an enlarged, well-nourished egg, is like a capitalist, whose progeny starts life well furnished with an inheritance. To them the initial struggle for life is less intense. Other things being equal, ultimate success should lie with the latter: and a study of the vegetable Kingdom from this point of view shows how successful the results of the differentiation have been.

All of the higher forms of Vegetation have the sexes fully differentiated. They have progressed on the footing of the relatively large, immobile, well-nourished egg. In many of them the comparatively small spermatozoid is still motile; but in the Higher Flowering Plants even this motility is lost, in accordance with circumstances which will be explained in the second Lecture. At the moment no more can be done here than to state the leading facts of sexuality as seen in the Land Vegetation, which stands higher in the scale of Evolution than the water-plants hitherto discussed. Two further examples of sexual propagation must suffice for the present, viz. a Fern, as illustrating the lower types of Land-Vegetation; 
and a Flowering Plant, as exemplifying the highest point reached in the Evolution of Plants.

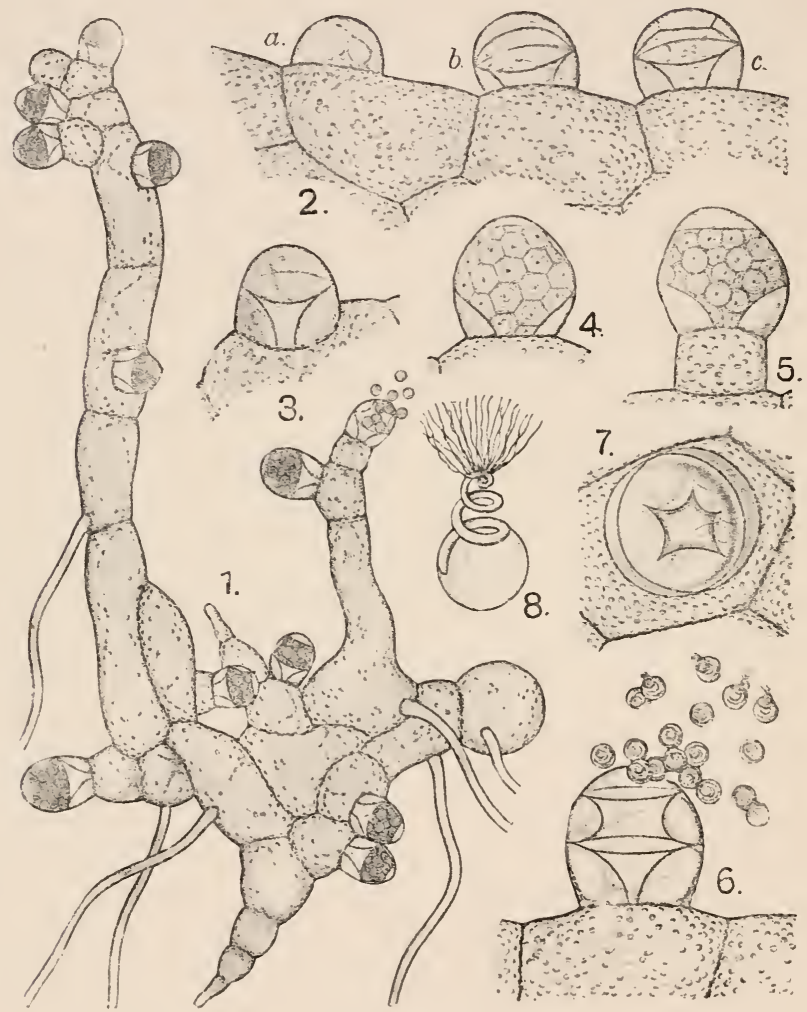

FIG. I2.

Antheridia and spermatozoids of a Fern (Nephrodium). 4, 5, Mature antheridia containing spermatocytes; 6 , rupture of an antheridium in water, and escape of the spermatozoids; 8 , a single spermatozoid more highly magnified. (After Kny.)

A Fern is a large leafy plant, and familiar examples are the "Male" Fern and the "Lady" Fern. But these are quite erroneous names, for the leafy plant is 
neither male nor female. It is neuter, bearing no organs of sex. The spores, which are commonly borne on the backs of the leaves in little brown capsules, when they are shed upon the ground, germinate, and produce each a small green scaly structure called a prothallus. This is the sexual generation, and it bears the organs of sex. The sexual cells, or gametes, produced by these differ widely in size and behaviour. The

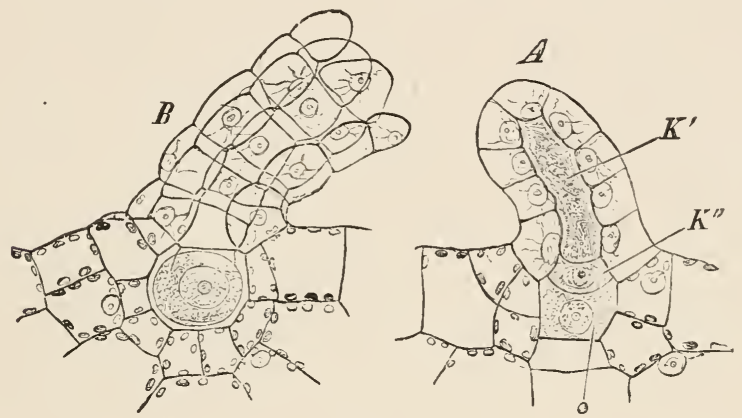

FIG. I3.

Archegonia of Fern (Polypodium). $A$, is still closed; $O=$ the ovum or egg ; $B$, shows an Archegonium with the canal of the neck open, and ready for fertilization. ( $\times 240$. After Strasburger. $)$

male gametes, or spermatozoids, are produced in large numbers within the hemispherical antheridia (Fig. I2 (I-5)), from which they escape on rupture caused by swelling in presence of water (Fig. I2 (6)). Each is a spirally coiled body, and shows active screw-like movements in the water into which it escapes. The movements are due to the lashing action of numerous fine cilia (Fig. I2 (S)). The form of this male gamete is different from those in the Algae previously described. But in its small size and active motility it resembles them; and in both cases the gamete is a naked living cell, including a nucleus. The female gamete or egg of a Fern is also 
a nucleated primordial cell; but it is much larger than the spermatozoid, and is not motile. It lies protected in a flask-like sheath called an archegonium, while at maturity the neck of the flask is open (Fig. I3, B). For the

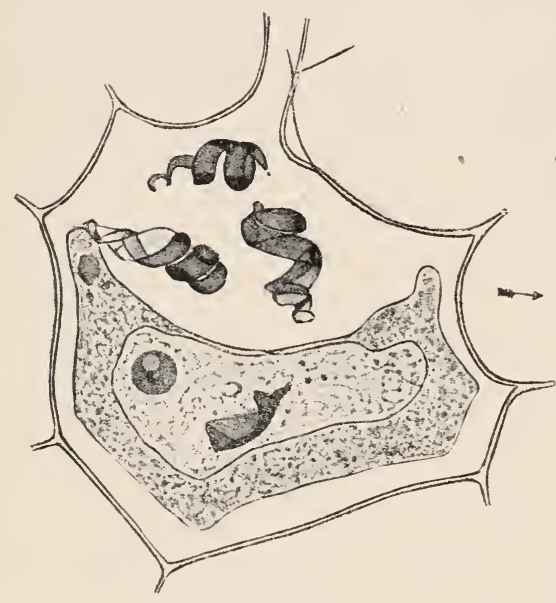

B

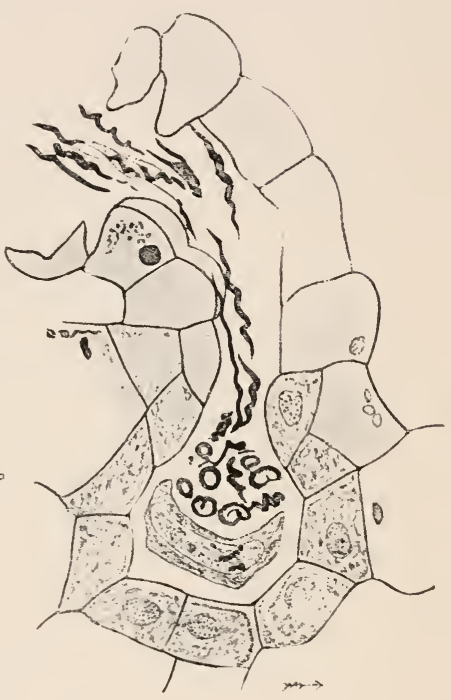

$A$

FIG. If.

Fertilization in a Fern (Onoclea). A=a vertical section through an open archegonium, probably within ten minutes after the entrance of the first spermatozoid. ( $\times$ 500.) $B=$ a vertical section of the venter of an archegonium containing spermatozoids, and the collapsed egg with a spermatozoid within its nucleus. Thirty minutes. ( $\times$ I200. After Shaw.)

archegonium also ruptures by swelling with water, and a channel of access to the egg is thus provided. The spermatozoids enter that channel in numbers (Fig. I4, $A$ ), and one of them finally penetrates the egg (Fig. I4, $B$ ). Its nucleus, still preserving the spiral form, may even be found embedded in the nucleus of the egg (Fig. It bis). But finally the two nuclei coalesce completely. The two 
unequal gametes fuse intimately, and the resulting zygote is the starting point for a new Fern. Thus syngamy in a Fern consists in the fusion of two cells differing in character, and derived from distinct sources, to form a zygote which grows into a new individual. The one is a large non-motile egg, the other is a small motile spermatozoid. In its essential features this corresponds to what

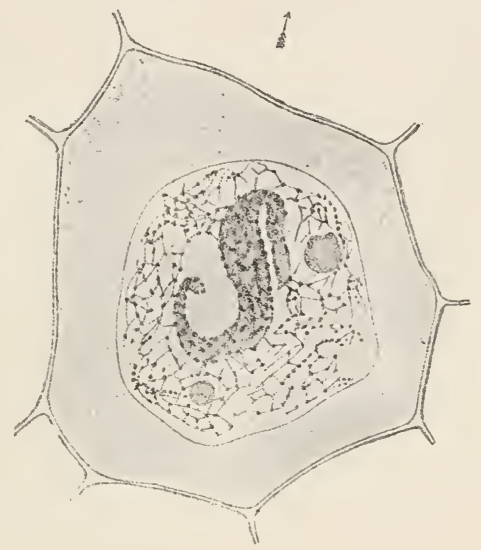

FIG. I 4 bis.

Section of an egg of a Fern, showing the spirally coiled male nucleus within the female nucleus, and fusing with it. Twelve hours after fertilization. ( $\times$ I 200. After Shaw.)

is seen in simpler plants, though the details and accessories are different.

In Flowering Plants the accessory circumstances are again different, though the essentials are the same. The parts which produce the sexual cells are grouped in that complex structure known as the Flower. The most showy parts of the flower, the petals, take no direct part in reproduction. It is the parts that lie within the petals, viz. the stamens and carpels, which produce the gametes 
(Fig. I5). The stamens produce pollen-grains. But these are not themselves gametes; the grains after transfer to the 1eceptive part of the carpel, which is called the stigma, germinate, and each forms a pollen-tube. Within this two cells are produced which are the male gametes themselves (Fig. I6, A). The female gametes are formed

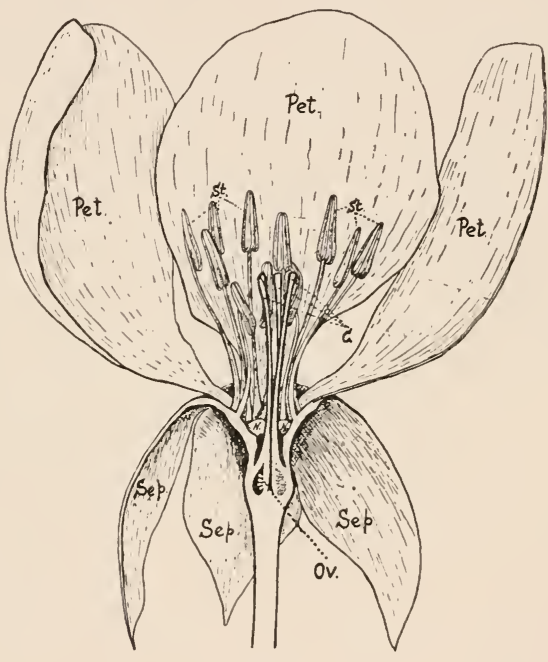

FIG. I5.

Flower of the Quince, in median section, showing the sepals (sep), petals (pet), stamens (st), and carpels (c). The ovary (ov.) contains the ovules. (After Church.)

within the carpels, which occupy the centre of the flower. Each carpel encloses one or more ovules which develop into seeds. The young peas within a pea-pod are familiar examples of such ovules covered in by the carpellary leaf. Deeply seated within each ovule is a single egg. This is the female gamete, which is to be fertilized by one of the male gametes (Fig. I6, B). At the moment we need not consider the mechanism by which the junction of these 
gametes is brought about. This will be described in the next Lecture. The immediate point is that the relatively small, and in this case non-motile male gamete is conveyed to the relatively larger ovum, both being primordial cells without cell-wall. The two gametes coalesce. At first their nuclei can still be distinguished, but gradually they become fully fused together (Fig. I7). The resulting

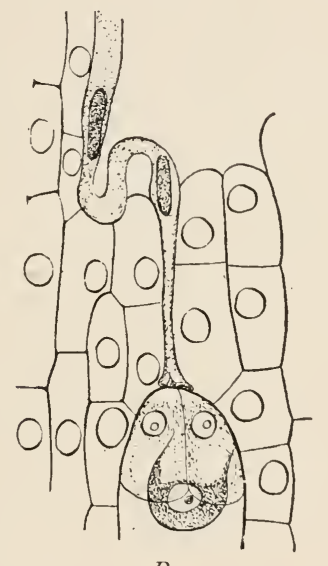

$B$

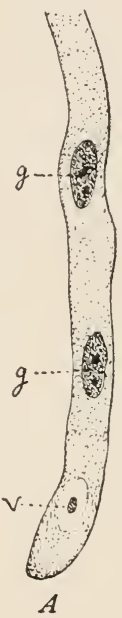

FIG. I6.

$A$, Pollen-tube of Orchis with the male gametes $(g)$ within; $B$, Pollen-tube of Orchis entering the "micropyle" of the ovule, so as to convey the male gametes to the ovum, which is the large cell more darkly shaded.

zygote gives rise to the embryo, which grows into the new individual. Here again, syngamy consists in the coalescence of two cells, differing in character, and produced from distinct sources, to form a new cell; though again the contributory circumstances are different. Such examples illustrate what is the general fact for all the Higher Plants, that the differentiation of sex established in the lower forms is maintained throughout the higher 
terms of the Vegetable Kingdom. The female cell, or egg, is relatively large and non-motile; the male cell is relatively small, and in more primitive forms it is motile in water, but in more advanced Plants of the Land that motility is finally lost.

It thus appears that though very primitive organisms may be sexless, there is a fundamental unity of the method of sexual propagation in Plants, when once it

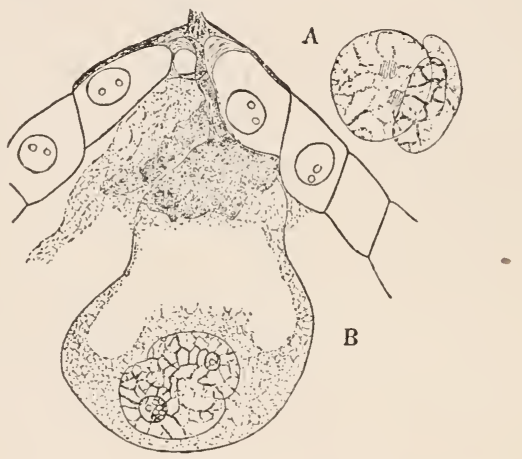

FIC. IT

Fusion of male and female gametes of Lily. (After Mottier.) A, shows the vermiform male nucleus applied to the egg-nucleus (I.ilium Martagon); $B$, shows the egg-cell of Lilium candidum with the two sexual nuclei fusing. The nuclear membranes have disappeared at the place of contact.

had become fully established. In certain of the rudimentary examples of sex the gametes may be indistinguishable as male or female. From such simple beginnings we have been able to trace the steps of differentiation of sex. Indications of a gradual increase in size of the female gamete, or ovum, and of its loss of motility have been seen; while the male spermatozoid remains relatively minute and active. A reasonable biological explanation of this has also been offered. A full sexual differentiation of this nature was already attained in the more advanced 


\section{THE ORIGIN OF SEX IN PLANTS}

Algae. The behaviour, and often approximately the proportions of the pairing gametes of the lower vegetation of the Land, such as the Mosses and Ferns, remain substantially the same as in the Algae. From Fern-like plants a gradual transition has led to the state seen in the Flowering Plants. But though in them the male gamete is no longer motile, the fusion of the gametes is still a coalescence in which the nuclear fusion is an essential feature. When stripped of all accessories, many of which find their explanation in the varied circumstances under which plants live and propagate, the actual fact of sexuality has remained the same for them all. We conclude then that syngamy consists for Plants at large in the coalescence of two sexual cells of more or less distinct origin, and especially of the muclei which those cells contain. There may be, and there are, differences in the mechanism by which this syngamy is brought about in Plants of various habitat and character. The next Lecture will be devoted to a study of those differences of method, and to the varied circumstances to which those differences may be ascribed. 


\section{LECTURE II}

\section{THE EFFECT OF A FIXED POSITION ON THE SEXUALITY OF PLANTS}

IF an average man were asked what is the most striking difference between Animals and Plants, he would probably reply that Animals move and Plants do not. But this would be an over-statement of the real facts. Living Plants do move, though their movements are slow and constrained. No organic Life is possible without movement of one sort or another. But there is an essential difference of structure between Animals and Plants which explains their respective powers of movement. The protoplasm of the former is not as a rule confined within a wall, and tissues-masses composed of such cells can move freely, as our own muscles do. But each of the cells of the Plant is enclosed in a resistant cell-wall, which checks the mobile protoplasm within, and at the best its movements are only slow. Plants have in fact bartered their free motility for the protection given by the cellwall. Already Euglena shows in its temporary encysted stage the condition usual in the plant-body (Fig. 3, D) ; but the cell-wall is a permanent feature in such simple plants as Protococcus viridis (Fig. 5) ; and in Ulothrix (Fig. 6, A) it is also, except in its propagative phase. The further circumstance that Plants are habitually fixed 
to the substratum, as are Ulothrix or Fucus, or eren rooted in the soil like Ferns and Flowering Plants, effectually prevents their movements as a whole from place to place. In respect of sexuality this imposes a vital difference. The mobile Animal is free to seek its mate; the encysted and rooted Plant is not. Hence the whole problem of sexuality for the Higher Plants appears to be a different one from that of the Higher Animals. Nevertheless in both a very similar coalescence of gametes is the end to be attained, and there are various analogies in the means employed to attain that end.

In Plants that live in the water the fact that all except the simplest are non-motile as a whole, and fixed to the substratum as Seaweeds are, does not present any serious obstacle to success. For they are mostly gregarious, and one of the gametes or both are commonly motile in the water into which they escape. In those which are sexually differentiated the male commonly retains, as a spermatozoid, its power of movement from place to place : and Algae so provided are believed to represent the remote ancestry of the Land-Vegetation. There is no need in such cases for both gametes to be motile, if the gamete which is sedentary can control the movements of that which is motile. That it can do so is demonstrated by any mixture of water containing living spermatozoids of Fucus with water containing its ova (Fig. Io (5)). The influence of attraction before syngamy and of repulsion of the remaining spermatozoids after syngamy suggests that the porver of the ovum lies in diffusion from it into water of some soluble substance, attractive or the reverse. A study of the cognate phenomenon in Ferns has shown that this is a true explanation. But it would only serve for organisms in which a water-medium is available at S.H. 
the time of fertilization. This immediately raises the question of how syngamy is effected in the Ferns and other primitive Land-Living Plants.

The method of syngamy in Ferns may be held to represent fairly that of all the more primitive Plants of the Land. Its main features have been described in the previous Lecture. The spermatozoid, set free and motile in water (Fig. I2 $(6,8)$ ), and the ovum, deeply seated in the archegonium (Fig. I3), are the gametes. The problem is to bring them together with certainty. The medium of transit is water. It is only in presence of water that the antheridia and archegonia open. In Nature this is provided by showers, or copious dews, and into that water the spermatozoids escape. A significant fact is that the spermatozoids are very numerous. But still the prospect of the fusion of spermatozoid and orum being carried out would be almost infinitely small were it left to mere chance. The ovum, lying protected in the cavity of the archegonium, would almost inevitably be missed in random wanderings of even numerous spermatozoids. But any microscopic preparation of them in the living state shows that the spermatozoids are attracted, and enter the archegonium with certainty, and in large numbers. Experiment has explained the source of the attraction.

If artificial archegonia be made in the form of minute glass flasks, it would be possible to fill them with solutions of various soluble substances. If they were then immersed in water the soluble substance would diffuse out, the neck of the flask being constantly the centre of greatest concentration. If the water contained living spermatozoids, the effect of each substance used could be noted, according as it influenced their movements. In this way a number 
of substances have been tried, and of various strengths. It has been found that a solution of malic acid, of strength about o.OoI p.c., diffusing out into water, serves as a positive attraction, leading the spermatozoids to the neck of the flask, which they actually enter as they would a real archegonium. It is therefore concluded as probable that a soluble substance, similar in its action to malic acid, is given out from the ovum, and serves to direct the movements of the spermatozoids.

The deeply seated position of the ovum in a Fern is clearly an advantage in the protection and nutrition of the fertilized egg (Fig. I3). The maternal tissue closely surrounds the embryo at first. A connection is kept up by means of a suctorial "foot," between the embryo that grows from the egg and the parent prothallus (Fig. I8). This persists until the young plant is established so as to be able to nourish itself by its own root and leaf. On the other hand we see that the position of the ovum at the base of the flask-shaped archegonium offers no serious obstacle to syngamy, provided the attraction of the motile spermatozoid is as effective as experiment proves it to be. This has been the method of sexual propagation of all the primitive Plants of the Land. They are represented by the Mosses, Ferns, Horsetails, and Club-Mosses. Such Plants proclaim their aquatic origin by retaining the ancestral method of syngamy through water. They are not typical Plants of the Land, but might be properly called the Amphibians of the Vegetable Kingdom. They have, speaking figuratively, one foot on land and one still in the water. They cannot complete the cycle of their life in its most critical point, that of the sexual production of a new individual, except when external fluid water is present. Without it the spermatozoids 
are not liberated, nor do the archegonia open. It is possible by watering cultures only by absorption from below to grow the sexual plants of Ferns or Mosses for long periods without any sexual propagation at all. This is a restricted existence from which the Higher Land-living Plants have finally broken away. In the

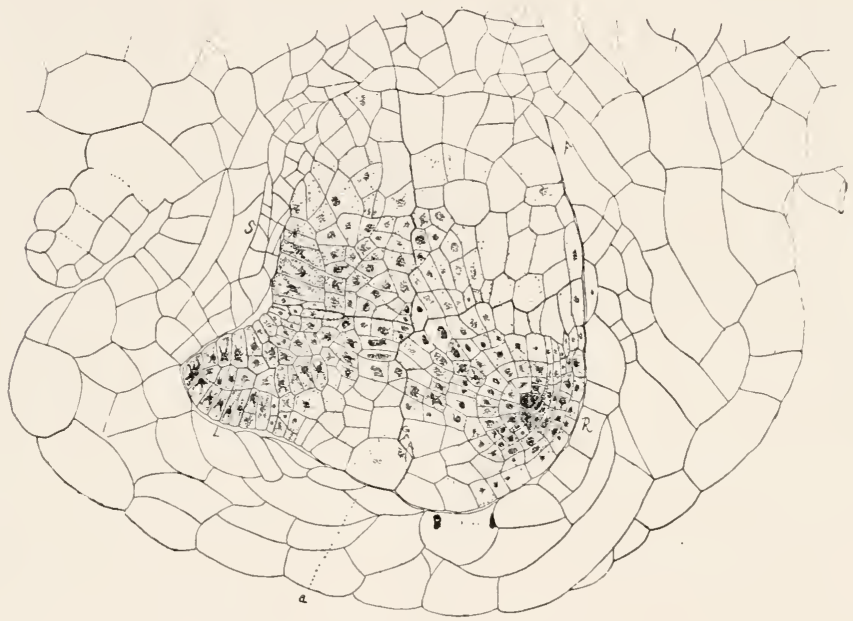

FIG. I8.

Emtryo of a Fern (Adiantum) embedded in the tissues of the parent prothallus. where it is protecied and fed by the surrounding tissues. $L=$ leaf; $R=$ root; $S=$ stem ; $F=$ suctoria! foot. (After Atkinson.)

Seed-Plants, as we shall see, external fluid water is no longer necessary for syngamy.

In the previous Lecture it has been seen that the bare facts of syngamy in Flowering Plants correspond to those in lower forms. The male gamete is produced from the pollen-grain. The female gamete, or egg, lies deeply seated in the ovule. These gametes fuse together to form a zygote that develops into the embryo. But as 
all ordinary Seed-Plants live on land, and neither the one gamete nor the other is set free into water, nor is motile, it is clear that the mechanism that brings about the fusion of gametes in Flowering Plants must be different from that in the Algae, or in the Ferns. It involves two stages. First the transfer of the pollengrain from the stamen where it is produced to the receptive surface of the stigma: this is called Pollination. The second is the transfer of the male gamete, derived from the pollen-grain, to the ovum with which it fuses: this fusion is called Fertilization, or Syngamy. The two stages are quite distinct in their nature, and should be studied separately. Pollination is only a means to the end: Fertilization is the end itself.

In Pollination the distance through which the pollengrain must travel from the stamen to the receptive stigma varies greatly, and depends upon the structure of the flower in question. Some flowers, which are called hermaphrodite, contain both stamens and carpels; in that case the distance to be traversed may be small (Fig. I5). But in many plants the stamens and carpels may be borne on different flowers, as in the Hazel, Beech, or Oak; or even on different plants, as in the Campion or Willow. There are thus various degrees of separation of the sexes in the space which has to be traversed by the pollen-grain. But a separation in Time of maturity is equally a cause of difficulty in pollination, and it may apply even in hermaphrodite flowers. For if the pollen is matured either before or after the stigma of the same flower is ready to receive it, clearly to be effective the pollen must be brought from a distance. Thus pollination is not so simple a problem as it looks at first sight. 
There is also another point to be considered. Within certain limits a difference of origin of the fusing gametes is an advantage. Already in Ulothrix and in Ectocarpus the conjugating gametes have been seen to arise from different sporangia. In Flowering Plants it has been shown in many cases that intercrossing gives on the average a larger and stronger progeny. By crosssing is meant that the pollen which produces the fertilizing gamete shall have been derived from a flower or plant distinct from that bearing the ovum which is to be fertilized. Seeds that result from such a crossing have been found to be on the average more numerous and heavier than those resulting from self-fertilization. The course of Evolution of Flowers has been such as to secure this advantage. The effect of the separation of stamens and carpels in space, and in time of maturing, is to promote intercrossing. But all such developments have still further complicated the mechanical problem of Pollination for Seed-Plants.

Such Plants being themselves immobile, as naturally follows from their being rooted in the soil, use is made of outside agencies, such as the movements of Wind and Water, or the mobility of Animals. The mechanism of flowers has been specialised in the most remarkable manner in accordance with these methods of transfer. Where use is made of Wind, as in the Grasses, the flowers produce abundance of dry dusty pollen, easily shaken out in clouds from anthers balanced on very flexible filaments. The stigmas meanwhile are much branched and feathery, so as to expose a large surface for catching the grains. These features go with close grouping of the flowers, which are individually small and inconspicuous (Fig. I9). Where animals are the active 
agents, the flowers are attractive and conspicuous by their scent, by honey-secretion, and by widely expanded floral envelopes of bright colour. The latter attract the eye, the former the other senses of the animal, and lead him to visit the flower for his own purposes of gathering

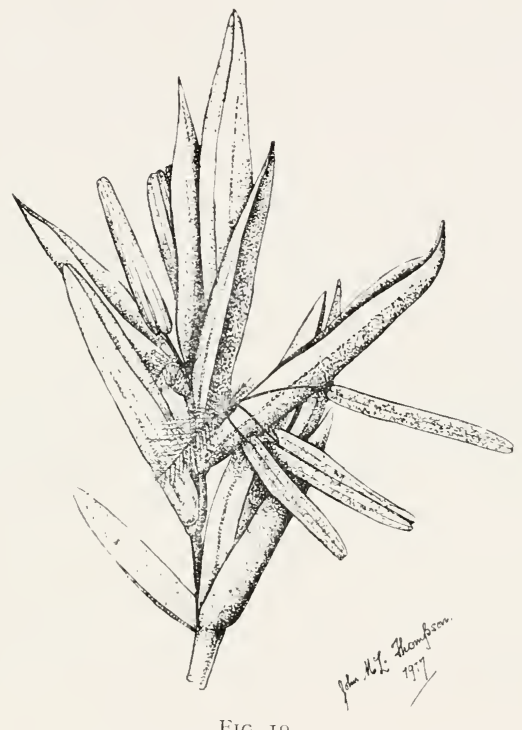

Fic. I9.

A spikelet of a Grass, showing one flower in bloom, with three anthers on their flexible filaments. and two feathery stigmas. These, with the inconspicuous size and colour, are common characters of plants pollinated by agency of wind.

honey, or pollen. Incidentally the floral mechanism is so arranged, in size and form of its parts, that as he visits the flower, pollen, often of a sticky nature, is deposited on his body. The flower may be so formed as to lead him to take a definite position, so that the pollen is deposited on a definite part of his body. The result of a succession of visits to a succession of flowers of like construction will then be that, if the stigmas correspond 
in position to the spots where he bears the pollen, some may be deposited upon them. Thus unwittingly he will have been the agent of transfer of the pollen from the pollen-sac to the receptive stigma (Fig. 20).

Such mechanisms have been elaborated in the course of Descent in an infinite variety of detail. This is the biological meaning of the attractive features of form, colour, and scent which flowers have assumed. It may

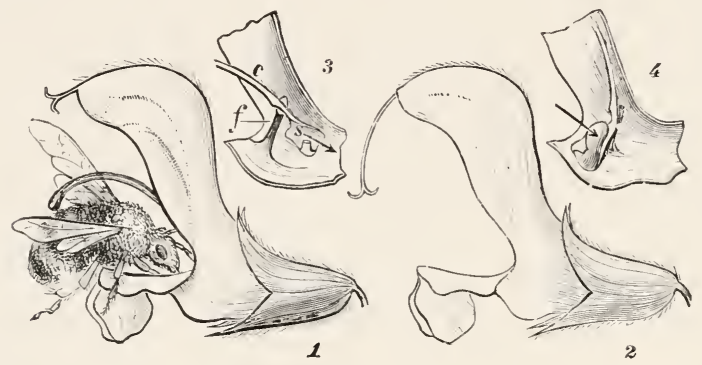

FIG. 20.

Pollination of Salvia. I =flower visited by Humble Bee, showing the projection of the curved connective of the anther from the helmet-shaped upper lip of the corolla, and the deposition of the pollen on the back of the Bee; $2=$ an older flower, showing the elongated style with its stigma in such a position as to receive pollen brought by a Bee from a younger flower; $3-4$, show the mechanism by which the anther swings when pressed forward (as shown by arrow) by the proboscis of the Bee. (After Strasburger.)

even be seen how certain floral types have been adjusted in relation to the visits of certain animals, and show development parallel with them. A good instance is that of the Aconite and the Humble Bee, in which the size and shape of the flower is such as to accommodate the animal. A study of their distribution across Europe and Asia shows that the northern limit of both almost exactly coincides. This suggests the importance of the Humble Bee in the transfer of the pollen of the Aconite, while the food which the flower offers may in some measure 
react in determining the distribution of the Bee. The methods of transfer of the pollen may be very varied. But the essential feature of them all is the same, viz. the conveyance of an immobile body essential to propagation from the pollen-sac where it is produced to the surface of the stigma, where it can germinate.

The study of the structure of Flowers as pollinating mechanisms has caught public attention, and the facts are often presented in sensational language. Floral mechanisms and their evolution parallel to the forms of their visitants are certainly wonderful instances of adaptation. But in studying them it should always be remembered that it is the immobility of the Plant that gives these adaptations their special value. Vegetation was originally aquatic. The spread of Plant Life to the Land raised a thousand difficult life-problems. One of the most urgent was how it was possible for Plants, being immobile, to maintain sexual reproduction under conditions of life in air instead of in water. A first step in the solution of that problem, the transfer of the immobile pollen, is carried out in that wonderful structure, the Flower, which is as beautiful to the understanding as it is to any of the senses.

Once landed on the surface of the stigma the pollengrain germinates and forms a pollen-tube, which, penetrating the tissue, traverses the carpel downwards to the cavity in which the ovule or ovules lie (Fig. 2I). There it is led to the apex of the ovule; it enters the micropyle, and impinges directly upon the embryo-sac where the egg is attached. Since it conveys two male gametes, these can be discharged at the apex into the embryo-sac. It is one of these which entering the egg fertilizes it. These are, briefly told, the steps leading to fertilization or 
syngamy in Flowering Plants. They will now be considered in detail.

The germination of the pollen-grain takes place normally

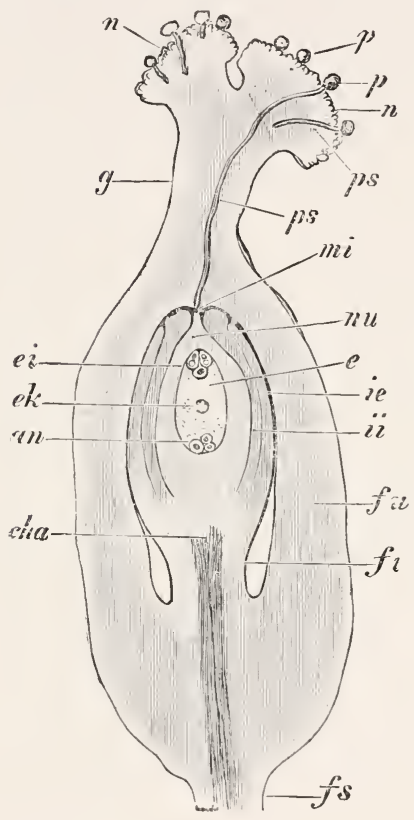

Fig. $2 \mathrm{I}$.

Ovary of Polygonum during fertilization, containing one straight ovule. $f_{S}=$ base of ovary; $f u=$ funiculus; $c h a=$ chalaza; $n u=$ nucellus; $m i=$ micropyle; $i i=$ inner, and $i e=$ outer integuments; $e=$ embryo sac; $\quad e k=$ central nucleus of sac; $e i=$ egg-apparatus; $a_{n}=$ antipodal cells: $g=$ style; $n=$ stigma ; $p=$ pollengrains; $p s=$ pollen-tubes. $\left(x_{4} 8\right.$. After Strasburger.) on the stigma, and the course of the pollen-tube can be followed, as in Fig. 2I. But germination can also be induced in a nutritive medium apart from the stigma, such as a solution of cane sugar of suitable strength. This makes it possible to observe the origin and behaviour of the pollen-tube. The germination may be very rapid. From fresh Pollen of the wild Hyacinth placed in 7-IO p.c. solution pollen-tubes will be formed in about fifteen minutes, and in an hour will have grown to a length several times the diameter of the grain. The effect of external influences upon the growth of the tube can be studied in such cultures. For instance, if grains be germinated under a cover-glass, the tubes first issue pointing indiscriminately in all directions. But soon those near the margin turn inwards from the free air, that is, they grow away from the source of oxygen (Fig. 22). If a similar culture be prepared, and a piece of the style and stigma of the same species be introduced, the tubes curve towards 


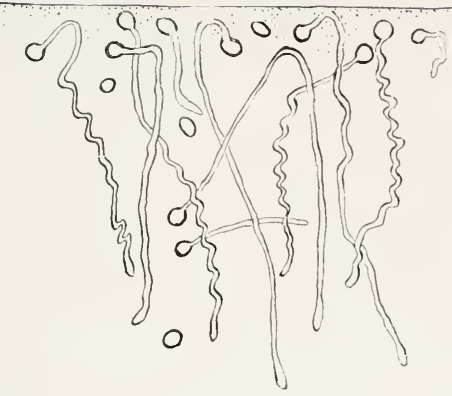

Fig. 22.

Pollen-grains germinated in a nutritive medium, under a cover glass, of which the margin is shown. The tubes curve away from the margin, that is, away from the supply of oxygen. (After Molisch.)

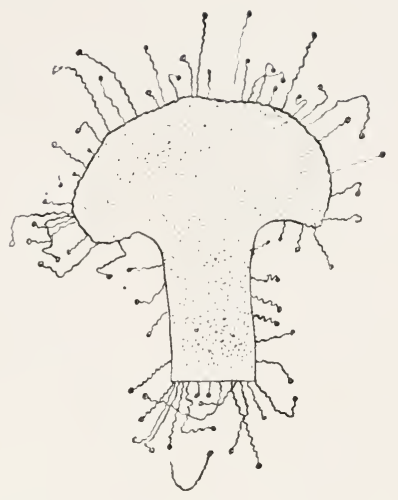

FIG. 23 .

Result of culture of pollen tubes of Narcissus Tazetta, in the neighbour. hood of the style and stigma, in 7 p.c. sugar, after sixteen hours; diagrammatic. ( io. After Molisch.)

it, and especially towards the cut surface (Fig. 23). They also tend when grown exposed to the air to follow a moist surface. These three factors all influence the growth of the tube in the same way, when pollen germinates on the stigma. Turning away from free air, adhering to the moist surface, and attracted by the tissue of the style, the tube penetrates it. Sometimes there is a channel down the style filled with mucilage; in which case the tube grows down it, and does not penetrate the tissue. In other cases the cells of the stigma are themselves perforated by the

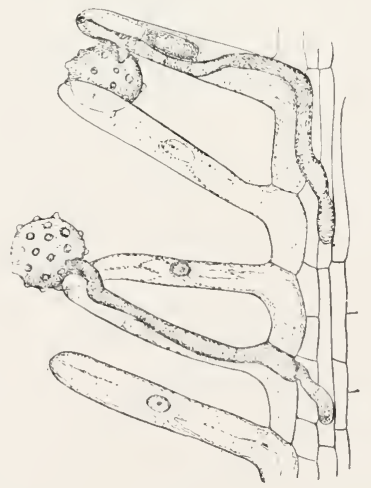

FIG. 24 .

Pollen-grains of the Corn Cockle (Agrostemma) germinating on the stigma, and the pollen-tubes pene. trating its tissue. (After Strasburger.) 
tube, which then passes on between the cells of the style (Fig. 24). Traversing the style in this way, it reaches the cavity of the ovary, where it may be conducted

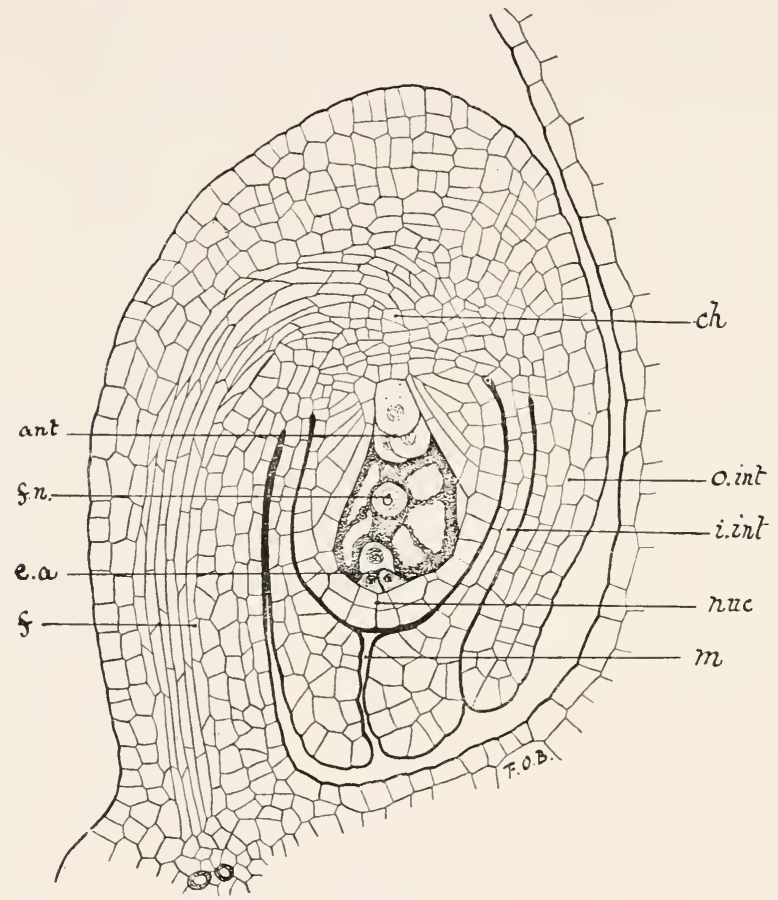

FIG. 25.

Median section of an ovule of the Marsh Marigold (Caltha), showing the eggapparatus (e.a) deeply seated, and consisting of the single ovum, which projects into the embryo-sac, and two adjoining cells (svnergidae). $f=$ funiculus; $c h=$ chalaza ; $m=$ micropyle ; $n u c=$ nucellus ; $o$. int. ; $i$. int. =outer and inner integuments ; $f i=$ central fusion nucleus; ant antipodals. The structure here shown is very general for ovules of Flowering Plants. ( Iro.)

mechanically by directing hairs to the apex of the orule. It there enters the narrow channel of the micropyle, and makes its way to the ovum itself (Fig. 27, B). It may be a question what are the influences which direct the last 
part of the course, but it is accomplished with a high degree of certainty.

The tube is a means of conveyance of the male gametes to the orule. The mature pollen-grain contains two cells (Fig. 26). One, the larger, is a vegetative cell, and takes no direct part in propagation. Shortly after germination begins the other divides into two, which are the male gametes. On germination thesecontents of the pollengrain pass into the growing tube, and ad-

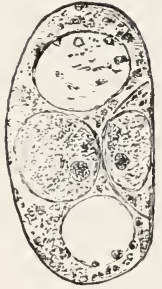

FIG. 26.

Pollen-grain, showing two cells: the larger is vegetative; the smaller, to the right, gives rise to the two gametes. $(\times 5+0$.$) . Ifter$ Strasburger. vance with it asit grows (Fig. 27, $A$ ). They are thus conveyed, always protected within the tissue of the style, to the ovary,

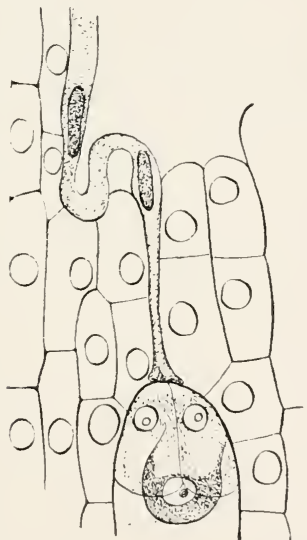

$B$

FIG. 27.

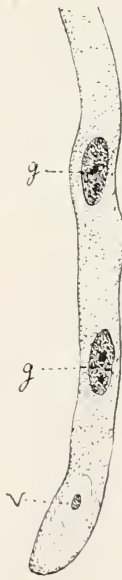

A

A, Pollen-tube of Orchis latifolia, teased out from the ovary. $r$-vegetative nucleus; $g g=$ gametes. $(\times 5$ oo. $) \quad B$, Pollen-tube of the same penetrating the micropyle of the ovule; just below its lip is the egg-apparatus, with the ovum shaded. The male gametes are still in the tube. (30o.) After Strasburger.

and finally to the ovule itself (Fig. 27, B). There they are extruded through the soft tip of the tube into the embryo- 
sac, and one of the two gametes entering the orum, its nucleus may be seen to fuse with that of the orum (Fig. 28). The result of fusion of the non-motile male gamete with the non-motile ovum is the zygote, and from this the embryo of a new plant develops. Here then is a syngamy in which neither gamete is capable of independent movement so as to secure the fusion. The opportunity for movement in water, after the ancestral fashion of the

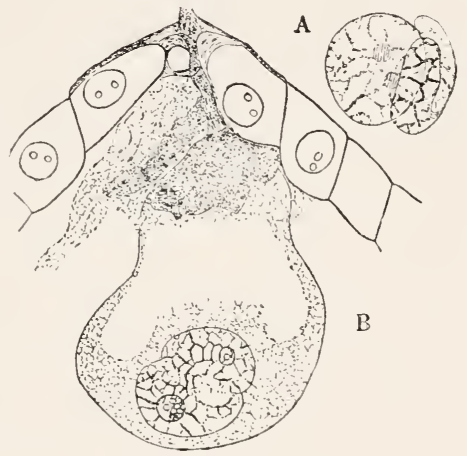

FIG. 28 .

Fusion of male and female gametes of Lily (after Mottier). $A$, shows the vermiform male nucleus applied to the egg-nucleus (Lilium Martagon); $B$, shows the egg-cell of Lilium candidum with the two sexual nuclei fusing. The nuclear membranes have disappeared at the place of contact.

Ferns, is absent in accordance with the Land-Habit. The fact that the flower is as a rule borne distally on the shoot, and blooms habitually in bright sunny weather, precludes the means of transit through water. In the course of the Evolution of Seed Plants a new means of transit has been substituted for it, better suited to their life on Land. But the wonderfully adaptive growth of the pollen-tube is in itself no more striking a phenomenon than is the adaptive movement of the active spermatozoid that it replaced. That it did replace it, and that 
Seed-Plants really were evolved from organisms which were fertilized as Ferns are, is shown by facts recently discovered. For certain primitive Seed-Plants have been found to have motile spermatozoids (Fig. 29). But they more only in the limited sphere of a small volume of fluid within the ovule. These Plants have been driven by the exigencies of their land-habit to secrete the medium in which their spermatozoids move. For Land-Plants such an archaic method so artificially maintained is clearly unpractical. The Cycads and the Maiden-Hair Tree that show it are rightly regarded as survivals, whose conservatism has almost cost them their lives. The rush of Evolution of Land-Plants, with a more practical method of fertilization, has passed them by. But they at least survive to tell the story of Descent, and to point its moral.

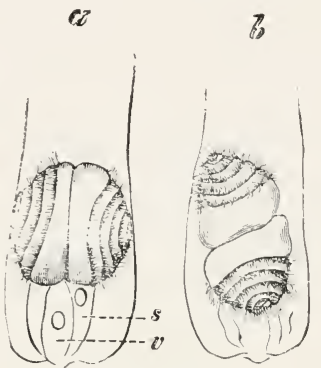

FIG. 29.

End of Pollen-tube of Zamia, showing the vegetative cell $(v)$, sterile cell $(s)$, and two spermatozoids. (a) before movement has commenced; $(b)$ after the beginning of ciliary motion. ( $\times$ about 75.) After Webber, from Strasburger.

The transition from water to land has thus profoundly affected the mechanism of sexuality in Plants, without altering the essential features of the process. Syngamy is still a fusion of two sexual cells of more or less distinct origin to form one, which is the starting point for a new individual. Witnessing the consequences of the change of medium, the mind is impressed by a sense of the vulnerability of primordial cells exposed to the air. In water the risk is not great. The gametes may be roided directly into water, as they are in Fucus. Syngamy is then carried out quite apart from the parent, and the new individual is independent of parental nursing. But 
in Land-Plants the egg is never shed. It is retained by the parent. In the Mosses and Ferns it is embedded in the flask-like archegonium, where it is still accessible to the free-swimming spermatozoid through the open channel of the neck. Thus mechanical protection of the egg is ensured, as well as the nourishment of the new germ by the parent after syngamy. In the Flowering Plant this protection and nutrition of the germ is still
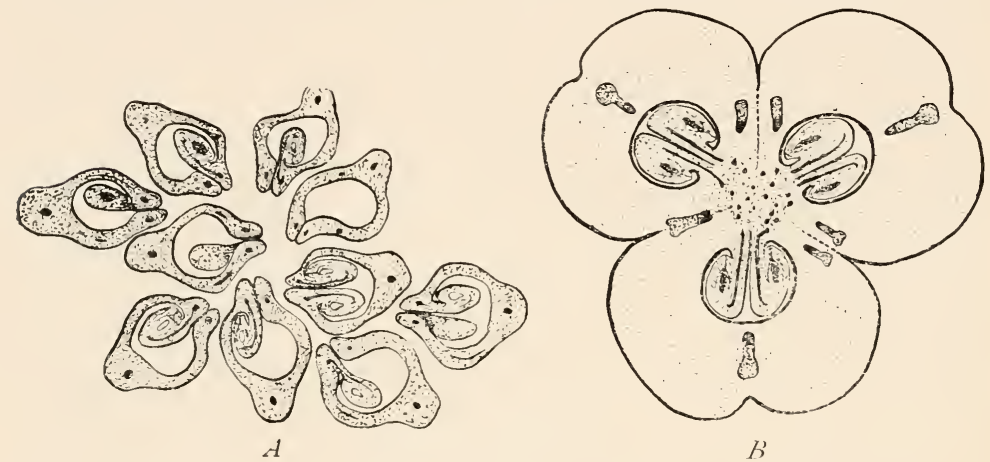

FIG. 30 .

$A$, Transverse section of the pistil of Ca!tha, showing the ovules protected in the separate, pod-like carpels; $B$, transverse section of the ovary of Lily, showing the carpels united (syncarpous), closely enveloping the ovules. In both cases the structure of the ovules themselves is substantially as in Fig. 25.

more effectively secured. It is noteworthy how deeply seated are the ova, and protected by successive coats of tissue. First they are covered in by the carpellary wall (Fig. 30); then by the integuments of the ovule; next follows the tissue of the nucellus; and lastly the primordial orum is contained in the embryo-sac, which lies centrally in the ovule (Fig. 25). Such repeated sheaths give a very perfect protection against exposure to the air, or to mechanical damage. But they increase the difficulties of fertilization. These are overcome by means of the exactly directed growth of the pollen-tube. On thcir 
way to the egg the male gametes are never exposed in land-living Plants. Even in the pollen-grain the cell that gives rise to them is protected by its usually yellow, corky wall from too intense sunlight, and from risks of evaporation from its surface. After the first stage is passed, the transfer of the gametes by the pollen-tube is consistently within the protecting tissues of the carpel. Doubtless these precautions are very necessary in Plants growing exposed upon the land, which bear their flowers containing the gametes at the ends of their branches. The protection and nutrition afforded by the parent is thus so well secured that a large number of eggs is unnecessary. Only one is present in each ovule. But this is handled physiologically with extreme care. Each germ, once established by syngamy, is evi-

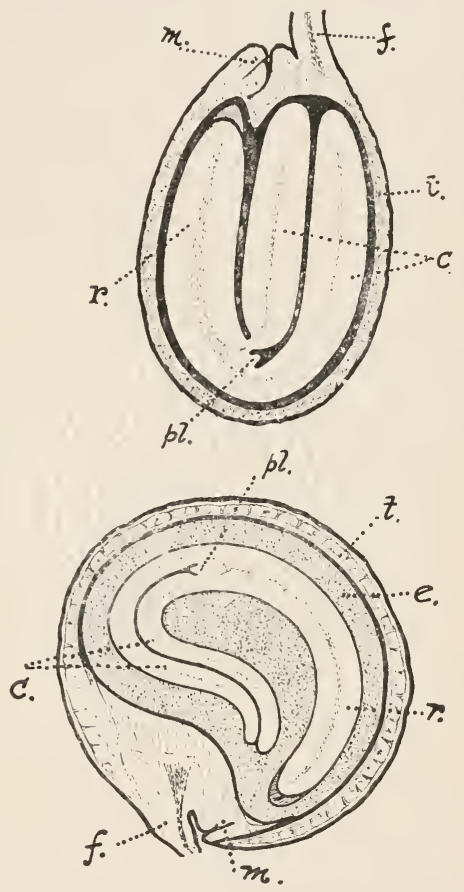

FIG. 31 .

Seeds in median section. The upper is of Shepherd's Purse, the lower of Datura. $f=$ funiculus : $m=$ micropyle : $t=$ seed-coat $: e=$ endosperm: $c=$ cotyledons : $p l=$ plumule : $r=$ radicle. Enlarged. dently a thing of individual worth (Fig. 3I). Yet Tennyson, the poet of the Darwinian era, has done scant justice to the value set on each germ. Impressed with the ruthless waste of Organic Nature he cries

"How careful of the type she seems, How careless of the single life." 
For once the Seer saw only a half truth. Had he visualised with his accustomed clearness each germ, with its deep-seated position, and its many protective coats; and realised how perfect are the conditions for nursing the embryo in the maternal tissues, Literature might have lost two epigrammatic lines, but Science would have secured a truer word-picture. It is not at the outset, but later in the individual life of Land Plants, that the full weight of the physical struggle for existence comes. In the period of embryology of new germs Nature appears in her most engaging mood ; not " red in tooth and claw," but as the nursing mother. That rôle is none the less attractive that it has been forced upon her by the ruthless conditions of Life on Land. In aquatic Plants, such as Ulothrix, Ectocarpus, or Fucus, the zygote has at once to meet unprotected the contingencies of Life. Many fail, but many succeed in passing that less drastic ordeal of early existence in water. But the ordeal of life in the air is more severe to the young in many ways. Hence all Land Plants, as a condition of the bare existence of their germs, have adopted the nursing habit. The ordeal of the young organism is thus deferred. The embryo, nourished and strengthened through the nursing period, is better fitted to meet it than the naked zygote would have been. This is the biological aspect of the facts of internal embryology. The parallel in this between the Higher Plants and the Higher Animals is singularly close. While noting it, we should always bear in mind that the results in the two Kingdoms have been independently achieved. They may be held as evidence of separate reaction to the exacting conditions of terrestrial life. But the incidence of these conditions has been the same for both the Kingdoms of Living Beings. 


\section{LECTURE III}

THE REPRODUCTIVE PROCESS IN ANIMALS: SOME OF THE GENERAL PRINCIPLES

Perhaps the most wonderful thing in Nature is a living animal. And there is nothing more terrible in its impressiveness than to be a witness when such a living creature is suddenly deprived of its life, and to see in the place where it was a moment before a mass of inert material bearing the same outward form that the living creature had, but without that characteristic-lifethat gave it its all-transcending interest. What that " Jife" really is in its ultimate nature is an absolute mystery, and there are many of us who believe that it must necessarily remain forever a mystery. For the main instrument upon which we are dependent for its investigation is our brain, and the whole activity of that organ is merely a phase of that living activity the nature of which it is our endeavour to understand.

Even when we leave on one side the ultimate nature of Life itself and restrict ourselves to the study of its more superficial phenomena we find ourselves up against quite unexpected complexities. Take the case of a human being and consider one of his very simplest actions. What can be more simple than to stand still doing nothing? One can observe the phenomenon at 
a street corner in any one of our great cities. If you ask one of the individuals concerned who and what he is he may reply that he is a worker-though the most careful watching may fail to detect any signs of a desire to work. What is the man really doing? Standing up-what more simple?

But now suppose you had the body of that same man frozen stiff - with every bit of him in precisely the same position as it has been during; life-and suppose you now stood him up on his feet on the same bit of flat pavement. You would find considerable difficulty in getting him balanced so as to stand up at all, and if at last you did succeed you would find that the slightest touch, or a slight breeze, would overturn him. And you would learn the lesson that there is something essentially different between the standing up of that mass of dead material and the standing up of the living man. As a matter of fact, when you look into the mere action of standing up you find that it is a matter of fearsome complexity.

Suppose you had a chain of iron or wooden rods, jointed loosely together end to end, you might be able-with a good deal of trouble - to arrange it so as to be kept upright by elastic bands passing from one rod to another and each under exactly the proper degree of tension. Now this is the sort of principle which is at work in the living human body - the rods are represented by the bones of the skeleton and the elastic bands by the muscles which pass from one bone to another and pull against one another so as to keep the whole arrangement upright. But what puts the human arrangement upon a totally different level of complexity as compared with the rough model I have described is that it is automatic and self-regulating. The equilibrium of the body is constantly being interfered 
with. A slight movement of the head or arm, a slight puff of wind, a slight touch by a passer-by would be enough to overturn the body were it not instantly met by a slight automatic increase in the tension of certain of the muscles. As a matter of fact, the body when apparently standing still is never really standing still for a moment: it is constantly commencing to fall over to one side or the other, and is constantly being automatically checked and pulled back towards the vertical. Hundreds of bundles of muscle-fibres are at work the whole time, all co-operating together, each doing exactly its share-no shirking, no strikes, no lockouts, every unit loyally doing its bit. If our friend at the corner were to realise that wonderfully co-ordinated activity within his own body it would surely break his heart: he would fling himself into the river; he might even take to work!

What I have been saying so far is merely to impress upon you what unsuspected complexities underly even the simplest actions of living creatures. The reproductive process is not one of these simplest processes but probably the most tremendously complex of them all. How it is that a speck of matter so small as to be invisible except under a powerful microscope, such that no details of its intimate structure can be made out even with the very highest magnification, can reproduce all the details of structure and function of the human being, nay of an individual human being with his obscure peculiarities of appearance, of manner, or of habit, is a mystery which must surely for all time transcend scientific knowledge. And yet, though the ultimate nature of this as of other vital processes is unknown, a vast and ever increasing amount of knowledge has been accumulated regarding 
the reproductive process in the Animal Kingdom, and in these two lectures I propose to deal with some of the

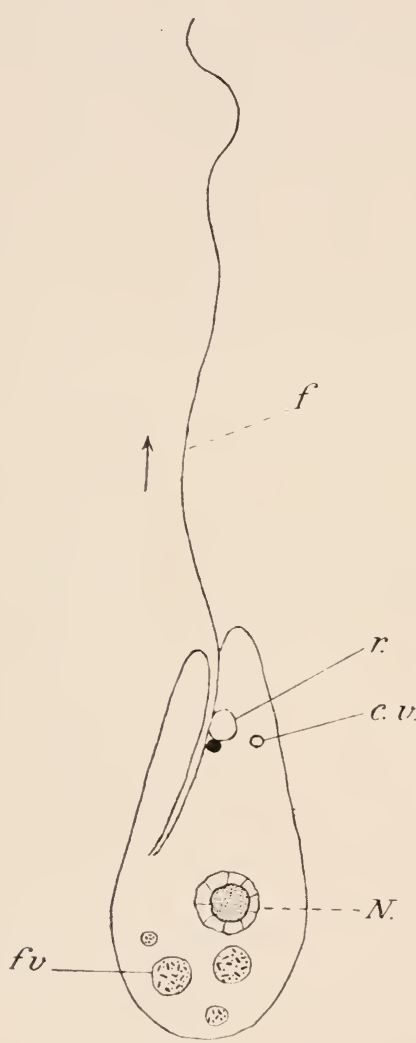

Fig. 32.

Copromonas, as seen under a very high magnification (after Dobell). c.v, contractile vacuole; $f$, flagellum; $f . v$, food vacuole (temporary stomach); $\mathrm{N}$, nucleus; $r$, reservoir.

definite shape. Projecting from the narrower end is a long very thin thread of protoplasm-the flagellum been elucidated, leaving on one side the phenomena of Heredity, which will be expounded to you later by a distinguished investigator of this subject.

The essential features of the reproductive process are most easily grasped by studying it in the lowest and simplest animals forming the group Protozoa--animals of minute size, in which the individual consists of a single cell which creeps, or swims, or floats, leading an independent existence. We will commence with Copromonas, a creature which occurs not uncommonly in water in which Frogs are kept. The creature consists of a minute pear-shaped cell, i.e. a mass of protoplasm containing a nucleus (Fig. 32, N). The outer layer of protoplasm is slightly stiffened, forming a thin skin or pellicle which keeps the creature in its

general principles which have 
(Fig. 32,f)-the end of which can be twirled round in such a manner as to draw the creature forwards through the water. The flagellum emerges from the mouth of a slender slightly curved tubular ingrowth of the pellicle, which serves as a gullet down which tiny food-particles are swept by the current sent back by the flagellum. Every now and then a droplet of water laden with such food-particles may be seen to detach itself from the inner end of the gullet, and travel away through the protoplasm, forming a little temporary stomach (Fig. 32, f.v), in which the process of digestion takes place. The water which is taken into the body in this process is eventually drawn out of the protoplasm and ejected into a pocket-like reservoir (Fig. 32, $r$ ) connected with the gullet, by a little pump known as the contractile vacuole (Fig. 32, c.v), a bulb of protoplasm which expands and contracts rhythmically.

The Copromonas under favourable conditions goes on living, feeding and growing. Like other animals it does not increase in size indefinitely, but after a time reaches a rough limit of normal, as we might say, adult size. Its increase beyond this is counteracted by what we recognize as the simplest type of reproductive processthe process known technically as Fission-in which the individual simply divides itself into two new individuals, each of half its size. The process is illustrated by the upper portion of Fig. 33. The ordinary adult individual (I) draws in its flagellum (2), and then begins to split longitudinally, the process commencing at the front end (3) and gradually extending until the individual is completely split into two new individuals exactly like itself, except that they are of half its size. It will be noticed that each of the young individuals has grown a new 
flagellum, and that each is provided with a nucleus by

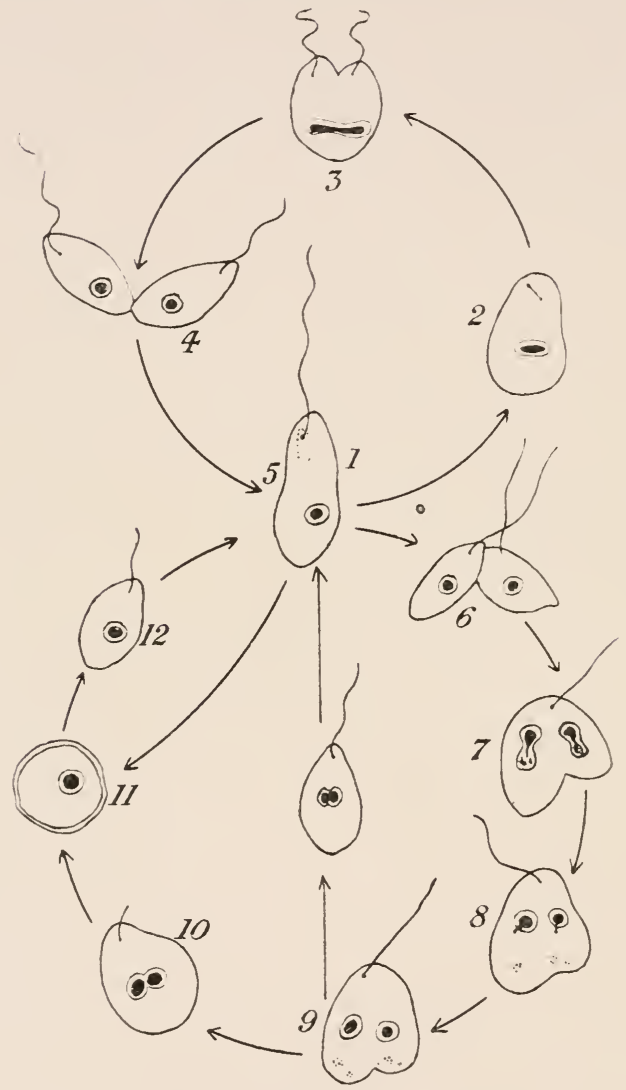

FIG. 33 .

Diagram illustrating the life-history of Copromonas (after Dobell).

The upper circle of figures ( $\mathrm{I}-5)$ illustrates the process of reproduction, the lower (5-12) that of syngamy.

[The diagram includes two departures from the normal which are not alluded to in the text, namely $(a)$ a short-circuiting from $9^{-I}$ so as to omit encystment, and (b) encystment without syngamy (I-II).]

the original nucleus growing out into a dumb-bell shape and then becoming nipped across into two. Each of the. 
new individuals under favourable conditions behaves just like its parent: it feeds, grows and eventually divides again by fission. And so generation after generationeach individual ends by resolving itself into two new individuals.

But this process of fission does not go on indefinitely. From time to time it is interrupted by an opposite kind of process in which, in place of one individual becoming divided into two, two individuals become fused into a single one in the process known as Syngamy-illustrated by the lower part of Fig. 33. Two individuals swimming about come in contact by their front ends (6), adhere together and become gradually merged into a single individual shaped like the parent (7-IO). An essential feature of this process of syngamy is that the nuclei of the two individuals, after undergoing complicated changes which need not be gone into, undergo complete fusion together (IO, II), just as the protoplasmic bodies do.

In the process just described we recognize a typical case of syngamy : the two individuals which fuse together are gametes; the single individual produced by their fusion is a zygote. A very usual sequel to the process of syngamy is well seen in Copromonas, in that the zygote rounds itself off, surrounds itself with a protective shell or cyst (II), and enters on a period of repose before it emerges again and resumes its pear-shape and its active swimming existence.

One of the most interesting things about Copromonas is that while it shows typical Syngamy-the essential phenomenon of Sex-there is no obvious sexual difference, no obvious sign of maleness or femaleness. To study these differences we will take two other minute Protozoa(I) Stylorhynchus, which lives as a parasite in the intestine 
of a beetle named Blaps, occasionally found in cellars and outhouses in our own neighbourhood, and (2) Plasmodium, the parasite which causes one of the most destructive of human diseases, namely Malaria.

In the case of Stylorhynchus (Fig. 34), the essentials of the process of syngamy are as before-the fusion

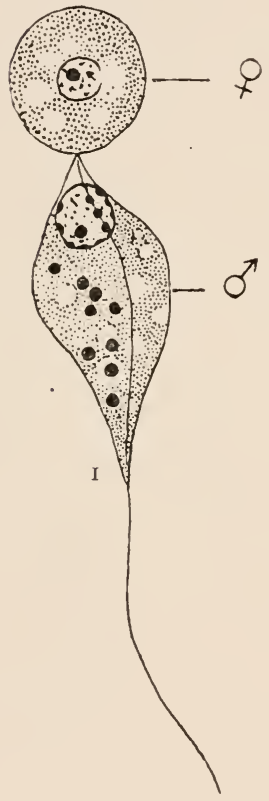

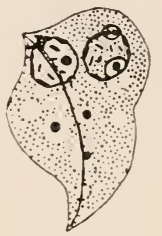

2

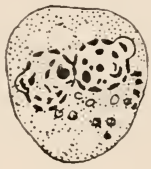

3

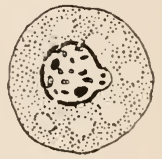

4

FIG. 34 .

Illustrating the proress of syngamy in Stylorhynchus (after Leger).

§. Male gamete; + , female gamete.

together of two cell-individuals (gametes) to form a single individual (zygote) - but in this case the two gametes are no longer exactly alike: one is a rounded motionless creature $(\mathrm{I}, \mathrm{q})$; the other is somewhat spindle-shaped, one end being prolonged into a powerful flagellum, and swims actively hither and thither, until coming into the neighbourhood of a gamete of the first type it is attracted 
to it and becomes completely fused with it to form the zygote (Fig. 34 (I-4)).

In the case of Plasmodium (Fig. 3.5), the difference between the two gametes which undergo syngamy is still more marked. The one $(q)$ is as before rounded and motionless, but it is also much larger in size owing to the fact that its body is distended by granules of condensed food-material which it has stored up in its protoplasm. The other gamete is slender, very much smaller, and swims

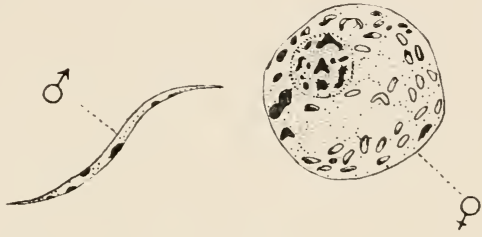

FiG. 35 .

Gametes of Plasmodium, the malaria microbe. $\S$, Male gamete; $\$$. female gamete.

with great rapidity until passing near a gamete of the first type it is drawn towards it by some apparently irresistible attraction and becomes merged in it to form the zygote.

In Plasmodium we find established the conspicuous sexual differences in size and appearance which are characteristic of the gametes as a general rule throughout the Animal Kingdom-differences so marked that the two types of gamete were formerly regarded as things essentially different in nature and given distinct namesova and spermatozoa. Further, we can recognise other features characteristic of maleness and femaleness in general-the active movements and roving disposition of the male; the relative inactivity, stay-at-homeness, of the female, her fatal attractiveness to the male, her tendency to hoard food. 
In the life-history of a simple Protozoon like Copromonas we have seen that there are associated together two very distinct processes - one of reproduction, in which the individual becomes resolved into two new individuals, and the other-syngamy-in which two individuals become merged into one. The same is the case amongst these lowly organized creatures in general : the zygotean individual formed by the fusion of two gametesreproduces by the simple process of fission over and over again; then syngamy takes place and the new zygote goes on reproducing as before-and so on indefinitely.

The process of syngamy appears as a general rule to be an essential part of the cycle. If a single individual be isolated in a ressel by itself, and kept under suitable conditions as to food supply and so on, it will go on reproducing for it may be some hundreds of generations. From time to time, however, waves of depression seem to pass over the culture, during which the reproductive activity becomes slackened. As time goes on these waves of depression become more and more marked: the vitality of the individuals becomes obviously impaired; they degenerate and undergo a kind of senile decay, and erentually the whole culture dies off.

Now it has been found that it is possible to tide a culture successfully through these periods of depression by making some marked change in the conditions under which the culture is living, or by applying some special stimulus. When this is done the individuals appear to renew their vitality, and proceed to reproduce over and over again as before.

Here then we learn a very important lesson. We have been accustomed to regard Death as a necessary sequel to Life, but we see that amongst these lowly 
organisms this is not so. The living substance that constitutes their body is potentially immortal : provided it gets an appropriate stimulus as a corrective to the period of depression it does not die, but simply divides into two and goes on living as before.

Now in Nature such a stimulus exists normally in the process of syngamy. If instead of the descendants of one zygote being kept in a vessel by themselves two distinct broods are mixed together there comes a time when the individuals of the two broods become gametes, each fusing with one of the other brood to form a zygote, and each zygote with its new lease of life proceeds to divide over and over again as before.

There is one other point we should notice before leaving these lowly organized Protozoa. It will be remembered that the zygote of Copromonas normally went through a resting period enclosed in a shell or cyst (Fig. 33 (II)). The use of this is clearly protective - to shield the living zygote from unfavourable external conditions. Now, such a process of encystment is very generally associated with the zygote stage of a Protozoan life-history. And, as we might expect from this, there is often an obrious tendency for the process of syngamy to be associated with some unfavourable change in external conditionssuch as the drying up of a pool, the absence of food, the coming on of winter. It will be understood that the onset of " unfavourable conditions" may consist either of actual alteration in the external conditions themselves, or of alteration on the part of the living organism itself, so that it gets in some way "out of joint" with its surroundings.

We may take it as a general principle that the process of syngamy tends to be associated with alteration in the 
normal relations between the protozoon and the surrounding world-whether the actual change takes place in the circumstances of the outer world or in the vital activities of the creature itself.

If we turn from the Protozoa to the more complicated types of animal we find processes taking place which are in their essence the same as those which we have studied in the Protozoa. Any one of these more complicated animals-say a Lobster, a Fowl, or a Man-begins its existence as a single cell - a zygote formed by the fusion together of two gametes. Then there follows a process of fission repeated over and over again-the zygote dividing into two cells, each of these dividing again and again, and so on for hundreds or thousands of generations.

But there is this striking difference from the Protozoon. In the latter, when the zygote divided into two, the two cells so formed separated, swam away, and lived their own lives as independent individuals. In the animals higher in the scale however, the cells remain attached together so that we get a coherent mass of cells, 2, 4, 8 , I6, 32, 64, I2S, and so on. This mass of cells becomes larger and larger with successive cell-divisions-it grows -it is the body of the individual -it goes on growing until at last cell-division slackens off and the animal attains a more or less definite adult size.

Just as a large community of civilized human beings, such as a great city, requires an enormously complicated organization to provide for its various needs, as compared with a savage community composed of a few almost independent individuals, so this immense community of cells which constitutes the body of one of the higher animals has to undergo an extraordinarily complicated process of organization. Certain tracts within its living 
substance become hard and stiff to form a framework to support the soft protoplasm-the skeleton. Masses of cells become developed into contractile muscles for pulling about the various parts of the skeleton, and consequent movement of the body as a whole. Other tracts of cells have to do with digesting and absorbing the food: others with the getting rid of poisonous waste materials. Others become developed into an elaborate transport system-the blood-which distributes the food material throughout the body and collects the waste material; still others into that marvellous nervous system which has to do with receiving impressions from the external world, with linking the various parts of the body together and controlling their activities, and with that wonderful process which we call thinking.

The myriads of cells which constitute the adult body become highly specialized for their various walks in life. But this specialization brings in its train the loss of that great primitive power-the power of undergoing fusion together-syngamy - with its accompanying drinking in of that elixir of life which renews their vitality and enables them to continue alive. And so it is that the body of these higher creatures is doomed to suffer unavoidable natural death. Whereas the living substance of the Protozoon is potentially immortal-provided that circumstances remain favourable and that from time to time it unites in syngamy with other living substance, it may go on living indefinitely - the higher animal has on the other hand its days upon the earth numbered, however favourable may be the conditions under which it exists.

But-and here is one of the most fascinating features of animal organization-there lurk somewhere or other in its body one or more clumps of cells which have not 
undergone this fatal specialization, which have not lost

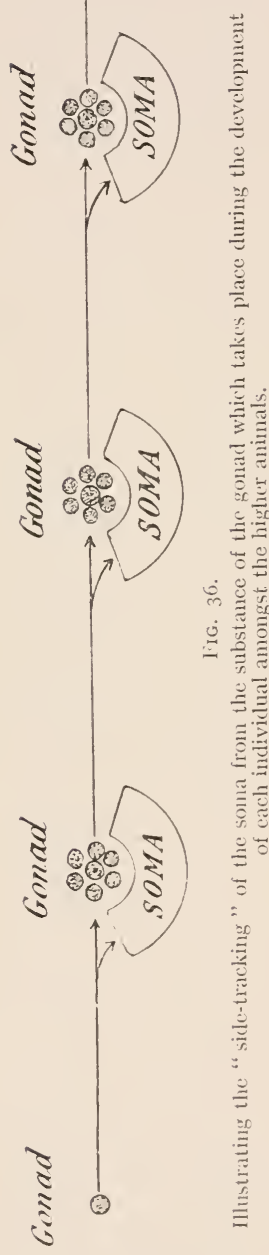

their power of undergoing syngamy, and which therefore have not lost their potential immortality. These cells constitute what is called the gonadthe mass of reproductive cells-while the rest of the body is known as the soma. It is only the soma whose days on the earth are numbered-any one of the reproductive cells if allowed to undergo syngamy receives in this process its new lease of life, just as was the case with the Protozoon, and proceeds with the repeated sub-divisions which build up the body of a new individual.

The gonad or mass of reproductive cells lives within the soma or main part of the body. It is in it, but yet not of it. It lives its own life, protected, nourished, and carried about by the soma. While the gonad is not mortal in the sense the soma is-not necessarily ending its existence in natural deaththose parts of it which remain within the body are subject to a violent and so to speak accidental death if anything happens to the soma upon which it is dependent for food and so on.

An important achievement of modern research has been the proof-in the case of certain animals - that the soma is, as it were, "side-tracked" from the gonad at an extremely early stage. In some cases indeed when 
the zygote undergoes its very first fission into two cells one of the two is seen to be already marked off as the somatic cell from the other which remains as gonad. The gonad is in fact simply a set aside portion of the substance of the zygote, in other words a persisting portion of the gonads of the two parents.

The fact that the gonad is not produced by the individual in whose body it lies, but is rather a persisting portion of living substance handed on from the previous generation and living its own life within the surrounding soma, is of great practical importance, for it renders less mysterious the fact that what are called acquired characters, or better impressed characters, are not inherited. If the soma or body has any striking modification impressed upon it during its lifetime-say a scar produced by disease or injury, or the loss of a limb-this feature is not handed on to the next generation. It is one of the few comforting reflections during this horrible war, when we so often see those dear to us maimed for life, that at least these injuries do not register themselves in the gonad so as to be passed on to the generation to come. And this fact ceases to be surprising when we remember that the gonad is not produced by the individual in whose body it is contained, but is a heritage from the generations that have gone before. 


\section{LECTURE IV}

SOME OF THE MODIFICATIONS OF THE REPRODUCTIVE PROCESS AS ADAPTATIONS TO LIFE UPON LAND

As was the case with the Vegetable Kingdom, all the evidence goes to show that animals were originally inhabitants of the water. However, as Evolution has proceeded, many different groups of animals have taken to the land, being enabled to survive there by various interesting modifications. The most conspicuous of these is the development all over the surface of the body of an impermeable layer to prevent the drying up of its substance-for living protoplasm has been unable to accustom itself to drying up. It may probably be said truly that "Dry protoplasm is dead protoplasm." The impervious outer coating of the land animal fulfils then an important function in retaining the moisture within the body.

Enclosed within this covering is the cell communitythese myriads of highly specialized and actively cooperating cells that constitute the living body. Each of these has its surface in contact with the watery fluid which everywhere permeates the body. The individual cells lives in this fluid just as a simple protozoan animal lives in its pool or pond; and Nature has adapted the 


\section{MODIFICATION OF REPRODUCTIVE PROCESS 67}

cell to live in this medium just as she has adapted the inhabitant of the pool or pond to its own watery medium. This internal medium of the animal body however is not pure water but a very complicated mixture. The incessant living activity of the protoplasm causes constant formation of waste materials, and these are discharged into the fluid. Now these waste products are by no means the same: they vary in different kinds of cells and in different organs-each of which contributes its quota to the mixture. If any particular organ omits its contribution, or if its contribution is abnormal in quantity or quality, then the composition of the internal medium is altered and the health of the whole body is liable to suffer, owing to the fact that its cells are adapted to live in the medium of a certain "normal" composition.

One of the chief obstacles which have lain in the way of animals becoming adapted to life on land has had to do with the early stages in their life-history. For these early stages repeat in a somewhat crude form earlier stages of evolution, in which the habit was purely aquatic. Thus if one examines an early stage in the development of one of the higher Vertebrates-say a fowl, or a human being-one finds along the sides of its neck gill-openings such as those of a fish, although the fowl or man will never have occasion to use them for breathing; again the main blood-vessels are arranged on the same plan as those of a Fish for the conveying of blood to and from the gills; again the skeleton is of a simple gristly nature like that of one of the lower fishes ; and so on with various other organs of the body. Any zoologist finding such a creature living free in Nature instead of within the egg-shell or the body of the parent 
would at once classify it with the fishes. It is in fact a Fish stage in development.

It will readily be understood what a serious difficulty the existence of such aquatic fish-like stages of development has constituted in the way of the assumption of a purely terrestrial habit. The present lecture will deal

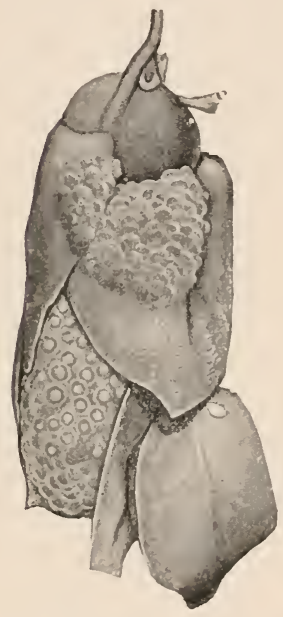

FIG. 37.

Phyllomedusa sauvagii, mass of spawn enclosed between leaves. (From Graham Kerr's Embryology, after Agar.)

with the methods by which the group of animals to which we ourselves belong-the Vertebrates-have overcome this particular difficulty.

We may commence with the Amphibians - the group of Vertebrates which includes Frogs and Toads-a group which is of special interest from the fact that it has not succeeded in emancipating itself entirely from the ancestral watery environment, but yet has made a number of very interesting attempts in this direction.

In the early spring one may see in ponds and ditches masses of spawn of the ordinary frog-the eggs or zygotes having the appearance, as seen from above, of little black spheres about $\frac{1}{12}$ inch in diameter, each enclosed in a larger sphere of clear crystal jelly. In due course the eggs develop into tadpoles, which represent the fish stage of development. In the case then of the ordinary frog or toad, although the adult has emancipated itself from the water to a certain extent-it is able to live on land though it needs a moist atmosphere-the early stages of its life-history are still purely aquatic.

In an interesting Tree-frog called Phyllomedusa, which 
Budgett and Agar studied in South America, the spawn is deposited between the leaves of plants overhanging the edges of pools. Here it hangs while the eggs undergo the early stages of their development, but when the Tadpole stage is reached a kind of digestive juice is secreted which causes the jelly round the eggs to soften and liquefy and trickle down into the pool, carrying the

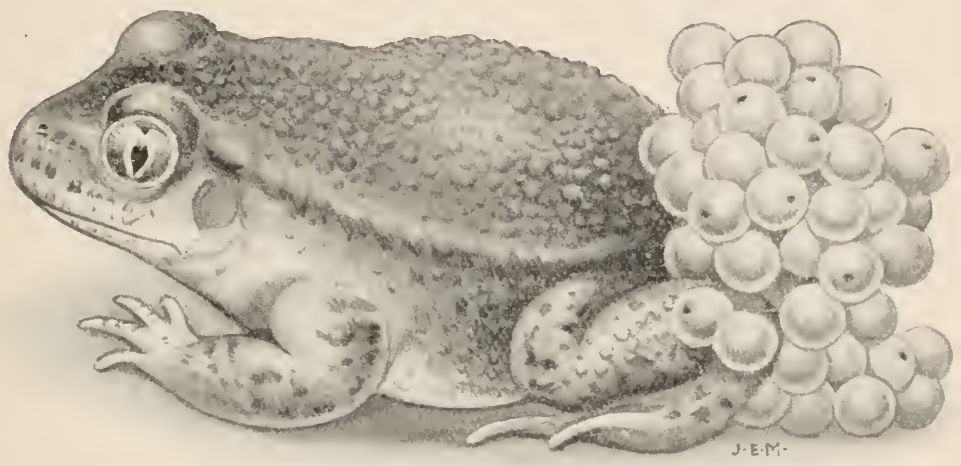

FIG. 38 .

Alytes obstetricans, male carrying eggs. (After Boulenger.)

tadpoles with it. Here then the tadpole has to pass the later part of its existence in the water, but all the earlier stages are independent of the water.

A somewhat similar case is that of a Japanese Treefrog (Rhacophorus schlegeli), where the mass of spawn is deposited in a burrow excavated in a bank of earth, by the margin of standing water. After depositing their spawn the parents make their way out by a tunnel sloping downwards towards the water's surface, and when the appropriate stage of development has been reached the jelly becomes liquefied and trickles, with its contained tadpoles, down this tunnel into the water. 
In the most interesting attempts on the part of frogs and toads to free their life-history from the aquatic environment, the eggs or young are carried about by the parent. In the case of Alytes, a Toad common on the

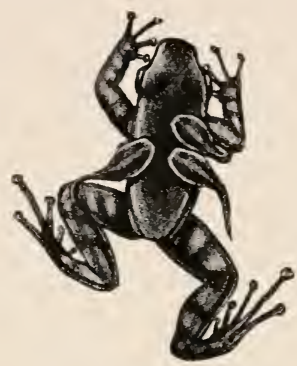

FIG. 39.

Male of Phyllobates trinitatis, carrying Tadpoles. (From Graham Kerr's Embryology, after Boulenger.)

continent of Europe, the eggs are laid on land, and the male parent carries them about in a mass, composed really of two bead-like strings, attached round his legs. At intervals he visits a pool of water and the eggs are moistened; eventually, on one of these visits, the tadpoles hatch out and thereafter lead a normal aquatic existence.

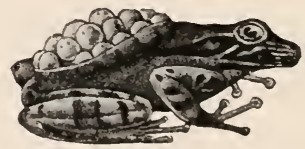

FIG. 40.

Female of Hyla gceldii, carrying eggs. (From Graham Kerr's Embryology, after Boulenger.)

In various other cases the tadpoles journey on land from one pool to another, hanging on to the back of the male parent (Fig. 39). In a Brazilian Tree-frog-Hyla goeldii - the eggs are placed on the back of the female, and their 
presence there causes, in some mysterious fashion, the skin to grow up into a ledge all round, forming a kind of saucer-shaped receptacle in which the eggs are borne about (Fig. 40). In another South-American FrogNototrema (Fig. 4I)-the same thing happens, but in this case the rim of the saucer grows more actively on each side and turns inwards, so that eventually the two edges meet and form a roof over the eggs, which thus come to be contained in a deep pouch, opening by a narrow slit which may be further reduced to a small pore at its hind end.

Then there is the extraordinary Surinam Toad-Pipa. In this case also the eggs are deposited on the back of the female, spaced out at intervals, and their presence causes the skin in their neighbourhood to grow up round the eggs so that each one comes to be enclosed in a deep pit or cell which is closed in by a closely-fitting lid. Each in its narrow cell, the young toads proceed with their development, passing through the Tadpole stage before eventually they emerge to lead their independent existence (Fig. 42).

Lastly may be mentioned the little South-American toad, Rhinoderma darwini, in which the male parent swallows the eggs into the croaking-sac or sounding chamber which lies under the skin of the breast, and in the safe seclusion of which the young toads proceed with their development.

It will probably be admitted by everyone that the cases of these Frogs and Toads constitute an extraordinarily interesting series of attempts to get rid of the free aquatic existence during the early stages of the lifehistory.

It is only, however, when we come to the Reptiles and 
Birds that we find complete emancipation from the watery environment. The successful attainment to this has been rendered possible partly by the development of a horny impermeable skin in the adult, and partly by modifications in the reproductive processes. It is the latter alone which concern us now.

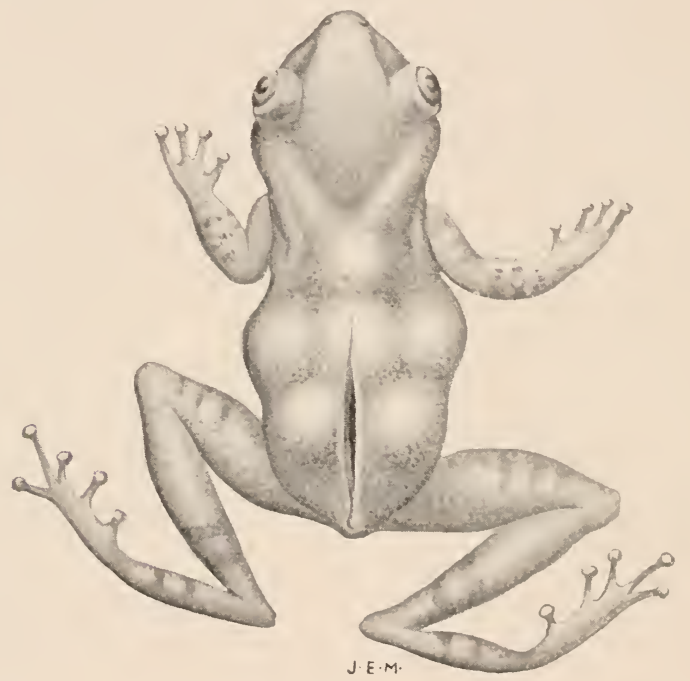

FIG. 4I.

Nototrema pygmaeum, female. The eggs, large in size and few in number in this species, are seen showing through the roof of the pouch in which they are contained.

In the Bird the female gamete-or macrogamete, or egg-is of relatively enormous size-a spherical cell, packed with reserve food-material or yolk, food-hoarding having here reached its maximum. It is what in domestic language is called the yellow or "yolk" in the case of the Hen's egg.

The act of syngamy - the fusion together of male and female gamete-takes place within the body of the bird, 
and the zygote so produced slowly travels along the tubular passage (oviduct) towards the outside. As it does so the lining of the tube deposits on the surface of the zygote layers of covering material-first the white or albumen (Fig. 43, alb), with thicker strands (ch) towards each end to moor the zygote in position, then a

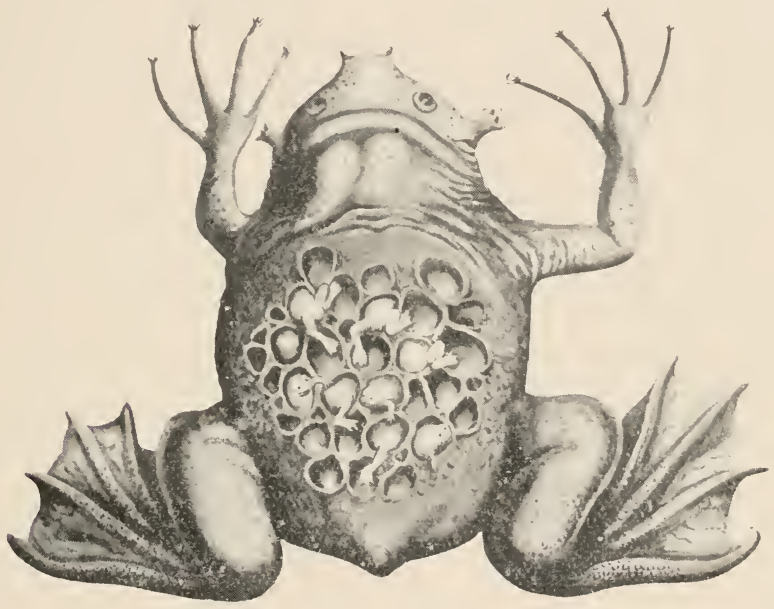

FIG. 42.

Pipa americana, female with young escaping from the cells upon her back.

tough white membrane $(s . m)$, and lastly, as the egg approaches the exterior, a layer of limy material which solidifies to form the hard porous shell. The membrane is split into two layers towards the broad end of the shell--the end which is directed towards the external opening of the oviduct as the egg travels along - and after the egg is laid, as the white gradually shrinks in volume, air accumulates in the space between these two layers (Fig. 43, a, s). Hence it is that when an egg not quite fresh is placed in water the broad end instantly 
bobs upwards. The air-space is of importance to the young bird, for when, just before hatching, it begins to struggle within the egg-shell, its beak penetrates the air space, it takes its first breath of air, and so invigorated the young chick is able to break the shell and step into the world which lies outside.

The egg-shell varies much in different birds. Where it is freely exposed to view and to daylight it often shows a beautiful protective colouring which renders it very

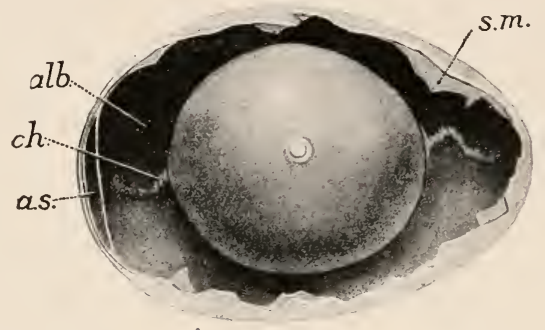

FIG. 43.

View of a Hen's egg, freshly laid, with part of the shell broken away so as to expose the contents.

The "yolk" or true egg is seen in the centre with the whitish protoplasmic portion (blastoderm) uppermost. a.s, air space; alb, albumen or white; ch, denser strand of albumen towards each end; s.m, shell-membrane. (From Graham Kerr's Embryology.)

inconspicuous, as for example in the case of the Peewit and other kinds of Plover. Its shape also varies: it is often pointed at one end, moulded within the parental body while still soft by the squeezing pressure of the oviduct forcing it onwards. And Nature has exaggerated this pointed shape in some of the eggs which are laid on shelves of rock, such as those of the Razorbill or Guillemot, so that when it gets a knock the egg merely runs round without rolling for any distance.

The young bird shows many interesting derelopments while it is contained within the egg-shell. The yolk 


\section{MODIFICATION OF REPRODUCTIVE PROCESS 75}

provides it with an ample supply of food, so that it does not have to get into the outer world and fend for itself until a very late stage in its development. Thus a watery environment is no longer necessary for the early fish-like

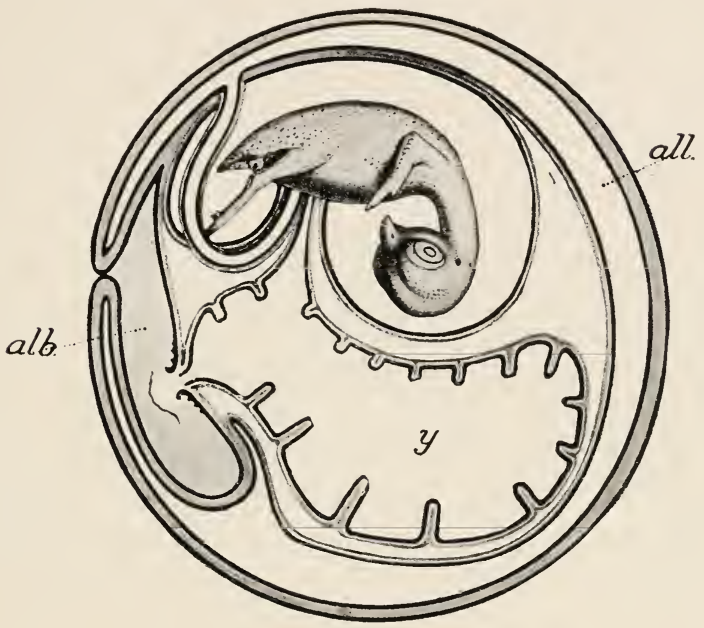

F1G. 44.

Diagram illustrating the contents of a Hen's egg which has been incubated for twelve days. The young bird is seen within the cavity of the amnion. Attached to its lower side are seen two stalks - the hinder one connected with the allantois (all) which lines the shell, the other with the yolk-sac in which the yolk $(y)$ is contained. alb, remains of albumen or white. (From Graham Kerr's Embryology, after a figure by Lillie in his Development of the Chick.)

stages, for these are passed through in the interior of the egg-shell.

Then the body of the young bird comes to be enclosed in a thin bag filled with watery fluid, and known as the Amnion (see Fig. 44), which forms a water-jacket to protect its delicate substance from the jars to which its being on land exposes it.

Again, a bladder-like organ-the Allantois (Figs. 44 and 45, all)-bulges out from its body and flattens itself 
out against the inner surface of the shell, gradually lining the whole of it and serving as the breathing organ by which the young bird absorbs the oxygen necessary to its life, through the pores of the shell. The remains of the allantois may be seen as a thin membrane containing

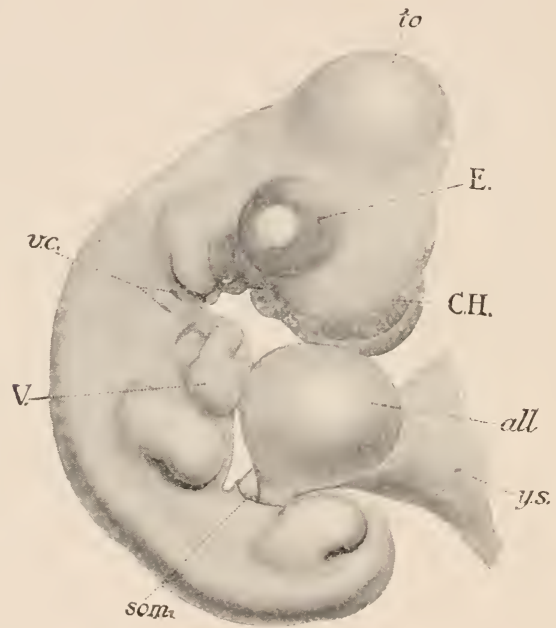

IIIG. 45 .

Young fowl extracted from an egg which has been incubated for $4 \frac{1}{2}$ days. all, allantois; C.H, cerebral hemispheres of brain; E, eye ; som, edge of opening through which the allantois and yolk-sac project; t.o, optic lobes of brain; $V$, heart ; v.c, gill-openings ; y.s, yolk-sac. (From Graham Kerr's Embryology.)

a rich network of bloodressels lining the pieces of shell from which a young bird has hatched.

The Mammals - those animals which possess hair and feed their young on milk-constitute the group to which we ourselves belong, and so we speak and write of them as the highest of living things - just as no doubt an Ant or a Cuttlefish, were it able to write books, would place in this position the Insects or the Molluscs! 
In these animals we find the modifications of the reproductive processes to fit a purely terrestrial existence at their highest level. Right down at the bottom of the scale of mammals we find two very ancient creatures still surviving in Australia and New Guinea (Echidna and Omithorhynchus) in which the eggs are large, provided with a supply of yolk as in the case of Reptiles and Birds, and are actually laid - in the case of Ornithorhynchus being deposited in an underground burrow, while in that of Echidna they are carried about by the mother in a specially developed pouch on the lower surface of the body.

In the next phase of evolution, represented by the Kangaroos and other Australian mammals and by the American Opossums, the eggs are hatched while still inside the mother's body, so that instead of eggs being laid, young are born. These young are very helpless and inperfectly developed, so the mother carries them about for some time, either hanging on to her body or contained in a pouch specially developed for the purpose, until they are able to look after themselves.

In the ordinary mammals a step further has been taken, the young animal being retained within the mother's body for a much longer period, until a much higher degree of development has been reached. In this way not only are the early stages which should be aquatic spared the need of a watery environment but they remain within the body and, as it were, part of the body of a fully developed adult creature, with all its capacity developed for looking after itself in the struggle for existence.

Here again we find very interesting arrangements adapting the embryo to its life within the body of the 
adult. As the young animal is able to absorb food from the blood of the mother it is no longer necessary to have a reserve supply of food-material or yolk stored up within the egg: hence we find that the egg of the mammal has reverted to the condition of a very minute cell, a simple sphere of protoplasm containing a nucleus, measuring perhaps the $\frac{1}{10 \overline{0}}$ of an inch (Man, see Fig. 2, B)-in striking contrast with the relatively huge egg of the Reptile or Bird.

Again, as the egg is to develop within the body of the mother, elaborate protective coverings, such as those seen in the case of the Fowl's egg, are no longer necessary and have disappeared. The amnion is present as before. So also is the allantois, but this has undergone a great increase in complexity. It comes into close contact with the lining of the enlarged oviduct or uterus. Its surface is covered with a thick layer of protoplasm which fits itself close to the uterine surface, insinuating itself into every little crevice, and finally eating its way into the wall of the uterus and spreading along the course of the blood-vessels in this wall-blood-vessels belonging to the mother. In the layer of protoplasm other bloodvessels develop, belonging to the embryo.

There thus come to be associated together two sets of blood-vessels - through one of which courses blood belonging to the mother and through the other blood belonging to the embryo. For a time these are separated by a considerable thickness of the protoplasm covering the allantois, but this gradually disappears and there is nothing left between the two blood-streams but an extremely thin, though unbroken, membrane walling in the vessels of the embryo. Through this thin membrane there diffuse into the blood of the embryo from that of 
the mother, (I) food-material for its nourishment and (2) the oxygen needed for its living activity. In the opposite direction there pass away from the blood of the embryo into that of the mother the various waste materials produced by the vital processes of the embryo. This arrangement of interlocking blood-vessels, by which interchange takes place between the blood of the mother and of the unborn young, constitutes the greater part of a very complicated organ known as the placenta, or in the case of man as the " after-birth," from the fact that it is shed and got rid of soon after the birth of the child.

The young individual leads its pre-natal life in the comparative safety and seclusion of the uterus, hanging on to its wall as a parasite, its needs being ministered to by the activities of the placenta. But it is already, from the zygote stage on, a new self-contained individual, possessing, though it may be in a latent form, all the normal characteristics of its race. So long as the mother remains in a normal state of health the young individual, when once it has come into existence by the act of syngamy, does not appear to be affected by her special peculiarities. Thus it has been found possible to take the eggs at an early stage of their development from the uterus of a Rabbit belonging to a particular breed (Angora) and transfer them to the uterus of a Rabbit of a quite different breed (Belgian Hare). The eggs so transferred went on with their development, and the young rabbits when born were found to be perfectly typical (Angora), showing no signs whatever of having been influenced in any way by the peculiarities of the foster-mother in whose uterus they had sojourned during almost the whole period of their development. 
This comparative independence, on the part of the young individual, of the peculiarities of the mother, holds under normal conditions. If, however, conditions become abnormal through disease, in particular if the bloodstream of the mother, upon which the welfare of the young individual is completely dependent, becomes abnormal, then there are apt to come about effects upon the health of the young individual which may be disastrous. Poisonous substances in the blood of the mother diffuse into the blood of the embryo and poison it. And various disease-producing microbes have the power of burrowing their way through the thin membrane separating the blood streams of mother and offspring, and thus infecting with the disease the new individual. 


\section{LECTURE V}

\section{HEREDITY}

In this lecture we have to consider the factors at work which determine the degree of similarity between parent and offspring, or between the various offspring of the same parents. The problem is fundamentally the same throughout the whole animal and vegetable kingdoms, though simplified in degree in the case of the lowest, unicellular, organisms. In what follows we shall neglect these and confine ourselves to the higher organisms, where the problem is conditioned by two main factors.

Firstly, that the bridge between two generations is the minute germ-cell or gamete which, being unicellular, is of a different order of structure from either the parent from whom it was derived, or the individual into which it develops.

Secondly, that each individual of the new generation is usually produced by the fusion of two cells (gametes) derived from different individuals of the parent generation.

The fact that the bridge between parent and offspring is the minute unicellular gamete at once raises the question of what is the physical substratum on which heredity depends. Is there any part of the gamete which can be recognised as presenting those properties which we should expect this substratum to possess?

S. H. 
This question can best be answered by considering a concrete case of syngamy and early development of an animal, and we will choose as our example the little, almost microscopic, shrimp-like creature Cyclops.

Fig. 46, A, shows the egg or macrogamete of Cyclops immediately after the entry of the spermatozoon $(m)$, or microgamete. The great bulk of the egg consists of protoplasm densely packed with yolk. Like all cells, the egg contains a nucleus $(f)$, which is seen close under the egg shell. It has travelled to this position prior to dividing into two and getting 1 id of one of the halves. This at once introduces us to one of the most important features of the hereditary substance. If, as we are bound to assume, this substance has a definite structure, it is obvious that there must be some method of reducing it by half once in each generation, since otherwise it would be doubled by the fusion of gametes in each act of syngamy. Now we find that a halving of the nuclear material of the gametes takes place at or before syngamy (in the case of the spermatozoon this halving has already taken place before it enters the egg). This fact in itself points therefore to a probability of the nuclear substance being the material substratum of heredity.

In Fig. 46, $B$, we see both the male and female nuclei travelling in towards the centre of the egg, the nuclear material $(p)$ discarded from the female nucleus being conspicuous just under the egg shell. It can be seen in this position for a long time in development, but itself plays no part in this process, being indeed dead and rejected.

Fig. $46, C$, shows the two nuclei ( $m$ and $f$ ) closely applied to one another in the centre of the egg, and we notice the important fact that they are now equal in size. Fig. 


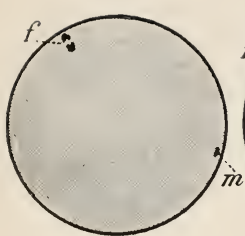

A

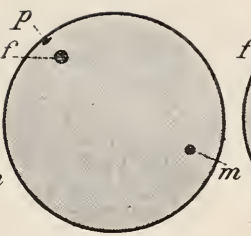

B

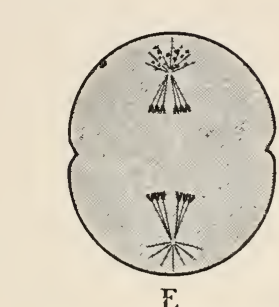

E

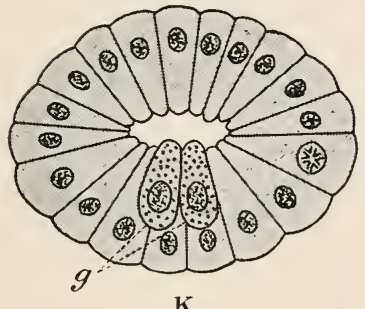

$\mathrm{K}$

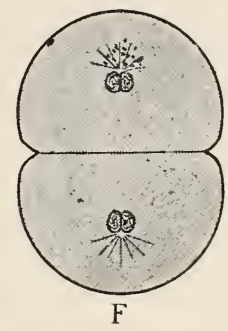

$\mathrm{C}$

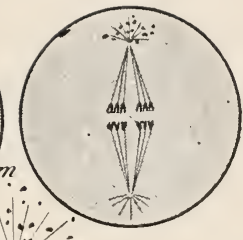

D

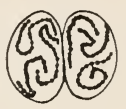

AMA AAA
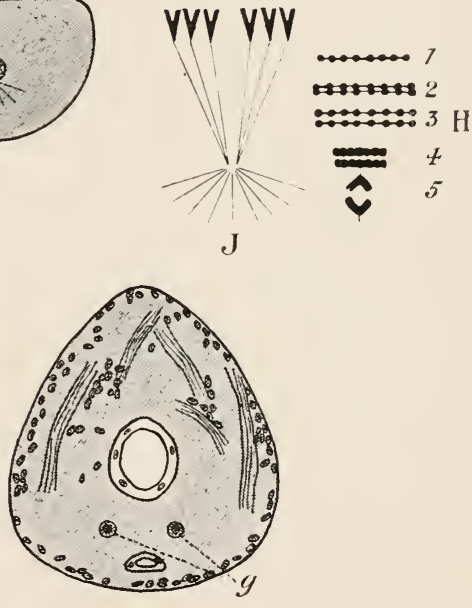

L

FIG. 46.

Syngamy and early development in the Crustacean, Cyclops (diagrammatized from Häcker and Amma) ; $f$, nucleus of macrogamete or egg ; $g$, primitive germ cells ; $m$, nucleus of microgamete or spermatozoon; $p$, rejected portion of female nucleus ; $A$, immediately after entry of microganete into the egg, female nucleus dividing into two; $B$, having thrown out half of its substance, $(p)$ the female nucleus is moving in towards the centre of the egg to meet the male nucleus; $C$, the male and female nuclei, now alike in size and constitution, have met in the centre of the egg to form the zygote nucleus; $D$, first division of the zygote nucleus. The six chromosomes (three derived from each gamete) have each divided into two $\mathbf{V}$-shaped bodies; $E$, two sets of six chromosomes separating. Division of the cell body beginning; $F$, division complete, the new nuclei reconstituted and the egg divided into two cells ; $G$, the zygote nucleus in $C$ shown under a higher magnification. Three chromosomes, in the form of long beaded threads are seen in each portion; $H, \mathrm{I}-5$, stages in the division of a single chromosome; $J$, a dividing nucleus (as in $D$ ), at a higher magnification; $K$, a later stage of development. The two cells with large nuclei, and granulcs in the cell body are the primitive germ-cells of the young Cyclops; $L$, a much later stagc, at a lower magnification. Stomarh, muscles, ctc., now developed. 
$46, A$, shows the enormous disparity in size between the microgamete, which consists almost wholly of nucleus, and the macrogamete. In many animals this disparity is very much greater, culminating in the birds with their enormous eggs. In the Ostrich it can be calculated that the macrogamete (yolk of the egg) is many billions of times as bulky as the microgamete. The amount of nuclear material in the two gametes is however equal, though owing to the fact that this is in a very concentrated state in the microgamete it may appear less bulky here. As a comparison between Figs. $46, A$, and $46, C$, shows however, by the time the nucleus of the microgamete has loosened out to the same texture as the female nucleus, the two nuclei are the same size.

Now it is a matter of general observation that inheritance throughout the animal and regetable kingdoms is on the average as strong from the male as from the female parent, and so it is reasonable to suppose that the physical substratum on which inheritance depends is provided in equal quantities by the two parents. Hence we are again led to look to the nuclear material as probably the substance of which we are in search.

The development of an animal (or plant) from the single celled zygote consists of two main processes :

(I) The division of this cell into a great number of cells.

(2) The differentiation of these cells into the various kinds of cells_-skin cells, muscle cells, nerve cells, etc.which compose the body. We will follow the first of these processes for a short distance in the development of Cyclops.

The division of the zygote into the first two cells of the embryo or young Cyclops is shown in Figs. $46, D, E, F$. 
In all cases, division of the cell as a whole is preceded by the division of its nucleus. In Fig. $46, C$, we see that each gamete nucleus (shown on a larger scale in Fig. $46, G)$, contains three long threads, the combined zygote nucleus therefore containing six. These threads are composed mainly of a substance called chromatin, and each of them is called a chromosome. The first step in the division of the nucleus consists in each chromosome splitting along its length into two. At about the same time fine fibres (shown in Fig. $46, D$, etc.), make their appearance in the protoplasm, stretching from points at opposite poles of the cell. Of the two chromosomes produced by the splitting of each original one, one becomes attached to a fibre running to one pole, and the other to a fibre running to the opposite pole of the cell. The chromosomes then travel up the lines of these fibres to congregate at the poles, where they form two new nuclei, one at each pole. Thus it will be seen that each gamete introduces three chromosomes, providing the zygote with six, and that each of the two nuclei formed by the division of the zygote nucleus gets a half of each one of these six chromosomes. In other words, the chromatin of each nucleus is derived in equal quantity from the male and female parent.

The developing egg, or embryo as we may now call it, now consists of two cells, each with its nucleus. By a process similar to that just described each nucleus again divides into two, followed by the division of its cell, so as to give four cells, and this process is repeated again and again until a large number of cells, each with a nucleus, has been formed. Thus the nuclei of all the cells of the embryo and adult Cyclops contain chromatinor hereditary substance as we may now call it-derived 
in equal amounts from the two parents. In later stages, it is true, the double appearance of the nuclei, indicating their origin from the two gametes, disappears (Fig. 46, $K$ ), owing to the two sets of chromosomes having mingled together. The nuclei, however, still contain the six chromosomes, which become visible in certain phases.

Figs. 46, H-J, show the nucleus and the division of the chromosomes on a larger scale. It can be seen that the chromosomes are not homogeneous, but that each consists of a row of chromatin granules like a string of beads. Fig. $46, H, I-5$, illustrates in detail the process of division of a chromosome, and shows that the splitting of the chromosome as a whole consists in the division of each one of these beads so that two parallel rows of beads are formed. Later, the chromosomes contract so much that the individual beads are no longer visible-hence they are not seen in Fig. $46, D$, which is the stage shown in Fig. 46, $J$, on a larger scale.

These chromatin beads are of course living and growing bodies, and hence the halving of the size of each bead which occurs in each division is compensated by growth in the intervals between divisions.

This mode of development, and of distribution of the chromatin, is of general occurrence in the animal and vegetable kingdom, though the number of chromosomes varies in different species. The general rule obtains, however, that the gamete has half the number found in the zygote, the former having thrown out half of its chromosomes, as we have seen in Cyclops, in preparation for syngamy.

Summing up, we are led to identify the chromatin, or some substance intimately bound up with the chromatin, 
of the nucleus with the material substance on which inheritance depends for the following, among other, reasons.

(I) Equality in quantity of chromatin in the two gametes, in spite of their enormous disparity in size as a whole.

(2) Accurate division of each element of this material at each nuclear division, so that every cell in the body gets a derivative of all the chromatin elements of both gametes.

(3) Reduction of the amount of chromatin to one half in the gametes, so that doubling is avoided when they unite.

With this knowledge of the physical basis of inheritance, we must proceed to consider the organism as forming one of an endless series of generations.

Perhaps the easiest way to grasp the point of view from which modern biologists regard the organism as a link in the chain of ascendants and descendants is to compare the two theories of heredity propounded, the one by Darwin and the other by Galton. With fuller knowledge, Darwin's hypothesis has had to be rejected. (It must not of course be supposed that we are referring in any way to his great work on Evolution by Natural Selection.)

Darwin proceeded from what may be called the natural or common sense way of looking at the organism. He and his contemporaries were exercised as to how the characters of the parent got into the gamete. In breaking into the endless chain of parent-germ-parent (the old problem: which came first, the chicken or the egg ?) he started with the parent, and the problem of heredity was: how could its characteristics be compressed into the minute and apparently nearly structureless gamete? 
The "provisional hypothesis" which Darwin proposed to account for this was that every cell in the body is continually throwing off ultra-microscopical particles, which he called gemmules, and which got into the blood stream and were thus carried to the reproductive organs and became stored up in the germ-cells. These latter were in fact, in his view, nothing more nor less than little packets of gemmules, and the development of the germcell into the individual of the next generation consisted in each gemmule growing into a cell like the one which had produced it.

Galton looked at the stream of life from a different point of view. He broke into the parent-germ-parent chain at the germ-or rather he denied the existence of a chain at all, but looked upon the stream of life as a straight line of germ-cells, giving off blind side alleys in each generation-the bodies of the organisms which we know.

This view was much elaborated by Weismann, to whom we are indebted for a more detailed conception of the relation between the germ-plasm and the body-plasmthe former being of course the protoplasm (more particularly, the nuclear material or chromatin) contained in the germ-cells, while the body-plasm forms the substance of the body cells. He pointed out that the germ-plasm is potentially immortal, that is to say, it does not die provided that its environment is of a suitable nature, whilst the body-plasm is mortal.

To a certain extent this proposition may be described as a truism, since it is of course obvious that the living substance of which all of us are composed is continuous back to the beginnings of life on this globe, millions of years ago. Such part of that living substance which has entered into our bodily structure, however, is doomed 
to perish, as did the vast array of bodies produced in the past by our own particular streams of germ-plasm. The germ-plasm alone endures, and may continue to endure for an indefinite number of millions of years, giving off further innumerable mortal bodies.

This conception of the relations between germ-plasm and body-plasm is well illustrated by the early development of Cyclops. In Fig. 46, C, we see at each side of the nucleus a number of radiating lines, the first appearance of a sort of anchor in which the fibres which guide the morements of the chromosomes will later be fixed (Fig. $46, D$ ). It is to be noticed that round about one of these radiations are a number of dark granules, while they are absent from the radiation at the opposite pole of the nucleus. This results in one of the two cells formed by the first division of the zygote possessing these granules, while the other one is without them (Fig. 46, E, F).

The next stage in development is that each of these two cells with their contained nuclei divide into two, in exactly the same way as before. The two cells derived from the cell which lacks the granules will of course have no granules. In the case of the other cell, the granules behave as before, all congregating at the one pole of the dividing nucleus, leaving the opposite pole free from them. Division therefore results as before in one cell with granules and the other without. Thus in the four cell stage of the embryo we find three cells without granules and one with them. For a time cell multiplication proceeds in the same manner, all the descendants of the cells without granules being free from them, while the cell containing the granules always divides into one cell with them and one without. The embryo thus always has one cell, and only one, containing granules. 
This mode of development continues till the embryo consists of sixty-one cells, of which therefore sixty are without the granules and one contains them. Before the next division of the granule cell, however, the granules instead of concentrating at one pole, scatter through the cell, so that both products of division contain granules, and the embryo has now two granule cells. From these two cells arise the germ-cells of the young Cyclops-and therefore eventually the gametes of the adult. They are shown in Fig. 46, $K$, and again in the much more advanced embryo in Fig. 46, $L$, where the main features of the fully formed animal (skin, muscles, stomach, etc.) are already apparent.

We see therefore that in Cyclops the relations of the germ-cells to the body is quite in accordance with the Galton-Weismann view. The body does not manufacture its gametes as, for instance, it secretes bile or saliva. On the contrary, at the beginning of each new generation the germ-plasm divides into two portions, one (destined to perish) to form the body of the organism, the other to lie dormant, enclosed in the body and fed and protected by it, till the proper time comes for it to break away from it in the form of gametes and continue the stream of life.

It should perhaps be mentioned that nothing is known of the nature of the granules which thus make visible the distinction between body-plasm and germ-plasm in Cyclops. They are probably unimportant in themselves, as they have not been observed in other animals, in many of which however the germ-plasm is equally clearly marked out from the body-plasm by other visible characteristics not found in Cyclops. While ignorant of the nature of these various distinguishing marks we can 
nevertheless avail ourselves of the convenient labels thus offered to us.

The Galton-Weismann view deserves to be emphasised, because it puts a meaning into the word "inherit" which is rather different to that usually conveyed by that wordor to the sense in which it would apply if Darwin's view were the true one. According to Darwin, parents truly transmit their characteristics to their offspring (by means of the gemmules). According to the modern view, howerer, children resemble their parents not, strictly speaking, because the latter have passed something on to them, but because both have been produced from the same germ-plasm. Of course it must be remembered that as a rule the relations of parent and child to the stream of germ-plasm are complicated by the fact that the offspring is the outcome of the fusion of two gametes each from a different stream of germ-plasm. A pictorial representation of the stream of life under these normal conditions, compared with the simple state of affairs where reproduction is carried out without union of the sexes (as for example in the greenfly, or Aphis), is attempted in Fig. 47.

The relations between germ-plasm and body-plasm lead us on to the consideration of the question of the inheritance of "acquired characters." It is obvious that the characteristics of an organism are dependent upon two factors, (I) its original inborn or innate constitution, which depends upon the germ-plasm (or two germ-plasms) from which it has sprung, and (2) the particular environment to which the organism has been exposed and the experiences which it has undergone during its growth and development. These two factors act with varying effect in the case of different characteristics. Thus the colour 
of a man's eye is but little affected by his environment, but is almost entirely determined by his innate constitution. On the other hand, the skill of a pianist is plainly dependent both on his innate mental and physical qualities, and on the fact that he has been provided with the opportunity of learning to play the piano.
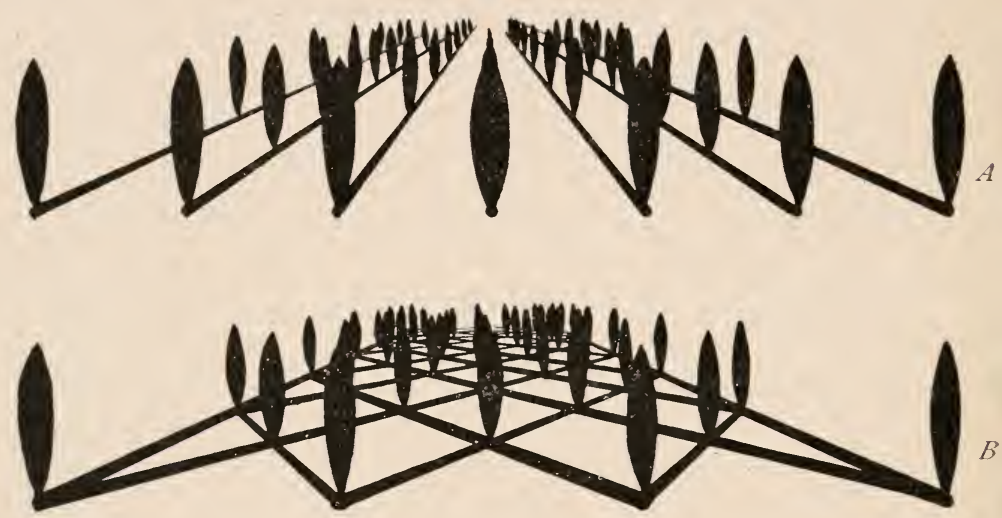

Fir. 47 .

Diagrams of the stream of life $-A$ under its simplest condition, as found in some of the lower animals and plants, where there is only one parent; $B$ under ordinary conditions, where two parents are concerned with each act of reproduction.

The base lines represent the continuous streams of germ-plasm, the uprights the bodies prodiuced by them. In $A$ the streams of germ-plasm flow independently, giving off bodies at intervals. In $B$ bodies are produced only at the intersection of two streams.

Now if our views as to the relation between individuals and the germ-plasm which gave rise to them are correct, only the innate qualities can be inherited, for the germplasm produces the body, not the body the germ-plasm. For example, take two children of equal (innate) musical capacity, and put one in a desert island where he will never see a musical instrument, and train up the other to music as a profession; there is no reason to believe that the children of the professional musician will show greater 
musical talent than, given equal opportunity, will those of the man reared under conditions which prevented him from ever exercising his talent.

A good deal of confusion exists in the unscientific mind in regard to the question of the "inheritance of acquired characters " owing to want of analysis of cause and effect. It is true, of course, that musical talent runs in families, but it must be remembered that a man chooses the profession of music because he has the innate capacity for music, and it is this innate capacity which is inherited, not his acquired musical attainments.

We must be careful, however, not to leave the impression that all biologists are agreed that the effects of environment on the body of the parent can never be registered in the germ-plasm in such a way as to be reproduced in the offspring. There are certain cases which are still under consideration by biologists. It is also of course true that acquisitions by the parent may affect the offspring in other ways, e.g. by the direct transference of disease-producing organisms to the embryo, as in syphilis. Here, however, we are not dealing with inheritance in the biological sense of the word. We may take it that one runs no practical danger in assuming that any particular acquisition will not be inherited.

The possibility of predicting the characteristics of the offspring from those of the parents depends therefore largely upon how truly the latter disclose the nature of the germ-plasm from which they themselves have sprung. Another important requirement is to know what combination will result when two diverse germ-plasms meet. The greatest advance ever yet made in our understanding of both these points was the discovery made by a 
monk, Gregor Mendel, in IS65, though its value was not appreciated till the beginning of the present century. Mendel's law, as it is now called, will best be explained by a concrete example, for which we will choose a case that has been worked out by Bateson in the domestic fowl (Fig. 4S).

If a black fowl of the right breed is crossed with a white $^{1}$ fowl, also of the right breed (top line of the

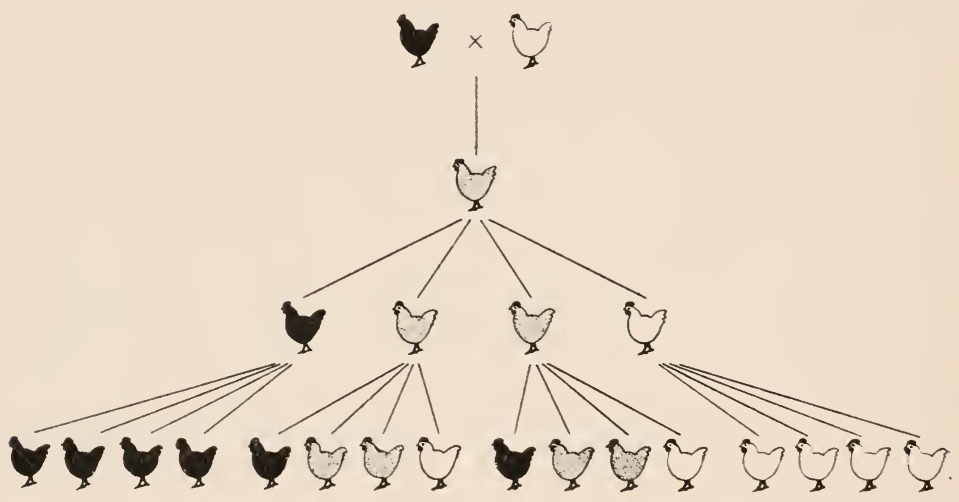

Fig. 48 .

Illustrating the inheritance of feather colcur in the Andalusian fowl.

diagram), the result is a bird of a slatey blue or gray colour (second line of the diagram). This bird is what is known to poultry breeders as the Andalusian fowl. The result of breeding two Andalusians together is shown in line three of the diagram. (To save space, in every case except the first cross, only one parent is shown. It is to be understood that each bird is mated with one of its own colour.) Out of every four chickens produced from

${ }^{1}$ This breed of fowl is not pure white, but has numerous little dark points among its plumage. For convenience, however, it will be called white. 
a pair of Andalusians we get, on an average, one black like the original black of the first cross, two grays or Andalusians like the immediate parents, and one white like the original white of the first cross. Breeding from these again we find (bottom line of diagram) that two blacks bred together give nothing but blacks, the whites give nothing but whites, while the grays again give all three kinds in the average proportions of one black, two grays, one white.

Now the interpretation of this result is as follows. Each separately inheritable characteristic-such as the colour of the feathers in the present instance-is supposed to be represented in the germ-plasm by a definite part or constituent of the hereditary substance, which may conveniently be called a "factor." Thus the germ-plasm of the white fowl contains the factor for whiteness, and that of the black fowl the factor for blackness-or as we may more shortly call them, white and black factors.

When a black and white fowl are crossed, as in the first line of the diagram, the resulting hybrid has both the black and white factors, which act together to cause the gray colour of its feathers. In the nuclei of the germplasm, however, the black and white factors do not mingle, but may be conceived of as lying separately side by side. When the gametes are formed-and this is the crux of "Mendel's law"- the two factors separate in such a manner that the number of gametes carrying the black factor is equal to the number carrying the white. No gamete, however, can carry both black and white factors. This process of sorting out of factors in the gametes is spoken of as segregation.

We are now in a position to understand the result of mating two gray birds together. The gray hens are 
producing in equal numbers eggs carrying black factors and eggs carrying white factors, and similarly the cocks are producing the same two kinds of spermatozoa. We have thus the following possible combinations in syngamy:

Eggs.
Black $\times$ Spermatozoz.
White $\times$ Zygotes.
Black $\times$ Black $=$ Gray.
White $\times$ White $=$ Gray.

As the combination of the different classes of gametes is supposed to take place by chance, we will get on an average of a large number about equal numbers of each combination-i.e. the zygotes will be in the proportions of one black, two gray, one white.

It must be understood that these numbers must not be expected to be realised exactly. The position can be paralleled by putting an equal number of white and black counters into a box, shaking them up, and then drawing them out in pairs without looking at them. Theory will then lead us to expect that 25 per cent. of the pairs will consist of two whites, 25 per cent. of two blacks, and the remaining 50 per cent. of one white and one black. It will of course be only by chance that these percentages are exactly realised, just as if we tossed up a penny a hundred times we should probably get an approximately equal number of heads and tails, but only by chance exactly fifty of each. Thus in one experiment with the Andalusian fowls the offspring of a number of them totalled up to

Black, 4I ; Gray, 7S ; White, 39.

The further breeding of these offspring of the gray hybrids is easily understood. Since blacks lack the white factor altogether, when bred together they can give 
nothing but blacks, and similarly the whites can give nothing but whites; while the grays, having the same constitution as their gray parents, when bred together give the same results.

It is not always the case, however, that the characteristics of the parents produce an appearance of blending in the offspring as in the case of the gray Andalusian fowl bred from a black and a white parent. If for instance we cross a red Antirrhimum (Snap-dragon) with a white one, the hybrids are not pink, but as red as the red parent. If we breed together two of these hybrid reds, or take seed from such a plant fertilized by its own pollen, we get red and white offspring in the proportions of three reds to one white. Further breeding shows that these whites bred together produce only white offspring, while the reds are of two kinds. Out of every three reds there is one which is incapable of giving any but red offspring, and two which show themselves to be of the same composition as their hybrid red parent, giving mixed offspring in the proportion of three reds to one white.

The fact that the hybrid red, though indistinguishable superficially from the pure red, gives a proportion of whites among its offspring, shows that the characteristic of whiteness is present, though concealed. In such cases the characteristic which is concealed is called recessive, while the stronger characteristic which alone makes its appearance is known as dominant.

A glance at Fig. 48 will show the relation of this result to the case of the Andalusian fowl. Supposing that black were dominant over white instead of blending with it, all the grays would appear as blacks, and the pedigree would read as follows: Line 2-hybrid black; line 3three blacks (i.e. one pure black and two hybrid blacks), s.u. 
one white; line 4-one of the blacks (the pure one) of line 3 produces only blacks, the other two blacks each produce three blacks (one pure and two hybrid) and one white, as before. Whites, of course, produce nothing but whites.

This is obviously the same as the case of the snapdragon, reading red for black. It will also be appreciated that the way in which the contrasted characteristics of the parents behave in the body of the hybrid,--blending or otherwise-is a purely subsidiary point, which does not in any way affect the important matter of their separation in the hybrid's gametes.

Although a case of blending characteristics has been chosen from the animal kingdom, and non-blending ones from the vegetable kingdom, it must not be supposed that these two types of inheritance are peculiar to animals and plants respectively. On the contrary, experiments on a very large number of characteristics-colours, sizes, shapes, etc., have shown that both kinds of inheritance are found in both kingdoms, animals and plants exhibiting an extraordinary similarity in the phenomena of heredity, which can only mean that these are dependent upon the most fundamental properties of living matter.

On a first consideration it would appear, having regard to our own experience of inheritance in man, that Mendel's law has a limited application. This is not the case, however, and it is conceivable that ultimately all inheritance will be shown to be of this type, it being merely the consequence of the hereditary material being composed of small units. Though here we are entering speculative regions, where we are far from reaching general agreement amongst biologists, it may be explained that it is supposed that the colour of the feathers (for example) is dependent 
upon a "factor" residing in one of the chromosomes. To give a mental picture we may suppose that it is one of the little chromatin beads as shown in Fig. $46, H$. Each gamete, as we have already seen, has one set of chromosomes (in the fowl the number is seventeen instead of the three in the species of Cyclops figured), but the zygote has two sets. Hence while each gamete has but one chromatin bead or factor for feather colour, the organism (zygote) has two. Hence its hybrid nature if the two are dissimilar. The gametes which issue from this hybrid individual have, however, again only one set of chromosomes, and therefore only the one colour factor, and therefore conform to Mendel's law.

The reason why Mendel's law is difficult or impossible to detect in many cases is certainly that the characteristics under consideration are complex ones, depending upon the interaction of many such factors, which exist in pairs in the zygote and in single in the gamete. The variety of ways in which the double set of factors of the zygote can be sorted out into the single set of the gamete, and the still greater variety of combinations that can result in syngamy of the various kinds of gametes will then result in such an enormous variety of zygotes as to render impossible the discovery of segregation, which is only detectable when the different types can be divided into a few well-marked categories. 


\section{LECTURE VI}

\section{HEREDITY IN MAN}

Most of our knowledge of inheritance in man has had perforce to be acquired by methods different to those used with the lower animals, or plants, owing partly to the fact that the experimental method is inapplicable, and partly to the fact that the characteristics in which we are for practical reasons most interested in man, are apparently not simple ones in the Mendelian sense-i.e. depending for their expression on only one or few factors in the germ-plasm, but complex ones depending upon the interaction of many.

Some simple cases of Mendelian inheritance in man are known, however, most of them concerning abnormalities. The inheritance of the condition known as Brachydactyly, or short fingers, is shown in the family history summarised in Fig. 49, the pedigree reading from above downwards as in the case of Fig. 48. Persons with this abnormality possess only two joints to the fingers and toes instead of three. All fingers and toes are affected alike, and the condition is associated with shortness of stature.

The first point to notice is that no case is known of two brachydactylous persons marrying each other. Hence the wives or husbands of the persons appearing in the pedigree are not shown, they being all normal. 


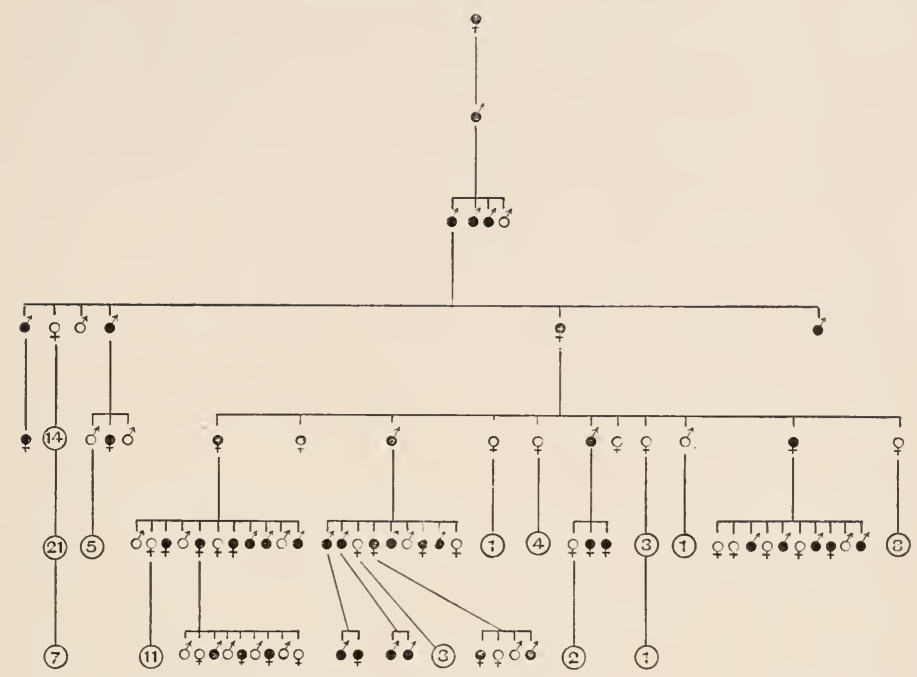

FIG. 49 .

Pedigree of Brachydactylous family, slightly condensed from Drinkwater. (Proc. Roy. Soc., Edinb., rgo8.)

$\boldsymbol{\sigma}$ Brachydactylous male.

$\delta$ Normal male.

\%rachydactylous female.

\& Normal female.

Figures in circles represent so many normal individuals without discrimination of sexes.

A glance at the table will show that brachydactylous persons (mated, as we have just seen, with normals) produce both normal and brachydactylous offspring, while normal individuals (also mated with normals) produce only normal offspring. We therefore conclude that the normal members of the pedigree produce nothing but normal gametes, while the brachydactylous persons produce both normal and brachydactylous gametes. In short, the normals are comparable to the white fowls, and the brachydactylous persons to the gray ones in Fig. 48. The main difference between the two pedigrees consists in the fact that the brachydactylous individuals instead of being mated with their like, are mated with 
normals. Hence we have the following possibilities in syngamy :

Gametes of Brachydactylous Persons.

Brachydactylous

Normal
Gametes of Norma! Persons.

$\times$ Normal $=$ Brachydactylous.

$\times$ Normal $=$ Normal.

Thus the result of the marriage of brachydactylous and normal persons should be, on the average, half the children brachydactylous and half normal-a result which is approximately realised in the pedigree.

However, for the reasons indicated above, Mendel's law will not take us very far in the investigation of inheritance in man, and different methods have to be employed which, while they may not have added much to our knowledge of the how and why of inheritance, have resulted in the discovery of formulae which describe in a simple way the relation between parent and offspring for a large number of characteristics.

The invention and development of these methods is almost entirely due to Sir Francis Galton and Professor Karl Pearson. The methods are much too elaborate and require far too advanced a knowledge of mathematics to attempt to describe here, but the general way of attacking the problem and the main results are easily intelligible.

To begin with, we will take the inheritance of height or stature, using the data provided by Pearson's measurement of over Iooo families. In this case we will limit ourselves to fathers and sons, as the results are practically identical for mothers and daughters, and indeed for fathers and daughters and for mothers and sons.

In Table I the left hand column gives the heights of the fathers (in inches) and the third column the average height of their sons. The other two columns show the 
number of inches by which the fathers or sons in question differ from the average height of all the fathers $(67.5$ inches) or of all the sons (68.5 inches) respectively. The fact that the average height of all the sons is an inch greater than that of all the fathers need not concern us particularly, as it affects the whole series of sons equally, and a discussion of the reason for the difference would be beyond our present scope.

Let us consider as an example the fathers of 65.5 inches tall (which class includes all between 64.5 and 66.5 inches), or two inches less than the average ( -2 in column 2 ). There were 237 of these fathers, with the same number of sons. ${ }^{1}$ The heights of these sons varied from 60 to $7+$ inches, but the average of them all was 67 inchesi.e. $I \cdot 5$ inches below the average for the total series of sons.

TABLE I. Inheritance of Stature. All figures are in inches. Correlation $=\cdot 5$.

\begin{tabular}{|c|c|c|c|}
\hline \multicolumn{2}{|c|}{ Fathers. } & \multicolumn{2}{|c|}{ Sons. } \\
\hline Heights. & $\begin{array}{l}\text { Difference from } \\
\text { Average. }\end{array}$ & Heights. & $\begin{array}{l}\text { Difference from } \\
\text { Average. }\end{array}$ \\
\hline $61 \cdot 5$ & -6 & 66 & $-2 \cdot 5$ \\
\hline $63 \cdot 5$ & -+ & $66 \cdot 5$ & -2 \\
\hline $65 \cdot 5$ & -2 & 67 & $-I \cdot 5$ \\
\hline $67 \cdot 5$ & 0 & $c 8.5$ & 0 \\
\hline $69 \cdot 5$ & +2 & $69 \cdot 5$ & $+\mathrm{I}$ \\
\hline $71 \cdot 5$ & +4 & $70 \cdot 5$ & +2 \\
\hline 73.5 & +6 & 72 & $+3 \cdot 5$ \\
\hline
\end{tabular}

Running our eye over the Table we see that it is invariably the case that fathers measuring so many inches

1 Owing to the method of arranging the data, both in this Table and in Table 2, the number of fathers is always equal to the number of sons. 
above or below the average have sons whose average heights differ from the average of all the sons in the same direction (above or below) as their fathers, but to a smaller degree. And the exact working out of Pearson's figures show that the degree is about one half. In other words, sons on an average inherit half the peculiarity of their fathers.

A word in passing may be said about a point which may occur as a difficulty to some readers. At first sight it might appear that the fact that tall fathers have sons on an average less tall than themselves, and that short fathers similarly have sons on an average less short than themselves implies that the population is getting more mediocre and less variable in each generation. This, however, is of course not the case, and the reason is seen at once when it is remembered that we are only dealing with average heights. As we saw above, the sons of fathers 65.5 inches tall ranged from 5 feet to 6 feet 2 inches, and in this way, although on the average sons are less peculiar than their fathers, there are always a number of them even more extreme, and thus the supply of tall and short men in the population is kept up.

We thus see that we cannot predict the height of individual sons of individual fathers, but we can say in general that given a large number of fathers of a given height the average height of their sons will be so and so. And that average height is obtained thus. If the height of the fathers is so many inches above or below the average, the average height of their sons will be about half that number of inches above or below the arerage. This ${ }^{1}$

1 Readers versed in statistical mathematics will know that properly speaking the prediction of the heights of sons from that of fathers is not obtained directly from the coefficient of corre- 
figure, one half or 5 is termed the coefficient of correlation between father and son, and is in this case a measure of the intensity of inheritance. The method of arriving at the exact figure is much more elaborate than the above condensed table would seem to imply, and is a general method of measuring the dependence of one thing upon another. It is a figure which, when the dependence is complete, gives the figure I; when there is complete independence, the figure 0 ; and when the dependence is partial, some figure in between. Thus, in the case in question, if the tallest fathers always had the tallest sons, the next tallest fathers the next tallest sons, and so on, the correlation would be I-i.e. inheritance would be complete. If, on the other hand, there were no inheritance, and tall fathers just as often had short sons as tall ones, then the correlation would be 0 .

It is quite essential to grasp clearly this idea of correlation, the measure of dependence of one thing upon another, as it is impossible to understand otherwise the bulk of the work done upon inheritance in man.

With this knowledge of the inheritance of a typical physical characteristic which can serve as a standard of comparison, we can consider the inheritance of a variety of different characteristics, and we will begin with Insanity, a condition which as everyone knows is liable to run in families. One of the best investigations on this subject was that made by Heron, who used as a basis the archives of the James Murray Royal Asylum, Perth, which contains the records of $33 \mathrm{I}$ family trees. Heron

lation, but through the mediation of the regression coefficient. It does not, however, appear necessary to burden the untechnical reader with this refinement. 
divided his material into males and females, treating the sexes separately. Table 2 gives the results for the male pedigrees, i.e. fathers and sons. The female pedigrees gave similar results.

\section{TABLE 2. Inheritance of Insanity. Correlation $=\cdot 6$.}

\begin{tabular}{|c|c|c|c|}
\hline & & $\begin{array}{l}\text { Numbers actually } \\
\text { found. }\end{array}$ & $\begin{array}{c}\text { Numbers to be } \\
\text { expected if there } \\
\text { were no inheritance. }\end{array}$ \\
\hline Father and son & f Both sane, - & 26,774 & 26,728 \\
\hline alike- & $\begin{array}{l}\text { Both insane, } \\
\text { Father insane, son }\end{array}$ & +9 & 3 \\
\hline $\begin{array}{l}\text { Father and son } \\
\text { unlike- }\end{array}$ & $\left\{\begin{array}{l}\text { sane, - } \\
\text { Father sane, son } \\
\text { insane, - }\end{array}\right.$ & $\begin{array}{l}\mathrm{I} 49 \\
36 \mathrm{I}\end{array}$ & $\begin{array}{l}195 \\
+07\end{array}$ \\
\hline
\end{tabular}

First, let us take the first number (both father and son sane) under " numbers actually found." It is clear that no lunatic asylum records will be able to furnish this figure, since it is only families of which at least one member is insane that come within the ken of such an institution. Nevertheless it is of the utmost importance to discover this figure if we wish to get a true measure of the inheritance of insanity, and it can be calculated from the known percentage of insane in the general population. The number of certified lunatics in Scotland on Ist January, I9or, was 15,475 or 6 per cent. This, however, only gives those certified insane on the date in question, and takes no account of those who have been insane at some period of their lives and subsequently discharged as "cured." It is reckoned that the percentage of the population which is or has been at some time or other certified as insane is about $\mathrm{I} \cdot 5$ per cent. On this basis it is easy to calculate the figure $26,77+$ to correspond on 


\section{HEREDITY IN MAN}

a $I \cdot 5$ per cent. basis to the number of insane sons dealt with in the table.

The column " numbers to be expected if there were no inheritance" shows the number to be expected if insane fathers were no more likely than sane fathers to have insane sons, and is calculated on the same $I \cdot 5$ per cent. basis. Thus there were IgS insane fathers, of whom 49 had insane offspring and I49 had sane ones. But if there were no inheritance-that is to say, if it were a pure matter of chance as to whether insane fathers had sane or insane sons, we should expect only $I \cdot 5$ per cent. of the IgS sons-i.e. only 3-to be insane, instead of the 49 actually found.

We are now in a position to consider the Table with a view to discovering whether insanity is inheritable or not. If inheritance is at work we should expect to find an excess of cases where father and son are alike, and a deficiency of cases where they are unlike, and on examining the Table we find that this is the case. By the application of appropriate mathematical methods we can measure the intensity of inheritance in the same way as we measured it for stature, and hence compare it with this as a standard. If this be done the correlation is found to be $\cdot 6$ - that is to say the records of the Perth asylum disclose an intensity of inheritance of insanity 20 per cent. stronger than the inheritance of stature, though too much reliance must not be placed upon the exact figure.

A large number of human characteristics can be examined on the same principle. Let us take another mental characteristic, namely Ability.

In this case a slight modification of the usual method has to be employed. It is very difficult to estimate the relative ability of adults. It is easy, however, to get 
some measure of intelligence in children. For instance, the class attained in the same school at a given age is an automatic indicator of a certain kind of intelligence. Therefore in this investigation we measure the resemblance. between brothers or sisters, instead of between parents and offspring.

Table 3 summarises the investigations of Schuster and Elderton on the school records at Charterhouse. The " division" in which each boy was situated when he reached the age of sixteen was extracted from these records, and the Table compiled in the usual way. (The divisions are numbered from .I to 7 , the first being the highest.)

TABLE 3. Position of pairs of brothers in Charterhouse School at age 16 . Correlation $=\cdot 46$

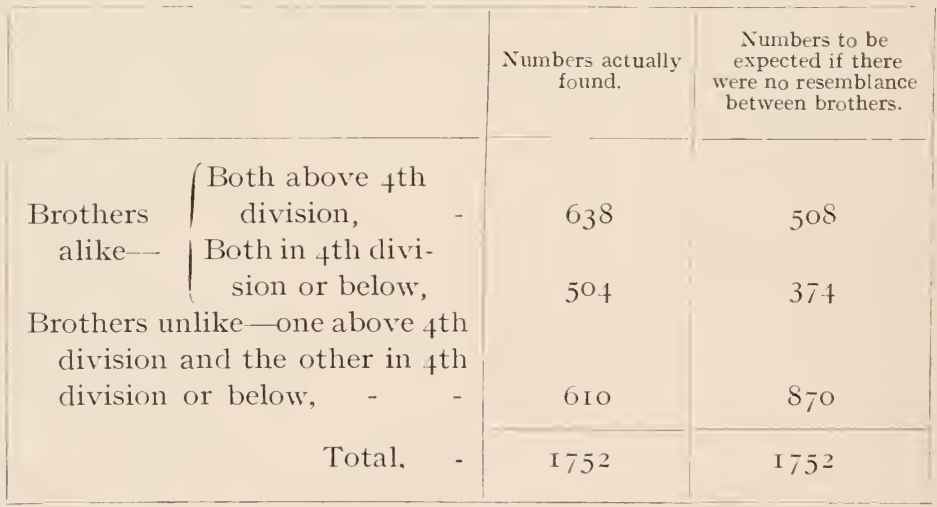

It is plain that we can measure the intensity of resemblance between pairs of brothers, etc., in the same way as we measured it between parent and offspring, and arrive at a figure for the correlation. In the above Table this figure works out to 46 . Now in the case of 
stature, where correlation both between father and son and between brothers has been measured, it is found that they give very nearly the same figure. If, therefore, we find that in the above Table the correlation between brothers is 46 , we may take it that for all practical purposes this is also the intensity of inheritance.

A similar investigation for Harrow School gave a slightly lower value, the average for the two schools being about 4. We can, therefore, say that these investigations indicate a strong inheritance of ability, though about 20 per cent. less intense than the inheritance of stature. It must be mentioned, however, that Pearson's school schedules, compiled on a different principle and with different material, gave the intensity of inheritance of intelligence as $\cdot 5$, or equal to that of stature.

Pearson has made an attempt to measure the inheritance of the most varied human characteristics by the same method of measuring the resemblance between members of the same family. His method was to send out schedules to a number of schools (nearly 200), containing directions, and tables to be filled up for (I) pairs of brothers, (2) pairs of sisters, (3) pairs consisting of one brother and one sister, for a number of physical and mental characteristics. Limiting ourselves again to the results for brothers (those for the other combinations being closely similar) we can take as examples Tables 4 and 5, noting again the excess of "numbers actually found " over those " expected" in the cases where the brothers are alike, and the deficiency in the cases where they are unlike, thus indicating the action of inlieritance. 
TABLE 4. Assertiveness. Correlation $=\cdot 5$.

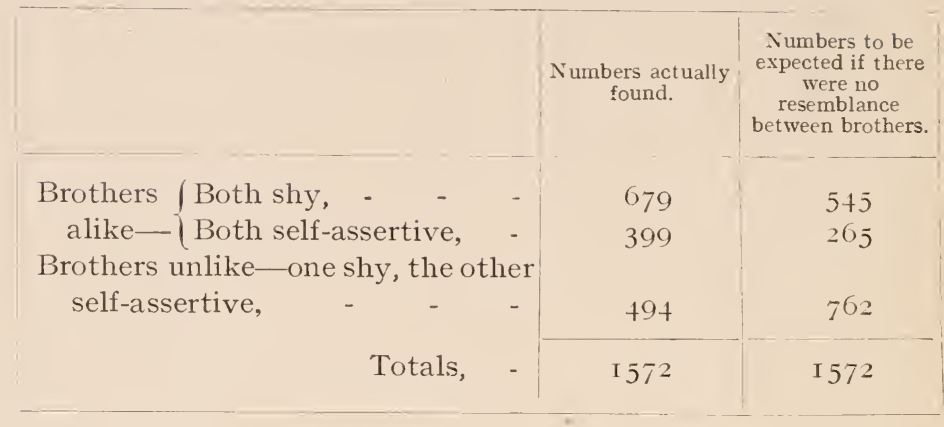

TABle 5. Popularity. Correlation $=\cdot 5$.

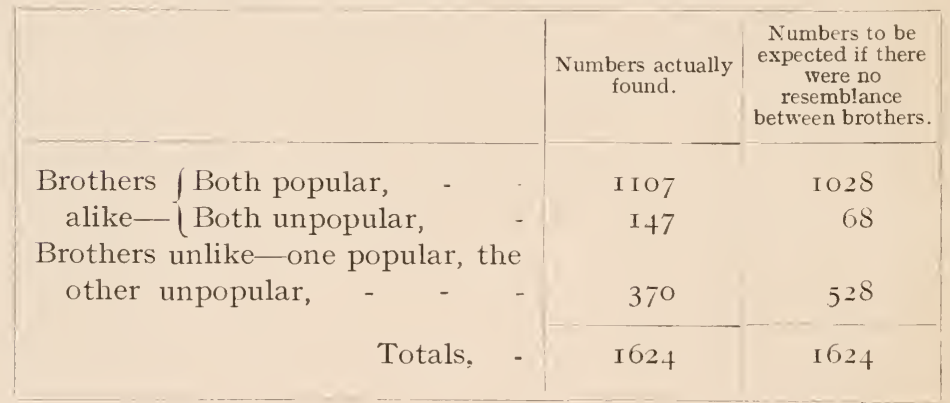

Table 6 gives some examples of the results of Pearson's investigations, and we note the close similarity between the intensity of resemblance (i.c. of inheritance) for physical and mental characteristics, as calculated from these school data. The objection might otherwise have been raised that the figures for the mental characters were of less value than those for the physical, owing to the greater liability of the former to be influenced by (I) errors of judgment, or of bias, on the part of the teachers who filled up the schedules, and (2) the similarity of 
environment (home training, etc.), to which brothers are subjected, and which might produce a resemblance independently of inheritance. Neither of these disturbing factors can, however, operate to any appreciable degree in the case of the physical characteristics considered, which are taken from the same schedules and filled up by the same teachers, so that the similarity in results strongly supports the view that the resemblance between members of the same family in regard to mental characteristics is actually due to inheritance.

TABLE 6. Examples of the intensity of resemblance between brothers for various characteristics.

\begin{tabular}{|c|c|c|c|}
\hline \multicolumn{2}{|l|}{ Characteristic. } & & \multirow[t]{2}{*}{ Correlation. } \\
\hline A. Physical. & & & \\
\hline Colour of eyes (light, medium, dark). & - & - & $\cdot 5$ \\
\hline Hair (smooth, wavy or curly), - & - & - & $\cdot 5$ \\
\hline Breadth of Head, _ - _ & - & - & $\cdot 6$ \\
\hline B. Mental. & & & \\
\hline Vivacity (quiet or noisy), - - & - & - & $\cdot 5$ \\
\hline Assertiveness (shy or self-assertive), & - & - & $\cdot 5$ \\
\hline Popularity (popular or unpopular), & - & - & $\cdot 5$ \\
\hline Conscientiousness (keen or dull), & - & - & $\cdot 6$ \\
\hline Intelligence (six categories), - & - & - & $\cdot 5$ \\
\hline
\end{tabular}

The figures which we have discussed in this chapter form only a small selection from the mass of data dealing with a wide range of characteristics, mental and physical, including the power of resistance to disease, which has been collected by Pearson and his colleagues. While they do not help us much to understand the physiology of inheritance, in the way for instance that Mendel's 


\section{SEX AND HEREDITY}

discovery has done, and which should be the chief aim of all scientific investigations of heredity, they possess the great practical importance of emphasising the dangers and possibilities which beset the human race.

Infirmity and disease are so common among civilised man that we have come to look upon them as part of the order of nature. Under conditions more natural in regard to natural selection, however, these afflictions would not have the chronic influence in our lives that they have at present. When a wild animal falls ill it generally either makes a quick recovery or dies. Thus the deformed and unfit, and those which are less resistant to disease, die off more rapidly, and therefore leave fewer offspring to inherit their weak constitution and poor powers of resistance than do the more fit animals.

In this way the power of resisting disease is maintained and increased under a state of nature; but in the case of man, and especially civilised man, humane considerations coupled with medical science keep alive large numbers of those who under natural conditions would perish, and thus the evolution against disease is impeded or even altogether suspended.

Now it cannot be denied that this is a very grave state of affairs. Indeed it is doubtful whether any other factor will affect more the welfare of the human race in the future, and it is considerations such as these which lead Eugenists to advocate the policy of a partial control of the birth-rate, preventing the multiplication of the obviously unfit (for example, the insane or feeble-minded) and encouraging a high birth-rate among the vigorous and intelligent.

The fact that the birth-rate in this country (as in all the highly-civilised ones) is diminishing has been so 
thoroughly ventilated in the popular press that everyone is familiar with it. The really serious aspect of the question, however, which has not been so well appreciated, is the fact that the diminution has not affected all classes of the community alike, so that very different birthrates obtain in the different classes of society. The birth-rates for a number of different occupations are given in the official publications of the I9II Census of England and Wales. A few representative samples, taken from the two ends of the scale, are given in Table 7 .

\section{TABLE 7 .}

\section{Occupation.}

Teaching Profession,

Lawyers,

Doctors,

Agricultural Labourers,

Dock Labourers, -

Coal Miners,
Birth-Rate per iooo married men under 55 years of age.

Now a differential birth-rate among the various sections of the community means, unless there are counterbalancing factors, that the sections with the lower birthrate will appear in smaller and smaller proportions in succeeding generations. In other words, there is danger of the average mental powers of the race declining, owing to the failure of the more intellectual members to reproduce themselves in proper proportion to the rest of the community.

It will be noted that the above conclusion assumes that the members of the intellectual professions have on the average greater mental capacity than those in the unskilled S. H. 
trades, and that the difference is not merely due to different education imposed on similar material. A proper discussion of this question would take us far beyond the scope of these lectures, and it must suffice to mention the single point, that the fact that entrance into a profession is dependent upon the ability to pass intellectual tests, and that success therein depends mainly on intellectual capacity, excludes all markedly unintelligent persons from such a profession. The exclusion of these obviously raises the average intellectual capacity of the members of the profession above that of these engaged in occupations into which men of all degrees of mental capacity -high or low-are admitted.

This question, however, like the problem of the physically unfit members of the population, is capable of an amount of argument quite out of place in a book of this size and character, and here we must leave it, content with having indicated certain practical problems arising out of our study of heredity, problems which are vastly more vital to the real welfare of the human race than those political questions which usually absorb the energies of governments. 


\section{GLOSSARY AND INDEX}

\section{Numerals in heary type signify that an illustration is given on the page quoted}

Acctabularia, isogametes of, 22. aconite, dependence on Humble Bee, 40.

acquired characters, those impressed on the organism in the course of its individual life : 65 , $9 \mathrm{I}$.

adiantum, a Fern, embryo of, 36. Agrostemma, pollen-tubes of, $\mathbf{4 3}$. a!lantois 75,76 .

Alytes, 69, 70 .

amnion, 75 .

amphibians, reproductive adaptations, 68.

Animal agency, in pollination, 39. Antheridium, the male organ, for instance of a Fern, which contains spermatozoids, 25.

Aquatic stages, in development, 67

Archegonium, the female organ, for instance of a Fern, which contains one ovum, 26.

Balance, of human body, 52 .

Birds, egg, 72, 74 , 75 : embryo, 76

Birth-rate, I 2.

Bladder-wrack (Fucus), I5: propagation of, I 8: gametes and fertilization of, 20.

Body-plasm. the protoplasm of the body-cells, as opposed to the germ-plasm 88 .
Brown Seaweeds, sexual differentiation in, 15-20.

Budding, in Plants; a separation of a part of the plant-body, which grows directly into a new individual, 4 : repeats the characters of the parent, 7 .

Carpels, the leaves at the centre of a flower, enclosing the ovules, 28, 48.

Cell, the structural unit of the body of animals and plants, 2, 3 .

Cell-division, the ordinary method of increase in number of cells, one cell dividing into two, 3 .

Cell-theory, 2.

Chromatin, the most conspicuous constituent of the nucleus, and generally identified as the physical basis of heredity, 85 .

Chromosomes, bodies into which the chromatin is concentrated before division of the nucleus. At other times the chromosomes are diffused through the nucleus, and their individual boundaries are not distinguishable, 83, 85 .

Conjugation, the coalescence of two equal gametes, 16, 22.

Co-operation, in living body, 53 .

Copromonas, 54 ; life-history, 56. 
Correlation, coefficient of, I05: the measure of degree of dependence of one variable upon another.

Crossing, 38 .

Cutleria, I8; 19.

\section{Datura, seed of, 49 .}

Death, not a necessary sequel to life, 6o, 88: in higher animals, 63.

Depression, 6o.

Dominant, a character of one parent, which develops in the body of a hybrid to the exclusion of the corresponding character of the other parent, 97 .

Echidna, 77 .

Ectocarpus secundus, male and female gametes of, $1 \%$.

Ectocarpus siliculosus, isogametes of, I 5, 16, I7.

Egg, 4: of birds, 72, 74 .

Embryo, internal in land-plants, 50: of bird, 76: of mammal, poisoning or infection, 80 .

Embryo-sac, a large cell within which is the ovum in flowering plants, 44.

Eugenics, the science of the improvement of the race, especially through the agency of selection, I 2 .

Euglena, 9: life history of, 10, 32.

Factor, (hereditary): the hypothetical physical entity in the germ-plasm which is concerned with the production of any particular feature of the body ; 95, 99.

Female gamete, or macrogamete, or ovum: the female sexual cell, which is usually nonmotile, and is larger than the male gamete which fuses with it : 4 .
Fern, sexual propagation of, 24 : attraction of spermatozoids by ovum, 34 .

Fertilization, the fusion of the male gamete or spermatozoid with the female gamete or ovum: the term is equivalent of syngamy: in a Fern, 26 : in a flowering plant, 29, 37, 4I, 46 : in Cyclops, 82, 83.

Fish-like characters in embryos, 67.

Fission, in Euglena, 10 : in Copromonas, 55: in body of higher animals, 62 .

Flower, a dense group of organs borne on the end of a stalk in flowering plants, in connection with which the gametes are produced, $2 \%$.

Foot, the suctorial organ of the embryo in Ferns, 35, 36.

Frog-spawn, 68.

Fucus, gametes of, 3 : fertilization of, 20: attraction of spermatozoids by ovum of, 33 . Funiculus, stalk of ovule or seed, $42,49$.

Fusion of sexual cells, or syngamy, 3.

Gametangium, a cell which produces gametes: of Ectocarpus, 17: of Cutleria, 19.

Gamete, or sexual cell: a cell which is capable of fusing with another cell in a sexual act, 3 : of Fucus, 5: of man, 5: of Ulothrix, 12: of Ectocarpus, 16, 17: of Cutleria, 19: of Orchis, 29: of Copromonas, 57: of Plasmodium, 59: of Stylorhynchus, $\mathbf{5 8}$.

Germ-cell, a gamete, or cell which will give rise to a gamete, $8 \mathrm{I}$.

Germ-plasm, living substance which is able to give rise to complete new incividuals, 88 . 
Gill-openings, in young bird, 76 .

Gonad, the aggregate of the germcells, 64 .

Grass, wind-pollination of, 38 .

Green algae, sexual differentiation in, 21.

Heredity, 6.

Hermaphrodite, of flowers, those which contain both stamens and carpels, $\mathbf{3} \%$.

Humble-bee, agent of pollination of aconite, 40 .

Hyla, $7 \mathrm{o}$.

Immobility of plants, its effect on propagation, 38 .

Immortality, potential, Protozoa, 6I : germ-cells, 64: germplasm, 88.

Impressed characters, not inherited, 65, 9r.

Inheritance, absence in impressed characters, 65, 91 : colour in fowls, 94: colour in snapdragons, 97: brachydactyly, IOO: stature, IO2: insanity, I05: ability, I08: mental characteristics, III : physical characteristics, I I I.

Isogametes, those which are of equal size and structure, 4.

Land, adaptation for life on, 66 . Life, nature unknown, 5I : complexity of vital processes, $5 \mathrm{I}$. Lily, ovary of, 48.

Macrogamete, the female gamete or ovum, which is usually nonmotile, and is larger than the male gamete which fuses with it : 4,82 .

Nale gamete, or microgamete, or spermatozoon, or spermatozoid, the male sexual cell which is usually motile, and is smaller than the macrogamete, with which it fuses: 4 .

Malic acid, its effect on movement of the spermatozoids of Ferns, 35.

Nammals, 76 .

Man, gametes of, $\mathbf{5}$.

Marsh Marigold (Caltha), ovule of, 44 : carpels of, 48.

Medium, internal, 67 .

Mendel's Law, 94, 98, Ioo.

Microgamete, or spermatozoon, or spermatozoid, the male gamete, which is smaller than the ovum with which it fuses: 4 .

Micropyle, the narrow channel through which the pollen-tube passes to the ovum in flowering plants : 44, 45.

Mortality, of animal body, 63 .

Motility of gametes, 22: of animals and plants, 32: of spermatozoids in water, 33 .

Multicellular organisms, which consist of a number of cells, 2 .

Narcissus, pollen-tubes of, 43.

Nephrodium, a Fern: antheridia and spermatozoids of, 24.

Nototrema, 71, 72.

Nucleus, a definite, frequently rounded body within the protoplasm, which contains chromatin and is the controlling centre of the cell: $\mathbf{2}, \mathbf{3}$.

Onoclea, a Fern : fertilization of, 26.

Organization of animal body, 62 .

Ornithorhynchus, 77.

Ovule, the future seed of flowering plants, which at the period of flowering contains an ovum, $28,42,44,48$.

Ovum, the female gamete, which is usually non-motile, and being larger than the male gamete which fuses with it, it is often called the macrogamete, $4, \mathbf{5}$. 
Phyllobates, 70.

Phyllomedusa, 68.

Pipa, 71, 73.

Placenta, 79 .

Plasmodium, 58, 59.

Pollen-grain, 45.

Pollen-tube, the result of germination of the pollen-grain, 28 : 4I, 42.

Pollination, the transfer of pollen from the anther to the stigma of the flower, 37 .

Polygonum, ovary of, 42.

Polypodium, a Fern, archegonia of, 25.

Prothallus, the sexual stage of a Fern, which bears the sexual organs, 25.

Protococcus, 11, 32.

Protoplasm, the physical basis of life, 2 : necessarily moist during life, 66.

Protoplast, the whole protoplasmic body of the cell.

Protozoa, compared with higher animals, 62 .

Quince, flower of, 28.

Rabbit, transference of eggs of, 79 . Recessive, a character of one parent, which is masked in the body of the hybrid by the exclusive development of the corresponding character of the other parent, 97 .

Reproduction, complexity of, 53 . Rhacophorus, 69.

Rhinoderma, $7 \mathbf{r}$.

Salvia, pollination-mechanism of, 40.

Segregation (Mendelian), the dissociation of the parental characters-or rather of their factors-during the formation of the gametes, 95 .
Sexual cells, or gametes, those cells which take part in syngamy, 3: minute and microscopic, 8: of Fucus, 5 : of Man, 5.

Sexuality, 2 .

Shepherd's Purse, seed of, 49.

Soma, the substance of the animal body apart from the gonad, 64 .

Specialisation of cells, 63 .

Spermatozoid, the microgamete of plants, 4: of Fucus, 20: of Fern, 24: of Zamia, 4\%.

Spermatozoon, the microgamete of the higher animals, 82 .

Spontaneous generation, unknown to scientific men, 6 .

Stamens, the parts of the flower which produce the pollen, and ultimately the male gametes, 27.

Stigma, the receptive surface of the carpel, 28.

Structural unit, the cell of animals and plants, 2 .

Stylorhynchus, 57, 58.

Surinam Toad, 7I, 73.

Syngamy, the fusion of two sexual cells, and especially of their nuclei, to form one zygote, 3: in Fucus, 20: in Fern, 26, 27: in flowering plants, 30: in Copromonas, 57: in Plasmodium, 59: in Stylorhynchus, 58 : in Cyclops, 82: necessity of, 60 : effect in staving off death, $6 \mathrm{I}$.

Tissue, a mass of cells of common origin, and showing a common life, composing the body of an animal or plant, $\mathrm{I}$.

Ulothrix, 12: vegetative increase of, I3: gametes of, I 4,32 .

Unicellular organisms, which consist of only one cell, 2 . 
Vaucheria, gametes of, 22.

Vegetative increase of number by separation of a part (bud), or a single cell from the parent, without syngamy: in Ulothrix, I3.

Yolk, 72 .

Zamia, spermatozoids of, $4 \%$.
Zoo-spores, or swarm-spores, naked cells capable of movement in water, which reproduce the plant vegetatively: of Ulothrix, 13 .

Zygote, the result of fusion of sexual cells or gametes: it is the starting point of a new individual, 3 : of Ectocarpus, 16 : of Copromonas, 57: resting stage, 6r : of Stylorhynchus, 58. 



176 


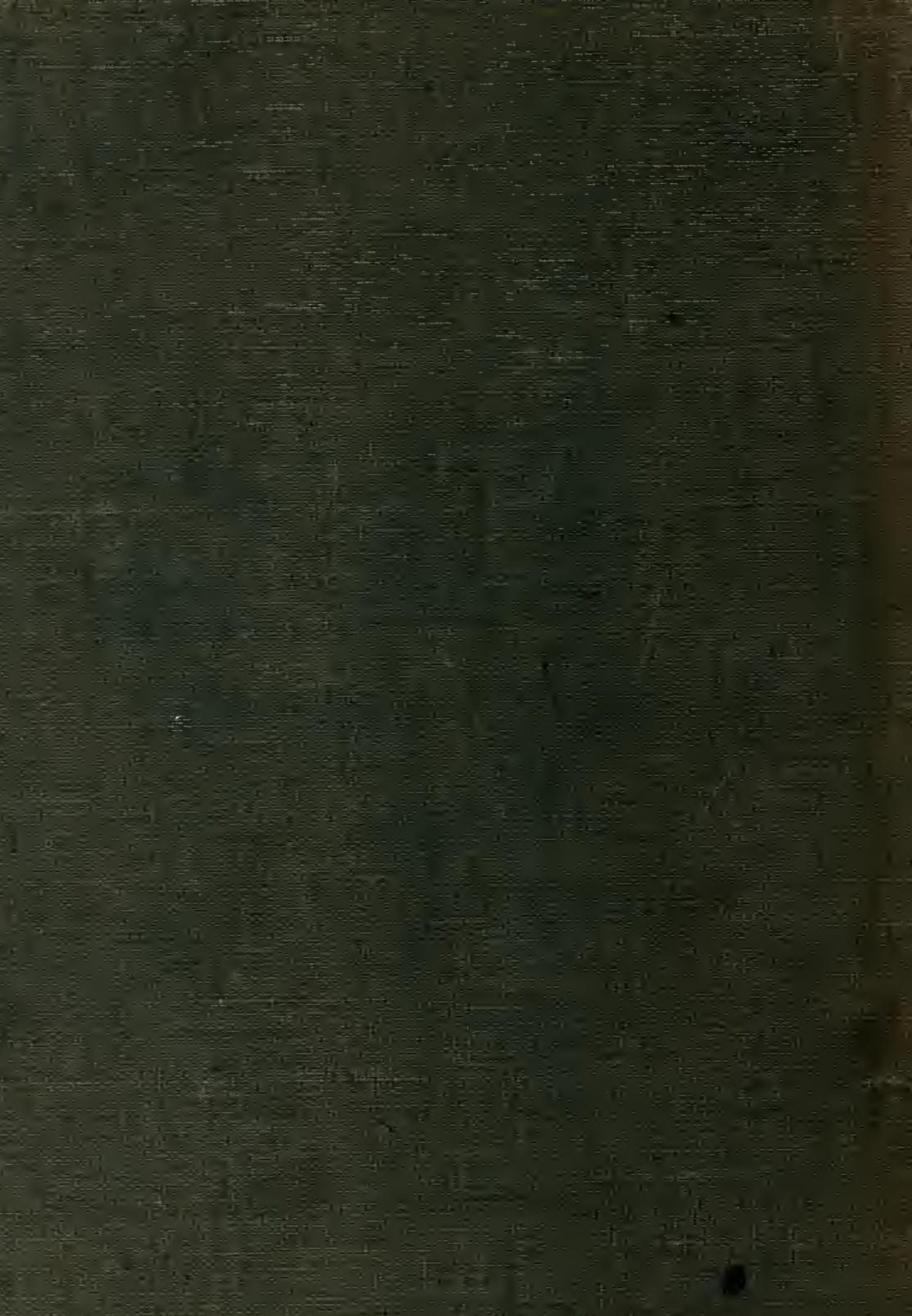

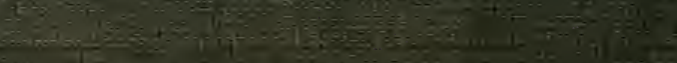

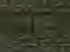

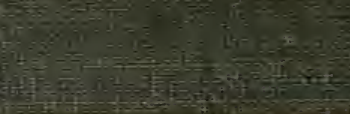

